\title{
A good laugh and a long sleep : insights from prospective and ambulatory assessments about the importance of positive affect and sleep in mental health
}

Citation for published version (APA):

Hartmann, J. A. (2015). A good laugh and a long sleep : insights from prospective and ambulatory assessments about the importance of positive affect and sleep in mental health. [Doctoral Thesis, Maastricht University]. Maastricht University. https://doi.org/10.26481/dis.20150114jh

Document status and date:

Published: 01/01/2015

DOI:

10.26481/dis.20150114jh

Document Version:

Publisher's PDF, also known as Version of record

\section{Please check the document version of this publication:}

- A submitted manuscript is the version of the article upon submission and before peer-review. There can be important differences between the submitted version and the official published version of record. People interested in the research are advised to contact the author for the final version of the publication, or visit the DOI to the publisher's website.

- The final author version and the galley proof are versions of the publication after peer review.

- The final published version features the final layout of the paper including the volume, issue and page numbers.

Link to publication

\footnotetext{
General rights rights.

- You may freely distribute the URL identifying the publication in the public portal. please follow below link for the End User Agreement:

www.umlib.nl/taverne-license

Take down policy

If you believe that this document breaches copyright please contact us at:

repository@maastrichtuniversity.nl

providing details and we will investigate your claim.
}

Copyright and moral rights for the publications made accessible in the public portal are retained by the authors and/or other copyright owners and it is a condition of accessing publications that users recognise and abide by the legal requirements associated with these

- Users may download and print one copy of any publication from the public portal for the purpose of private study or research.

- You may not further distribute the material or use it for any profit-making activity or commercial gain

If the publication is distributed under the terms of Article 25fa of the Dutch Copyright Act, indicated by the "Taverne" license above, 



\section{A good laugh and a long sleep}

Insights from prospective and ambulatory assessments about the importance of positive affect and sleep in mental health

Jessica Anna Hartmann 
Cover design: Birgit Severin en Guillaume Neurinaudo Layout \& Printing: Ridderprint BV, Ridderkerk

ISBN: 978-90-5335-990-7 


\title{
A good laugh and a long sleep \\ Insights from prospective and ambulatory assessments about the importance of positive affect and sleep in mental health
}

\author{
PROEFSCHRIFT
}

Ter verkrijging van de graad van doctor aan de

Universiteit Maastricht, op gezag van

de Rector Magnificus,

Prof. dr. L.L.P. Soete,
volgens het besluit van het College van Decanen, in het openbaar te verdedigen op woensdag 14 Januari 2015 om 12.00 uur
door

Jessica Anna Hartmann

Geboren op 27 maart 1983 te Siegburg, Duitsland 


\section{Promotor}

Prof. dr. J. van Os

\section{Copromotores}

Dr. C.J.P. Simons

Dr. M. Wichers

\section{Beoordelingscommissie}

Prof. dr. R.W.H.M. Ponds (voorzitter)

Prof. dr. D.J. Dijk (Surrey University, United Kingdom)

Dr. A.G. Havermans

Dr. N.A. Nicolson

Prof. dr. E.J.W. van Someren (Nederlands Herseninstituut, Amsterdam)

The research presented in this thesis was performed at the School for Mental Health and Neuroscience (MHeNS), department of Psychiatry and Psychology, Maastricht University, Maastricht, the Netherlands

The publication of this thesis was financially supported by:

Servier Nederland Farma B.V.

NSWO, Nederlandse Vereniging voor Slaap- en Waak Onderzoek

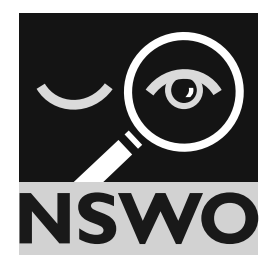


A good laugh and a long sleep are the best cures in a doctor's book

Irish Proverb

Für meine liebste Lissy 



\section{Contents}

$\begin{array}{lll}\text { Chapter } 1 & \text { Introduction } & 8\end{array}$

Part I Experience Sampling Method as assessment tool

Chapter 2 Exploring the construct of subjective sleep quality in those 28

with insomnia

Chapter 3 Day-to-day associations between subjective sleep and affect in regard to future depression in a population-based female sample

Chapter 4 The serotonin transporter 5-HTTLPR polymorphism in the association between sleep quality and affect

Chapter 5 Diurnal variation of affect: a comparison among depression, 74 psychosis, and controls

\section{Part II Experience Sampling Method as therapeutic tool}

Chapter 6 Translating assessments of the film of daily life into persontailored feedback interventions in depression

Chapter 7 Personalized feedback on positive affect in daily life: a randomized controlled trial using the experience sampling method as intervention in depression

Chapter 8 Effects of momentary self-monitoring on empowerment in a randomized controlled trial in patients with depression

Chapter 9 Discussion

Valorisation, clinical implications and future directions

Summary

Samenvatting

Publications

Dankwoord

Curriculum vitae 


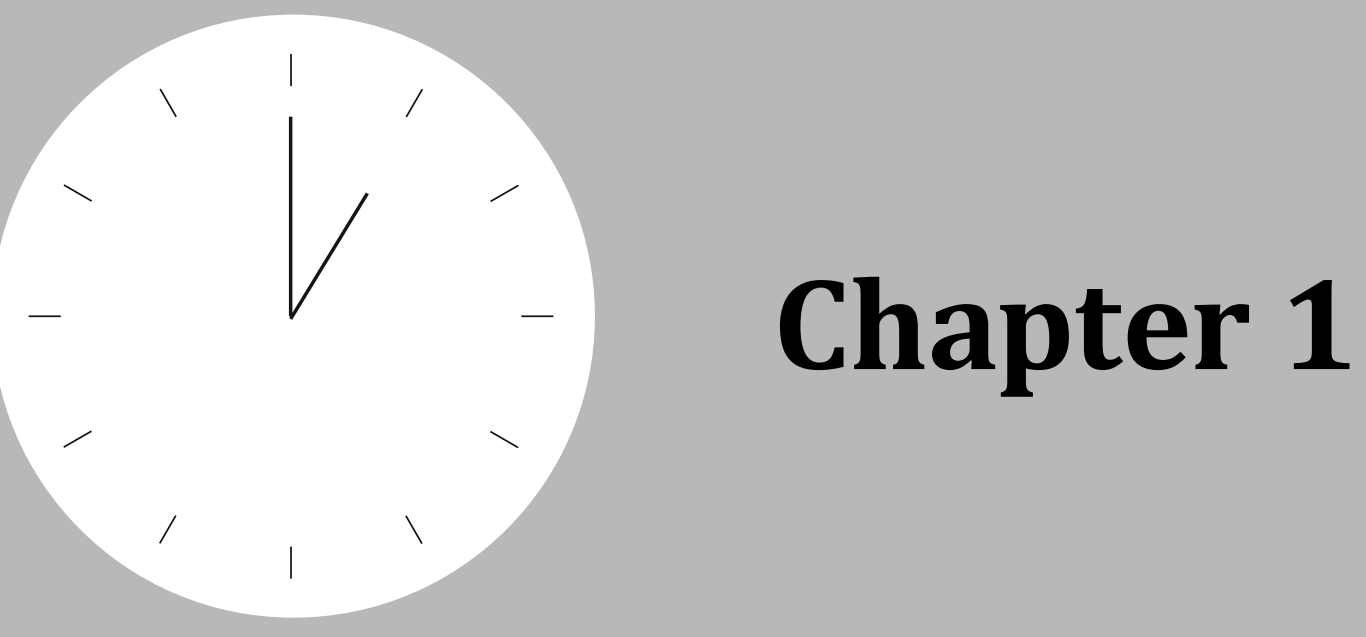




\section{Introduction}



The (clinical) assessment of mental states and behaviour is still heavily based on single-point, retrospective self-assessment questionnaires and retrospective face-toface interviews in artificial settings. However, there is an increasing awareness that the reliability of these self-reports is questionable. An alternative to the traditional retrospective measures are ambulatory assessment techniques; methodological approaches assessing variables of interest prospectively and repeatedly in daily life. Other than offering improved reliability, these techniques can be employed for two specific, yet understudied objectives: (I) the investigation of underlying mechanisms and dynamics of psychopathology at a micro-level and (II) the administration of interventions. In the first part of the present dissertation, ambulatory assessments are used to investigate potential mechanisms underlying mental disorders, focusing on depression, and its relation to sleep and affect regulation. In the second part, the potential to use ambulatory assessments as a tool to intervene in depression by providing personalized feedback, is explored.

The remainder of this introduction presents concepts important for the comprehension of this thesis, followed by an outline of the thesis chapters.

\section{Depression}

Depression, affecting more than 350 million people across all communities worldwide (WHO, 2012 [1]), is characterized by symptoms such as disturbed mood, loss of interest or pleasure, disturbed sleep, low energy, low self-worth, and concentration problems (American Psychiatric Association [2]). According to the World Mental Health Survey conducted in 18 countries, 1 out of 20 persons experienced an episode of depression during the last year [3]. Due to the disabling and recurrent nature of depression, it is the leading cause of disability worldwide and the second leading cause of disease burden after low back pain [4,5]. Although depression is known to be treatable by psychopharmacological (i.e. antidepressants) and psychotherapeutic interventions (i.e. cognitive behavioural therapy), only a fraction of individuals affected by depression receive adequate treatment $[1,6]$. Furthermore, of those who receive treatment, a large proportion remain treatment resistant $[7,8]$, and even for individuals who are treated effectively, relapse rates remain high [9]. Therefore, it is important to gain further insight into the mechanisms underlying the development and course of depression, as well as to inform on the development of novel, costeffective and evidence-based interventions. 


\section{Sleep}

Every human being will spend about one third of his or her life asleep. While the somnolent state impacts the whole organism in terms of reduced metabolism and motor activity, the loss of consciousness is probably its most outstanding characteristic. The exact function of sleep is not yet elucidated; however, it may be broadly considered as a 'state of adaptive inactivity' that 'optimizes the timing and duration of behaviour' [10; p. 747].

The sleep-wake cycle is subject to a 24-hour circadian rhythm [11-13]. A circadian rhythm refers to an endogenous rhythm in physiological processes, behaviours and affect which is self-sustainable and can persist in the absence of environmental cues $[14,15]$. This rhythm is internally generated by a 'pacemaker'; the suprachiasmatic nucleus in the hypothalamus, and is synchronized to the 24-hour day by external cues ('Zeitgebers') such as daylight $[16,17]$. A circadian rhythm can be conceptualized as a cyclic process whose period, phase and amplitude of oscillation are determined by clock genes $[14,18]$.

The sleep-wake cycle in humans is consolidated by the interaction of two opponent processes: process $S$ (the homeostatic drive for sleep) and process C (circadian) [1114]. Process $S$ accumulates as a function of prior wakefulness and dissipates during sleep. Process $C$ is under circadian control and, depending on circadian phase, has either a wake-promoting (i.e., usually during the day) or a sleep-consolidating function (i.e., usually during the night) [11-14]. In other words, process $C$ helps keeping the sleep-wake cycle in sync with environmental light-dark cycles. See Figure 1 for a graphical depiction of the two-process model of sleep regulation.

Wakefulness is associated with ascending pathways originating from neurons in upper brainstem structures, either through cholinergic projections to the thalamus

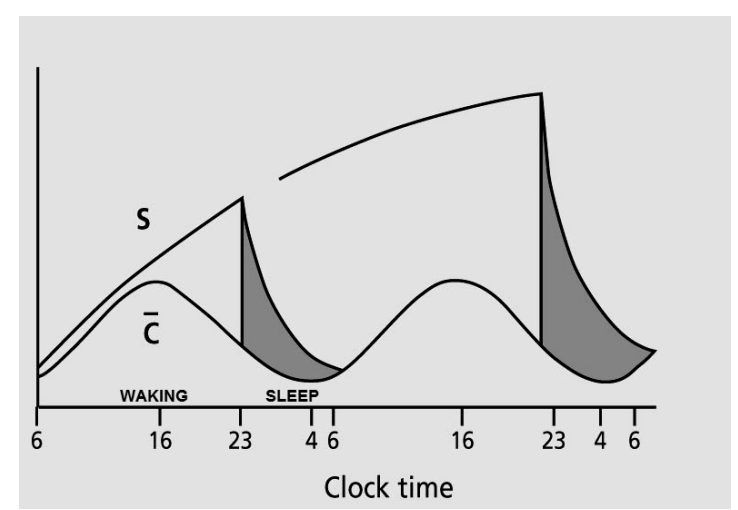

Figure 1 | The two-process model of sleep regulation [adapted from 24]. 
(path 1), or monoaminergic projections to the hypothalamus, basal forebrain and cortex (path 2) [19-22]. Sleep, on the other hand, is associated with GABA-ergic sleeppromoting neurons in the ventrolateral preoptic nucleus of the hypothalamus (VLPO) [19-22]. As further explored in Chapter 4, the monoaminergic neurotransmitter serotonin may play a special role in the association between sleep, affect and depression [23].

\section{Affect}

Human behaviour is thought to underlie two motivational systems, a 'behavioural approach' or 'behavioural activation' system (BAS) [25-29], and a 'withdrawal' or 'behavioural inhibition' system (BIS) [25-30]. As the name implies, BAS is associated with goal-directed behaviours focused on obtaining rewards and/or pleasure. It is an appetitive system that directs an individual towards certain (potentially incentive) situations. From an evolutionary perspective, this system primarily functions to ensure that the individual is supplied by basic needs such as food. Conversely, BIS is associated with withdrawing behaviour, focused on preventing behaviour which could possibly lead to pain or punishment. Therefore, this system directs an individual away from certain (potentially aversive) situations and may function adaptively by keeping the individual out of danger [27-29, 31].

The BIS and BAS are thought to be the origin of the affective experiences associated with approach and avoidance related behaviour: positive affect (PA) and negative affect (NA) [26, 28, 31, 32]. Supported by several studies into the factorial structure of affect, PA reflects affective states such as enthusiasm, cheerfulness, and excitement, while NA reflects states such as anxiety, guilt, and distress [31, 33, 34]. Interpreted in the context of the two fundamental motivational systems, the logic of this dichotomous structure emerges: feelings of cheerfulness motivate the individual to approach a novel situation, while feelings of fear stimulate the individual to back up from a potential threat. As explored in Chapter 5 in more detail, this theory is supported by the finding that PA, but not NA, shows a diurnal (presumably circadian) rhythm, priming the individual to be active during daytime when the chance of reward is high $[31,33]$.

As we have seen, PA and NA are associated with certain behavioural tendencies. In the case of NA, a dangerous situation is believed to narrow down the individual's scope of attention and reduce the thought-action repertoire in order to facilitate the quick choice of the most appropriate behavioural strategy (i.e. escape) [35-37]. Unlike the threatening situations which require quick action typically linked to high NA, the call 
for action in situations linked to high PA is usually less imminent; therefore, it allows for a broadening of the thought-action repertoire [35-37]. In this way, high levels of PA are associated with wider and more flexible behavioural and cognitive strategies. This idea is elaborated in the 'broaden and build theory of positive emotions', emphasizing the adaptive benefits of the mind-broadening consequences of PA in terms of creating lasting personal resources: resilience, social capacities, general health [35, 36], as well as empowerment [38,39]. In depression, the role of PA has received special attention, as described in more detail below.

\section{Depression and the role of positive affect}

Depression has been conceptualized as a disorder of affect regulation; specifically, it has been conceptualized as a state characterized by high levels of NA and low levels of PA [40-43]. A state of high levels of NA appears to be nonspecific for depression, as it has been shown to be shared with other psychopathologies, including anxiety [40]. Conversely, a state of low levels of PA appears to be specific to depression [4043]. Several cues have been identified suggesting that the role of PA in depression should be emphasized. First, anhedonia, the 'loss of pleasure in all, or almost all activities' or a 'lack of reactivity to usually pleasurable stimuli' (American Psychiatric Association, 2000, p. 418 [2]), is a fundamental symptom of depression, especially in the melancholic subtype. Anhedonia seems to be a prime example of reduced PA or a dysfunctional BAS system: motivated and goal-directed behaviours decrease remarkably [31,44]. Second, except for the overall amount of PA, the diurnal variation of PA has been shown to be altered in depression, which is a possible indicator of disturbed endogenous rhythmicity [45-47] (further investigated in Chapter 5). Third, the ability to experience PA appears to be predictive of the development and course of depression $[48,49]$.

In other words, positive affectivity seems to play a crucial role in depression, making the PA system a promising target for novel interventions in depression, which traditionally focus on negative affectivity [50]. Indeed, first studies show that mindfulness approaches to increase PA are efficient in those vulnerable to depression [51]. Furthermore, cognitive bias modification techniques are efficient in increasing positive appraisal bias [52]. In Chapters 6, 7 and 8, a novel intervention in depression, based on the Experience Sampling Method (ESM, see below) and consisting of personalized feedback focusing on positive affective experience in daily life, is investigated.

However, next to the processes primarily related to affect regulation, other processes seem crucial to depression as well. One of these processes is sleep. 


\section{Linking sleep, affect, and depression}

There appears to be a very palpable link between sleep and affect. As familiar to most of us, a lack of sleep or poor sleep has been associated with subsequent mood dysregulation (i.e. decreased PA and increased NA or increased physiological reactions to negative events). This mood dysregulation has been demonstrated when sleep deprivation is either experimentally induced [53-61] or when sleep is measured using ambulatory methods [62-65]. On the other hand, negative mood has been associated with poor subsequent sleep $[66,67]$. The directionality of the day-to-day associations between sleep and affect is further investigated in Chapter 3.

The link between sleep and affect is most apparent in the case of affective disorders, especially in major depression. The vast majority of patients suffering from depression reports sleep disturbances, predominantly in the form of insomnia (i.e. the inability to fall asleep or maintain sleep) [68-71]. Furthermore, individuals diagnosed with depression show an altered sleep architecture such as decreased slow wave sleep and increased REM (rapid eye movement) sleep density [72].

In the past, sleep disturbances were merely considered and treated as a symptom of depression. However, during the last decades, several findings challenged the notion of sleep disturbances as a mere epiphenomenon to depression. Epidemiological studies identified poor sleep as an independent and prominent risk factor for the development of depression [for a meta-analytic evaluation, see 73]; a finding which is further explored in Chapter 3. Sleep disturbances appear to predict the trajectory of depression in terms of relapse rates and severity [74-79]. Similarly, preliminary evidence has indicated that the successful treatment of insomnia, either pharmacologically or psychologically, also favourably affects other depressive symptoms such as mood [80, 81]. Furthermore, depression is overrepresented in individuals diagnosed with a sleep disorder [e.g. 82, 83, but see 84]. Paradoxically, partial or total sleep deprivation leads to a short-lived, rapid antidepressant response in $40-60 \%$ of depressed patients $[85,86]$. The mechanisms for this effect are not yet elucidated; however, among recent theories conceptualizing the effects of sleep deprivation in terms of resetting the abnormal functioning of circadian clock genes [87], one points towards the monoaminergic neurotransmitter serotonin [23]. Serotonin plays a key role in both sleep and wakefulness $[88,89]$. It has been suggested that the underlying mechanisms associated with the antidepressant effects of a night of sleep deprivation are similar to the mechanisms associated with serotonin reuptake inhibitors (i.e. antidepressants) [23]. As such, serotonin has been proposed as one possible neurobiological link between sleep and depression [23]. There is evidence that genes involved in the regulation of serotonin (i.e. the serotonin transporter gene 5-HTTLPR) 
are associated with depression [90,91], but also with insomnia and sleep quality [92-94]. In Chapter 4, a functional polymorphism in the serotonin transporter gene (5-HTTLPR) as a moderator in the association between sleep and affect is examined in detail.

To conclude, these findings emphasize the necessity and significance of more research into the underlying mechanisms linking sleep and affect regulation, in both healthy and depressed individuals.

\section{Measuring sleep and affect prospectively in daily life}

\section{Sleep}

Traditionally, the 'gold standard' for sleep assessment has been polysomnography (PSG), the objective evaluation of sleep in terms of sleep staging. While this measure reflects a fundamental aspect of sleep, it does not appraise another indispensable aspect of sleep, that is, the perceived, or subjective, quality of sleep. Perceived sleep (which can profoundly deviate from objective sleep measures [95-97]), is particularly important when studying the association between sleep and depression; by definition, the symptom of disturbed sleep in depression is a subjective one (American Psychiatric Association, 2000). Unfortunately, although the term 'subjective sleep quality' is used universally through countless disciplines, there is no real consensus as to the construct of subjective sleep quality and how best to assess it $[96,98,99]$. One of the most frequently used measures to assess subjective sleep quality is the Pittsburgh Sleep Quality Index (PSQI) [96]. This questionnaire is well-validated [96, 100, 101]; however, it is highly retrospective since it assesses sleep quality during the previous month. As will be introduced in the next section, such retrospective self-reports are highly problematic [102]. As further explored in Chapter 2, an alternative to these retrospective sleep questionnaires may be the use of ambulatory sleep diaries [103], in which self-reported sleep is evaluated every morning upon waking in order to minimize memory load and increase ecological validity.

\section{Affect}

The valid and reliable assessment of affective states is one of the biggest challenges for mental health research. In the majority of cases, current research relies on global, retrospective self-reports in the form of questionnaires at the researcher's or clinician's office (i.e. 'How often, on average, did you experience anxiety during the last week/month?'). While representing a seemingly convenient and cost-effective technique, it conveys two major problems. First, research has convincingly shown that 
retrospective self-reports are associated with substantial systematic bias, calling into question the reliability and validity of those reports [i.e. 104; for an overview, see 102,]. Second, by relying on self-reported 'mean scores' aggregated over days, weeks or even months, it prevents investigations into the underlying dynamics and mechanisms (i.e. changes over time and across context, and interactions with certain context or behaviour) as they unfold in everyday life [105-107].

A solution to these challenges forms the experience sampling method (ESM), an ambulatory assessment technique in which individual's affective states, behaviour, and context are assessed prospectively, repeatedly and in the real world [105-111]. Through the prospective character, also referred to as the momentary aspect of ESM, bias associated with retrospective recall can be eliminated. By assessing variables of interest repeatedly (i.e. PA and NA together with contextual information ten times a day for several days), fine-grained, high-resolution information is gained, enabling investigations into the dynamic changes over time, across context and behaviour, and within a person (i.e. the 'micro-level' of experience). Through the everyday, real-world character, these ESM-derived findings are ecologically valid, making them highly generalizable [105-111].

\section{Using ambulatory assessment as intervention}

Although not yet systematically investigated, ESM may be an attractive source for new interventions (herein referred to as ESM-I) for two primary reasons. First, daily life affect, behaviour and context is mapped in great detail, allowing the exploration of underlying associations. Second, with the advent of electronic sampling devices (i.e. PDA's, smart phones) any information collected by ESM is readily available to both patient and clinician [112-114]. The prospect of ESM-I is further explored in Chapters 6-8, in which ESM-based personalized feedback, focused on positive affective experience in daily life, is given in order to enhance PA in a sample of depressed patients (Chapter 7). Furthermore, through the high degree of self-monitoring produced by ESM-I methods, the patient takes a more active role, possibly leading to a better informed patient. This may in turn be associated with better self-management strategies and perceived empowerment. The effects of ESM-based personalized feedback are investigated in Chapter 8. 


\section{Aims and outline of this thesis}

The current thesis exploits two unique potentials of ambulatory assessment techniques: (I) investigating the specific mechanisms and dynamics underlying psychopathology at a micro-level, and (II) applying ambulatory assessment techniques therapeutically to intervene on these micro-mechanisms. Specifically, in part I of this thesis, we investigated micro-mechanisms underlying depression by studying this disorder in regard to subjective sleep, affective experience, and the diurnal variation of affect. In part II, we explored the use of ambulatory assessments as a tool to intervene on these micro-mechanisms in depression, in the form of ESM-based personalized feedback.

\section{Part 1: Prospectively assessing self-reported sleep, (diurnal variations of) affect, and their associations: investigating mechanisms underlying depression}

Part 1 opens with a preface in the form of a methodological investigation of two forms of subjective (self-reported) sleep assessment: a retrospective sleep questionnaire (PSQI) and a prospective, ambulatory sleep diary (Chapter 2). In Chapter 3, we investigated the day-to-day associations between self-reported sleep and affect and how this relates to follow-up depressive symptoms. In Chapter 4, we examined the role of the serotonin transporter polymorphism 5-HTTLPR in this previously identified association between sleep and affect. In Chapter 5, we investigated the diurnal variation in PA and NA in depression, psychosis and controls.

\section{Part 2: The Experience Sampling Method as intervention in depression}

Part 2 opens with a general introduction into the idea and feasibility of using ambulatory assessments as an intervention (Chapter 6). In Chapter 7 and 8, the results of a randomized controlled trial (RCT), in which PA-focused feedback based on ESM self-reports is implemented as an intervention (ESM-I) in depression, are described. In Chapter 7, we examined the effects of this ESM-I RCT on momentary PA and NA. In Chapter 8, we examined the effects of this ESM-I RCT on patient's feelings of empowerment.

Finally, this thesis closes with a general discussion, synthesizing the results of the research conducted and highlighting important areas for future research and theoretical advancement (Chapter 9). 


\section{References}

1. World Health Organization. Depression: A global crisis: World Mental Health Day. Geneva, Switzerland: World Health Organization Links. 2012.

2. American Psychiatric Association. Diagnostic and Statistical Manual of Mental Disorders (DSM-IVTR). Washington, DC: American Psychiatric Association; 2000.

3. Bromet E, Andrade LH, Hwang I, Sampson NA, Alonso J, de Girolamo G, et al. Cross-national epidemiology of DSM-IV major depressive episode. BMC Med. 2011;9:90.

4. Vos T, Flaxman AD, Naghavi M, Lozano R, Michaud C, Ezzati M, et al. Years lived with disability (YLDs) for 1160 sequelae of 289 diseases and injuries 1990-2010: a systematic analysis for the Global Burden of Disease Study 2010. Lancet. 2013;380(9859):2163-96.

5. Ferrari AJ, Charlson FJ, Norman RE, Patten SB, Freedman G, Murray CJ, et al. Burden of depressive disorders by country, sex, age, and year: findings from the global burden of disease study 2010. PLoS Med. 2013;10(11):e1001547.

6. González HM, Vega WA, Williams DR, Tarraf W, West BT, Neighbors HW. Depression care in the United States: too little for too few. Arch Gen Psychiatry. 2010;67(1):37-46.

7. Little A. Treatment-resistant depression. Am Fam Physician. 2009;80(2):167-72.

8. Shelton RC, Osuntokun 0 , Heinloth AN, Corya SA. Therapeutic options for treatment-resistant depression. CNS Drugs. 2010;24(2):131-61.

9. Hirschfeld R. The epidemiology of depression and the evolution of treatment. J Clin Psychiatry. 2012;73(Suppl 1):5-9.

10. Siegel JM. Sleep viewed as a state of adaptive inactivity. Nat Rev Neurosci. 2009;10(10):747-53.

11. Borbély AA. A two process model of sleep regulation. Hum Neurobiol. 1982.

12. Achermann P. The two-process model of sleep regulation revisited. Aviat Space Environ Med. 2004;75(Supplement 1):A37-A43.

13. Dijk D-J, Czeisler CA. Paradoxical timing of the circadian rhythm of sleep propensity serves to consolidate sleep and wakefulness in humans. Neurosci Lett. 1994;166(1):63-8.

14. Czeisler CA, Gooley J, editors. Sleep and circadian rhythms in humans. Cold Spring Harb Symp Quant Biol; 2007: Cold Spring Harbor Laboratory Press.

15. Kleitman N. Sleep and wakefulness. Chicago, Illinois: University of Chicago Press; 1963.

16. Klein DC, Moore RY, Reppert SM. Suprachiasmatic nucleus: the mind's clock. New York: Oxford University Press; 1991.

17. ReppertSM, Weaver DR. Coordination of circadian timing in mammals. Nature. 2002;418(6901):93541.

18. Vitaterna M, Pinto L, Turek F. Molecular genetic basis for mammalian circadian rhythms. In: Kryger M, Roth T, Dement W, editors. Principles and Practices of Sleep Medicine. 4. Philadelphia: Elsevier Saunders; 2005. p. 363-74.

19. Saper CB, Chou TC, Scammell TE. The sleep switch: hypothalamic control of sleep and wakefulness. Trends Neurosci. 2001;24(12):726-31.

20. Saper CB, Fuller PM, Pedersen NP, Lu J, Scammell TE. Sleep state switching. Neuron. 2010;68(6):102342.

21. Saper CB, Scammell TE, Lu J. Hypothalamic regulation of sleep and circadian rhythms. Nature. 2005;437(7063):1257-63.

22. Schwartz JR, Roth T. Neurophysiology of sleep and wakefulness: basic science and clinical implications. Curr Neuropharmacol. 2008;6(4):367. 
23. Adrien J. Neurobiological bases for the relation between sleep and depression. Sleep Med Rev. 2002;6(5):341-51.

24. Borbély AA. Sleep homeostasis and models of sleep regulation. In: Kryger MH, Roth T, Dement WC, editors. Principles and practice of sleep medicine. 2nd ed. Philadelphia: Saunders; 1994. p. 309-20.

25. Gray JA. Perspectives on anxiety and impulsivity: A commentary. J Res Pers. 1987;21(4):493-509.

26. Gray JA. Brain systems that mediate both emotion and cognition. Cogn Emot. 1990;4(3):269-88.

27. Gray JA. Personality dimensions and emotion systems. In: Ekman P, Davidson R, editors. The nature of emotion: Fundamental questions. New York: Oxford University Press; 1994. p. 329-31.

28. Gray JA. Three fundamental emotion systems. In: Ekman P, Davidson R, editors. The nature of emotion: Fundamental questions. New York: Oxford University Press; 1994. p. 243-7.

29. Davidson RJ. Affective style and affective disorders: Perspectives from affective neuroscience. Cogn Emot. 1998;12(3):307-30.

30. Cloninger CR. A systematic method for clinical description and classification of personality variants: a proposal. Arch Gen Psychiatry. 1987;44(6):573.

31. Watson D, Wiese D, Vaidya J, Tellegen A. The two general activation systems of affect: Structural findings, evolutionary considerations, and psychobiological evidence. J Pers Soc Psychol. 1999;76(5):820.

32. Carver CS. Affect and the functional bases of behavior: On the dimensional structure of affective experience. Pers Soc Psychol Rev. 2001;5(4):345-56.

33. Murray G, Nicholas CL, Kleiman J, Dwyer R, Carrington MJ, Allen NB, et al. Nature's clocks and human mood: the circadian system modulates reward motivation. Emotion. 2009;9(5):705-16.

34. Watson D. Intraindividual and interindividual analyses of positive and negative affect: their relation to health complaints, perceived stress, and daily activities. J Pers Soc Psychol. 1988;54(6):1020.

35. Fredrickson BL. The role of positive emotions in positive psychology: The broaden-and-build theory of positive emotions. Am Psychol. 2001;56(3):218.

36. Fredrickson BL, Branigan C. Positive emotions broaden the scope of attention and thought-action repertoires. Cogn Emot. 2005;19(3):313-32.

37. Schmitz TW, De Rosa E, Anderson AK. Opposing influences of affective state valence on visual cortical encoding. J Neurosci. 2009;29(22):7199-207.

38. Diener E, Biswas-Diener R, editors. Findings on subjective well-being. Workshop on 'Measuring Empowerment: Cross Disciplinary Perspectives' conducted at World Bank, Washington DC; 2003.

39. Clore GL, Huntsinger JR. How emotions inform judgment and regulate thought. Trends Cogn Sci. 2007;11(9):393-9.

40. Watson D, Clark LA, Carey G. Positive and negative affectivity and their relation to anxiety and depressive disorders. J Abnorm Psychol. 1988;97(3):346.

41. Clark LA, Watson D. Tripartite model of anxiety and depression: psychometric evidence and taxonomic implications. J Abnorm Psychol. 1991;100(3):316.

42. Watson D, Clark LA, Stasik SM. Emotions and the emotional disorders: A quantitative hierarchical perspective. Int J Clin Health Psychol. 2011;11(3).

43. Watson D, Naragon-Gainey K. On the specificity of positive emotional dysfunction in psychopathology: Evidence from the mood and anxiety disorders and schizophrenia/schizotypy. Clin Psychol Rev. 2010;30(7):839-48.

44. J. Tomarkenand A, Keener AD. Frontal brain asymmetry and depression: A self-regulatory perspective. Cogn Emot. 1998;12(3):387-420. 
45. Murray G. Diurnal mood variation in depression: a signal of disturbed circadian function? J Affect Disord. 2007;102(1-3):47-53.

46. Peeters F, Berkhof J, Delespaul P, Rottenberg J, Nicolson NA. Diurnal mood variation in major depressive disorder. Emotion. 2006;6(3):383.

47. Wirz-Justice A. Diurnal variation of depressive symptoms. Dialogues Clin Neurosci. 2008;10(3):337.

48. Geschwind N, Nicolson NA, Peeters F, van Os J, Barge-Schaapveld D, Wichers M. Early improvement in positive rather than negative emotion predicts remission from depression after pharmacotherapy. Eur Neuropsychopharmacol. 2011;21(3):241-7.

49. Wichers M, Kenis G, Jacobs N, Myin-Germeys I, Schruers K, Mengelers R, et al. The psychology of psychiatric genetics: evidence that positive emotions in females moderate genetic sensitivity to social stress associated with the BDNF Val-sup-6-sup-6Met polymorphism. J Abnorm Psychol. 2008;117(3):699-704.

50. Dunn BD. Helping depressed clients reconnect to positive emotion experience: current insights and future directions. Clin Psychol Psychother. 2012;19(4):326-40.

51. Geschwind N, Peeters F, Drukker M, van Os J, Wichers M. Mindfulness training increases momentary positive emotions and reward experience in adults vulnerable to depression: a randomized controlled trial. J Consult Clin Psychol. 2011;79(5):618-28.

52. Lang TJ, Moulds ML, Holmes EA. Reducing depressive intrusions via a computerized cognitive bias modification of appraisals task: Developing a cognitive vaccine. Behav Res Ther. 2009;47(2):13945.

53. Dinges DF, Pack F, Williams K, Gillen KA, Powell JW, Ott GE, et al. Cumulative sleepiness, mood disturbance, and psychomotor vigilance performance decrements during a week of sleep restricted to 4-5 hours per night. Sleep. 1997;20(4):267-77.

54. Franzen PL, Buysse DJ, Dahl RE, Thompson W, Siegle GJ. Sleep deprivation alters pupillary reactivity to emotional stimuli in healthy young adults. Biol Psychol. 2009;80(3):300-5.

55. Franzen PL, Siegle GJ, Buysse DJ. Relationships between affect, vigilance, and sleepiness following sleep deprivation. J Sleep Res. 2008;17(1):34-41.

56. Paterson JL, Dorrian J, Ferguson SA, Jay SM, Lamond N, Murphy PJ, et al. Changes in structural aspects of mood during 39-66 h of sleep loss using matched controls. Appl Ergon. 2011;42(2):196201.

57. Penetar D, McCann U, Thorne D, Kamimori G, Galinski C, Sing H, et al. Caffeine reversal of sleep deprivation effects on alertness and mood. Psychopharmacology (Berl). 1993;112(2-3):359-65.

58. Talbot LS, McGlinchey EL, Kaplan KA, Dahl RE, Harvey AG. Sleep deprivation in adolescents and adults: changes in affect. Emotion. 2010;10(6):831-41.

59. Yoo SS, Gujar N, Hu P, Jolesz FA, Walker MP. The human emotional brain without sleep--a prefrontal amygdala disconnect. Curr Biol. 2007;17(20):R877-8.

60. Dagys N, McGlinchey EL, Talbot LS, Kaplan KA, Dahl RE, Harvey AG. Double trouble? The effects of sleep deprivation and chronotype on adolescent affect. J Child Psychol Psychiatry. 2011;53(6):6607.

61. Kahn-Greene ET, Killgore DB, Kamimori GH, Balkin TJ, Killgore WD. The effects of sleep deprivation on symptoms of psychopathology in healthy adults. Sleep Med. 2007;8(3):215-21.

62. Buysse DJ, Thompson W, Scott J, Franzen PL, Germain A, Hall M, et al. Daytime symptoms in primary insomnia: a prospective analysis using ecological momentary assessment. Sleep Med. 2007;8(3):198-208. 
63. McCrae CS, McNamara JP, Rowe MA, Dzierzewski JM, Dirk J, Marsiske M, et al. Sleep and affect in older adults: using multilevel modeling to examine daily associations. J Sleep Res. 2008;17(1):4253.

64. Talbot LS, Stone S, Gruber J, Hairston IS, Eidelman P, Harvey AG. A test of the bidirectional association between sleep and mood in bipolar disorder and insomnia. J Abnorm Psychol. 2012;121(1):39-50.

65. Zohar D, Tzischinsky 0, Epstein R, Lavie P. The effects of sleep loss on medical residents' emotional reactions to work events: a cognitive-energy model. Sleep. 2005;28(1):47-54.

66. Akerstedt T, Kecklund G, Axelsson J. Impaired sleep after bedtime stress and worries. Biol Psychol. 2007;76(3):170-3.

67. Vandekerckhove M, Weiss R, Schotte C, Exadaktylos V, Haex B, Verbraecken J, et al. The role of presleep negative emotion in sleep physiology. Psychophysiology. 2011;48(12):1738-44.

68. Hamilton M. Frequency of symptoms in melancholia (depressive illness). Br J Psychiatry. 1989;154(2):201-6.

69. Tsuno N, Besset A, Ritchie K. Sleep and depression. J Clin Psychiatry. 2005;66(10):1254-69.

70. Casper RC, Redmond Jr DE, Katz MM, Schaffer CB, Davis JM, Koslow SH. Somatic symptoms in primary affective disorder: presence and relationship to the classification of depression. Arch Gen Psychiatry. 1985;42(11):1098.

71. Riemann D, Berger M, Voderholzer U. Sleep and depression--results from psychobiological studies: an overview. Biol Psychol. 2001;57(1-3):67-103.

72. Pillai V, Kalmbach DA, Ciesla JA. A meta-analysis of electroencephalographic sleep in depression: evidence for genetic biomarkers. Biol Psychiatry. 2011;70(10):912-9.

73. Baglioni C, Battagliese G, Feige B, Spiegelhalder K, Nissen C, Voderholzer U, et al. Insomnia as a predictor of depression: a meta-analytic evaluation of longitudinal epidemiological studies. J Affect Disord. 2011;135(1-3):10-9.

74. Buysse DJ, Tu XM, Cherry CR, Begley AE, Kowalski J, Kupfer DJ, et al. Pretreatment REM sleep and subjective sleep quality distinguish depressed psychotherapy remitters and nonremitters. Biol Psychiatry. 1999;45(2):205-13.

75. Dew MA, Reynolds III CF, Houck PR, Hall M, Buysse DJ, Frank E, et al. Temporal profiles of the course of depression during treatment: predictors of pathways toward recovery in the elderly. Arch Gen Psychiatry. 1997;54(11):1016.

76. Liu X, Buysse DJ, Gentzler AL, Kiss E, Mayer L, Kapornai K, et al. Insomnia and hypersomnia associated with depressive phenomenology and comorbidity in childhood depression. Sleep. 2007;30(1):8390.

77. Pigeon WR, Hegel M, Unützer J, Fan M-Y, Sateia MJ, Lyness JM, et al. Is insomnia a perpetuating factor for late-life depression in the IMPACT cohort? Sleep. 2008;31(4):481.

78. Perlis ML, Giles DE, Buysse DJ, Tu X, Kupfer DJ. Self-reported sleep disturbance as a prodromal symptom in recurrent depression. J Affect Disord. 1997;42(2):209-12.

79. Troxel WM, Kupfer DJ, Reynolds CF, Frank E, Thase M, Miewald J, et al. Insomnia and objectively measured sleep disturbances predict treatment outcome in depressed patients treated with psychotherapy or psychotherapy-pharmacotherapy combinations. J Clin Psychiatry. 2012;73(4):478.

80. Krystal A, Fava M, Rubens R, Wessel T, Caron J, Wilson P, et al. Evaluation of eszopiclone discontinuation after cotherapy with fluoxetine for insomnia with coexisting depression. J Clin Sleep Med. 2007;3(1):48-55. 
81. Manber R, Edinger JD, Gress JL, San Pedro-Salcedo MG, Kuo TF, Kalista T. Cognitive behavioral therapy for insomnia enhances depression outcome in patients with comorbid major depressive disorder and insomnia. Sleep. 2008;31(4):489.

82. Buysse DJ, Reynolds CF, Kupfer DJ, Thorpy MJ, Bixler E, Manfredi R, et al. Clinical diagnoses in 216 insomnia patients using the International Classification of Sleep Disorders (ICSD), DSM-IV and ICD10 categories: a report from the APA/NIMH DSM-IV Field Trial. Sleep. 1994;17(7):630-7.

83. Vandeputte $M$, de Weerd A. Sleep disorders and depressive feelings: a global survey with the Beck depression scale. Sleep Med. 2003;4(4):343-5.

84. Franzen PL, Buysse DJ. Sleep disturbances and depression: risk relationships for subsequent depression and therapeutic implications. Dialogues Clin Neurosci. 2008;10(4):473-81.

85. Benedetti F, Barbini B, Colombo C, Smeraldi E. Chronotherapeutics in a psychiatric ward. Sleep Med Rev. 2007;11(6):509-22.

86. Wu JC, Bunney WE. The biological basis of an antidepressant response to sleep deprivation and relapse: review and hypothesis. Am J Psychiatry. 1990.

87. Bunney BG, Bunney WE. Mechanisms of rapid antidepressant effects of sleep deprivation therapy: clock genes and circadian rhythms. Biol Psychiatry. 2013;73(12):1164-71.

88. Guzmán-Marín R, Alam MN, Szymusiak R, Drucker-Colín R, Gong H, McGinty D. Discharge modulation of rat dorsal raphe neurons during sleep and waking: effects of preoptic/basal forebrain warming. Brain Res. 2000;875(1):23-34.

89. Portas CM, Bjorvatn B, Ursin R. Serotonin and the sleep/wake cycle: special emphasis on microdialysis studies. Prog Neurobiol. 2000;60(1):13-35.

90. Canli T, Lesch KP. Long story short: the serotonin transporter in emotion regulation and social cognition. Nat Neurosci. 2007;10(9):1103-9.

91. Caspi A, Sugden K, Moffitt TE, Taylor A, Craig IW, Harrington H, et al. Influence of life stress on depression: moderation by a polymorphism in the 5-HTT gene. Science. 2003;301(5631):386-9.

92. Barclay NL, Eley TC, Mill J, Wong CC, Zavos HM, Archer SN, et al. Sleep quality and diurnal preference in a sample of young adults: associations with 5HTTLPR, PER3, and CLOCK 3111. Am J Med Genet B Neuropsychiatr Genet. 2011;156B(6):681-90.

93. Brummett BH, Krystal AD, Ashley-Koch A, Kuhn CM, Zuchner S, Siegler IC, et al. Sleep quality varies as a function of 5-HTTLPR genotype and stress. Psychosom Med. 2007;69(7):621-4.

94. Deuschle M, Schredl M, Schilling C, Wust S, Frank J, Witt SH, et al. Association between a serotonin transporter length polymorphism and primary insomnia. Sleep. 2010;33(3):343-7.

95. Rosa RR, Bonnet MH. Reported chronic insomnia is independent of poor sleep as measured by electroencephalography. Psychosom Med. 2000;62(4):474-82.

96. Buysse DJ, Reynolds CF, 3rd, Monk TH, Berman SR, Kupfer DJ. The Pittsburgh Sleep Quality Index: a new instrument for psychiatric practice and research. Psychiatry Res. 1989;28(2):193-213.

97. Edinger JD, Fins AI, Glenn DM, Sullivan Jr RJ, Bastian LA, Marsh GR, et al. Insomnia and the eye of the beholder: are there clinical markers of objective sleep disturbances among adults with and without insomnia complaints? J Consult Clin Psychol. 2000;68(4):586.

98. Harvey AG, Stinson K, Whitaker KL, Moskovitz D, Virk H. The subjective meaning of sleep quality: a comparison of individuals with and without insomnia. Sleep. 2008;31(3):383.

99. Akerstedt T, Hume K, Minors D, Waterhouse J. The subjective meaning of good sleep, an intraindividual approach using the Karolinska Sleep Diary. Percept Mot Skills. 1994;79(1):287-96.

100. Backhaus J, Junghanns K, Broocks A, Riemann D, Hohagen F. Test-retest reliability and validity of the Pittsburgh Sleep Quality Index in primary insomnia. J Psychosom Res. 2002;53(3):737-40. 
101. Doi Y, Minowa M, Uchiyama M, Okawa M, Kim K, Shibui K, et al. Psychometric assessment of subjective sleep quality using the Japanese version of the Pittsburgh Sleep Quality Index (PSQI-J) in psychiatric disordered and control subjects. Psychiatry Res. 2000;97(2-3):165-72.

102. Schwarz N. Retrospective and concurrent self-reports: The rationale for real-time data capture. In: Stone A, Shiffman S, Atienza A, Nebeling L, editors. The science of real-time data capture: Selfreports in health research. New York: Oxford University Press; 2007. p. 11-26.

103. Carney CE, Buysse DJ, Ancoli-Israel S, Edinger JD, Krystal AD, Lichstein KL, et al. The consensus sleep diary: standardizing prospective sleep self-monitoring. Sleep. 2012;35(2):287-302.

104. Clark DM, Teasdale JD. Diurnal variation in clinical depression and accessibility of memories of positive and negative experiences. J Abnorm Psychol. 1982;91(2):87.

105. Shiffman S, Stone AA, Hufford MR. Ecological momentary assessment. Annu Rev Clin Psychol. 2008;4:1-32.

106. Trull TJ, Ebner-Priemer U. Ambulatory assessment. Annu Rev Clin Psychol. 2013;9:151-76.

107. Wichers M. The dynamic nature of depression: a new micro-level perspective of mental disorder that meets current challenges. Psychol Med. 2013:1-12.

108. Hektner J, Csikszentmihalyi M. The experience sampling method: Measuring the context and content of lives. In: Bechtel R, Churchman A, editors. Handbook of environmental psychology. New York: John Wiley \& Sons, Inc. ; 2002. p. 233-43.

109. Myin-Germeys I, Oorschot M, Collip D, Lataster J, Delespaul P, van Os J. Experience sampling research in psychopathology: opening the black box of daily life. Psychol Med. 2009;39(9):1533-47.

110. Csikszentmihalyi M, Larson R. Validity and reliability of the Experience-Sampling Method. J Nerv Ment Dis. 1987;175(9):526-36.

111. Delespaul P. Assessing schizophrenia in daily life. The experience sampling method. Maastricht: Maastricht University Press; 1995.

112. Palmier-Claus J. The clinical uses of momentary assessment. Acta Psychiatr Scand. 2011;124(4):2412.

113. Wichers M, Hartmann JA, Kramer IM, Lothmann C, Peeters F, van Bemmel L, et al. Translating assessments of the film of daily life into person-tailored feedback interventions in depression. Acta Psychiatr Scand. 2011;123(5):402-3.

114. Wichers M, Simons CJ, Kramer IM, Hartmann JA, Lothmann C, Myin-Germeys I, et al. Momentary assessment technology as a tool to help patients with depression help themselves. Acta Psychiatr Scand. 2011;124(4):262-72. 




\section{PART I}

Experience Sampling Method as assessment tool 


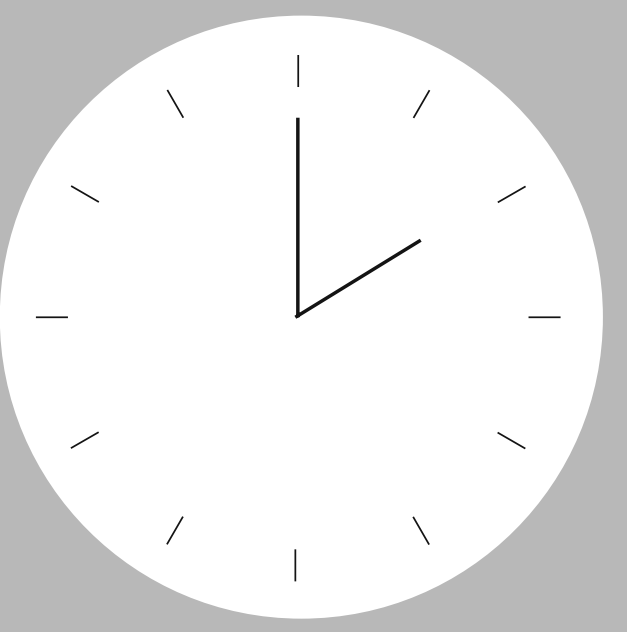

\section{Chapter 2}




\title{
Exploring the construct of subjective sleep quality in those with insomnia
}

\author{
Hartmann, JA, \\ Carney, CE, \\ Lachowski A, \\ Edinger, JE
}




\section{Abstract}

Background: The construct of subjective sleep quality is poorly understood. One widely used measure of subjective sleep quality is the Pittsburgh Sleep Quality Index (PSQI). The role of psychiatric illness in the association between the PSQI and a prospective, sleep-diary based sleep quality measure (SDSQ), was investigated plus the degree to which the PSQI may reflect mood states.

Method: A sample of 211 insomnia patients (ICDS-2), divided by the presence or absence of a comorbid psychiatric disorder (DSM-IV-TR) recruited between 01/2004 and 02/2009, completed the PSQI (primary outcome) and two weeks of sleep diary monitoring. First, correlations between PSQI and SDSQ were compared; second, it was investigated if the association between PSQI and SDSQ depends on diagnostic status using regression analyses; third, the differences in sleep quality between the groups, plus the contribution of anxiety and depression in explaining these differences, were explored.

Results: The correlation between PSQI and SDSQ was significant only in the nonpsychiatric group $(\mathrm{P}<.001)$. The association between PSQI and SDSQ was moderated by diagnostic status: it was weaker in psychiatric patients ( $\mathrm{P}=.047)$. Patients with psychiatric comorbidity scored significantly higher on the PSQI than those without $(\mathrm{P}<.001)$; this difference disappeared after controlling for anxiety. There were no group differences for the SDSQ.

Conclusions: The present findings suggest that: (1) psychiatric patients may be more biased in their retrospective sleep quality ratings, and (2) the PSQI total score may reflect sleep-related distress. The use of a prospective sleep diary measure in those with a psychiatric disorder is recommended.

Key Words: Subjective sleep quality, insomnia, PSQI, sleep diary, anxiety, depression, psychiatric comorbidity 


\section{Introduction}

The construct of 'subjective sleep quality' and the assessment thereof has been a complex matter [1-3]. Although being universally used in research and elsewhere, there is no clear consensus of the exact definition of subjective sleep quality and how to measure it; furthermore, it may differ from individual to individual [3]. The Pittsburgh Sleep Quality Index (PSQI), the most widely used questionnaire to assess subjective sleep quality, has been the result of a salient effort to develop a measure tapping the complex construct of sleep quality [3]. The PSQI is a retrospective self-administered questionnaire assessing subjective sleep quality over the previous month; since the publication in 1989, its excellent psychometric qualities have been demonstrated in numerous studies [3-7].

The PSQI scores have been shown to be strongly correlated with measures of depression [6, 8-10] and anxiety [6, 11-14]. A number of studies suggest that retrospective PSQI ratings are especially sensitive to negative mood and may partly reflect negative cognitive viewpoints $[4,15,16]$, a reporting bias which may be more pronounced for those with a psychiatric history $[17,18]$. As such, it may be argued that due to its retrospective nature, the PSQI may not tap the construct of subjective sleep quality purely, but other (negative) states as well, possibly in particular in patients with a psychiatric condition [19].

To confirm this speculation, the present study investigated the retrospective PSQI in relation to a prospective measure of subjective sleep quality in the context of different diagnostic insomnia subtypes, i.e., in patients diagnosed with insomnia either with or without comorbid psychiatric conditions. It was hypothesized that (a) the correlation between PSQI-derived sleep quality and sleep quality derived by a prospective sleep diary would be higher among insomnia patients without psychiatric comorbidity, (b) the association between PSQI-derived sleep quality and sleep diary derived sleep quality would be moderated by psychiatric status, and (c) the two groups would show differences in their appraisals of their sleep quality, but PSQI-derived sleep quality measures would show greater group differences than diary-based sleep quality ratings. In addition, we conducted analyses to determine the contribution of depressive and anxiety symptoms to the group differences observed. 


\section{Methods}

\section{Participants}

Participants were recruited within the framework of a large two-center (Duke University Medical Center, Durham, NC and Rush Medical Center, Chicago, IL) diagnostic insomnia study, described elsewhere [20]. The study was approved by the Institutional Review Boards of both centers and all participants gave their written consent before participation. Participants were either those seeking insomnia treatment or research volunteers recruited via local advertisements; recruitment took place between January 2004 and February 2009. Interested persons were eligible for participation if they were 18 years or older, fluent in English and able to provide informed consent. Participants were not eligible if they reported any severe psychiatric or medical condition that required imminent treatment attention (i.e. requiring referral to a psychiatric hospital), or showed signs of significant cognitive impairment as demonstrated by a Mini Mental Status Exam [21] below 24. For the purpose of this study, only participants diagnosed with an insomnia disorder as the primary diagnosis according to the International Classification of Sleep disorders, second edition (ICSD-2) [22] were included. Those participants who enrolled in the parent study but were found to have polysomnographic evidence of sleep-disordered breathing or periodic limb movement disorder (e.g., $\mathrm{AHI} \geq 15$ ) were excluded from the analyses.

\section{Measures}

\section{Pittsburgh Sleep Quality Index (PSQI)}

The Pittsburgh Sleep Quality Index (PSQI) is a retrospective, self-rated 19-item questionnaire of perceived sleep quality during the last month [3]. It consists of seven domains of sleep difficulties (sleep quality, sleep latency, sleep duration, habitual sleep efficiency, sleep disturbances, use of sleeping medications, and daytime dysfunction) which are summed into a single global score varying from 0 to 21, with higher scores suggesting worse sleep quality. The PSQI has been investigated in various languages and clinical populations, showing good internal consistency, test-retest reliability, and construct validity [3-7], whereas the concordance with objective measures of sleep quality has been low $[3,15]$.

\section{Sleep Diaries}

Over a period of two weeks, participants rated their subjective sleep quality on a 10-point Likert scale (higher scores indicating better sleep quality) using a hand-held personal digital assistant (PDA) programmed using Satellite Forms software (Thacker 
Network Technologies, Inc, Lacombe, Alberta). Participants were instructed to record their sleep quality ratings along with other information about their previous night's sleep daily upon arising from bed. In the analyses conducted herein, each participant's mean sleep quality rating for the two-week period was used.

\section{Beck Anxiety Inventory (BAI)}

The Beck Anxiety Inventory (BAI) is a self-report questionnaire assessing prevailing symptoms of anxiety; it is specifically designed to differentiate anxiety symptoms from depression [23]. The BAI has been shown to have high internal reliability, as well as good factorial and discriminant validity [24], and generally has acceptable psychometric properties in those with insomnia [25].

\section{Beck Depression Inventory (BDI)}

The Beck Depression Inventory, second edition (BDI) is a self-report questionnaire, assessing the severity of common depressive symptoms in 21 4-point Likert items [26]. The BDI is widely used and has acceptable psychometric properties [27, 28, but see also 29]. Since the BDI includes two items measuring changed sleep patterns and fatigue, these items were removed.

\section{Structural Clinical Interview for DSM-IV-TR Axis I (SCID-I)}

The Structural Clinical Interview for DSM-IV-TR Axis I disorders (SCID-I) is a widely used diagnostic instrument to assess the presence of one or more mental disorder(s) according to the DSM-IV-TR [30]. The SCID-I was used to obtain current as well as lifetime DSM-IV-TR diagnosis.

\section{Procedure}

After an initial brief insomnia screening via the telephone, participants were invited to the lab interview, during which the SCID was administered. Participants subsequently completed two weeks of sleep monitoring by using the PDA sleep diary, after which they returned to the research site for two consecutive nights of laboratory polysomnography (PSG) and to complete the self-report questionnaires (i.e. BAI, BDI, PSQI). Thus, the period of sleep monitoring by the sleep diary fell within the fourweek period assessed retrospectively by the PSQI. Upon completion of the measures, participants were assigned a sleep disorder diagnosis by sleep specialists (for a detailed description of the procedures and purposes of the parent study, please see [20]). For the purpose of the current study, only those participants assigned a diagnosis of insomnia according to the ICSD-2, American Academy of Sleep Medicine) and 
having no PSG evidence (mean of two nights) of clinically significant sleep disordered breathing (e.g., AHI $\geq 15$ ) or PLMD (e.g., PLMAI $\geq 15$ ) were selected [31].

\section{Analyses}

Using the ICSD-2 insomnia diagnoses and SCID based DSM-IV-TR psychiatric diagnoses, two groups of participants were formed: One group of participants diagnosed with insomnia without a psychiatric comorbidity (Insomnia, 'I') and one group of participants who were, in addition to insomnia, diagnosed with a current or recently remitted (within last two months) psychiatric condition (Comorbid Insomnia, 'Cl'). All analyses were repeated with the recently remitted patients included in I instead of CI.

\section{Association between PSQI and sleep diary derived sleep quality (SDSQ)}

In our first analysis, we examined the correlation between perceived sleep quality as assessed by the PSQI, and perceived sleep quality as assessed by the sleep diary (SDSQ) in the two insomnia groups. Subsequently, we examined if the association between PSQI sleep quality and SDSQ would depend on diagnostic group (I vs. CI). A regression analysis was performed (STATA 12 [32] routine REG) with the PSQI global score as the outcome variable and mean score of the SDSQ as predictor; subsequently, an interaction term between diagnostic group and SDSQ was added to the model. Post-estimation analyses were performed using the MARGINS and MARGINSPLOT routine in STATA 12.

\section{The contribution of anxiety and depression}

In our second analysis, we investigated if the two insomnia groups differed significantly on the PSQI and assessed the contribution of anxiety and depression. A multiple regression analysis was performed (STATA 12 routine REG) with the PSQI global score as the outcome variable and diagnostic group (I vs. CI), BAI and BDI mean scores as a predictors. In a sensitivity analyses, all patients diagnosed with an anxiety disorder were excluded. The same analysis was repeated with SDSQ as dependent variable instead of the PSQI.

\section{Results}

Means and standard deviations for the PSQI, SDSQ and mood measures are displayed in Table 1. 
Table 1 | Demographic and clinical sample characteristics

\begin{tabular}{|c|c|c|c|}
\hline Variable & $\begin{array}{l}\text { Insomnia without a } \\
\text { comorbid diagnosis }\end{array}$ & $\begin{array}{c}\text { Insomnia with a } \\
\text { comorbid diagnosis }\end{array}$ & Total \\
\hline $\mathrm{N}$ & 96 & 115 & 211 \\
\hline \multicolumn{4}{|l|}{ Demographics } \\
\hline Age (SD) & $49.5(15.5)$ & $45.7(13.8)$ & $47.4(14.7)^{\mathrm{c}}$ \\
\hline Female (\%) & 73.7 & 61.4 & $67.0^{\mathrm{c}}$ \\
\hline Years of education (SD) & $15.1(3.1)$ & $15.0(2.9)$ & $15.0(3.0)^{\mathrm{c}}$ \\
\hline Full/ part time work (\%) & 41.1 & 37.5 & $39.1^{\mathrm{d}}$ \\
\hline Living alone (\%) & 22.1 & 34.5 & $28.9^{\mathrm{a}, \mathrm{e}}$ \\
\hline \multicolumn{4}{|l|}{ Race (number) } \\
\hline - Caucasian & 54 & 68 & 122 \\
\hline - African American & 34 & 39 & 73 \\
\hline - Asian American & 5 & 2 & 7 \\
\hline - $\quad$ American Indian & 1 & 0 & 1 \\
\hline - $\quad$ Other & 1 & 5 & 6 \\
\hline \multicolumn{4}{|l|}{ Clinical characteristics } \\
\hline BAI mean (SD) & $7.8(6.4)$ & $14.1(9.2)$ & $11.2(8.7)^{\mathrm{b}, \mathrm{c}}$ \\
\hline BDI mean (SD) & $10.8(7.4)$ & $19.2(10.9)$ & $15.4(10.4)^{\mathrm{b}, \mathrm{c}}$ \\
\hline PSQI mean (SD) & $11.8(3.3)$ & $13.6(2.9)$ & $12.8(3.2)^{\mathrm{b}, \mathrm{f}}$ \\
\hline SDSQ mean (SD) & $5.1(1.5)$ & $5.1(1.4)$ & $5.1(1.4)^{\mathrm{c}}$ \\
\hline
\end{tabular}

BAI=Beck Anxiety Inventory; BDI=Beck Depression Inventory, PSQI=Pittsburgh Sleep Quality Index; SDSQ=Sleep diary sleep quality

${ }^{a}$ Groups differ significantly $\left(\chi^{2}(1)=3.87, P=.049\right)$

${ }^{\mathrm{b}}$ Groups differ significantly (see results section)

${ }^{\mathrm{c}}$ Missing for 2 participants (1 I, 1 IC)

${ }^{\mathrm{d}}$ Missing for 4 participants (3 I, 1 IC )

${ }^{\mathrm{e}}$ Missing for 3 participants (2 I, 1 IC)

${ }^{\mathrm{f}}$ Missing for 14 participants (7 I, 7 IC)

\section{Participants}

A total of 372 participants were recruited for the parent study, of which 211 met the selection criteria for the current investigation. Of those 211 participants, 96 participants did not suffer any psychiatric condition (I) while 115 participants currently suffered a comorbid psychiatric condition (CI). Table 2 provides an overview of the DSM-IV primary psychiatric diagnoses of the participants in the CI group.

Table 1 provides an overview of the demographic and clinical sample characteristics for the I and CI group. With the exception of their current living arrangements (more participants in CI lived alone as compared to $\left.\mathrm{I}, \chi^{2}(1)=3.87, \mathrm{P}=.049\right)$, the two groups did not differ statistically in demographic variables. 
Table 2 | Participants' primary comorbid diagnosis (CI)

\begin{tabular}{ll}
\hline DSM-IV Mental Disorder & No. of patients \\
\hline Psychotic Disorders & 1 \\
Mood Disorders & 87 \\
Anxiety Disorders & 14 \\
Alcohol Related Disorders & 5 \\
Substance Related Disorders & 3 \\
Adjustment Disorder & 5 \\
\hline Total & 115 \\
\hline
\end{tabular}

$\mathrm{CI}=$ Insomnia with psychiatric comorbidity

\section{Association between PSQI and sleep diary derived sleep quality (SDSQ)}

The correlation between the PSQI and SDSQ was significant for I $(r=-0.38, P<.001)$, but not for $\mathrm{CI}(\mathrm{r}=-.13, \mathrm{P}=.177)$.

In the linear regression model, SDSQ significantly predicted PSQI score $(\beta=-0.24$, $\mathrm{P}=.001$ ). Adding diagnostic group (I vs. CI) as moderator to the model yielded a significant interaction between diagnostic group and SDSQ in predicting PSQI score ( $\beta$ $=-0.51, P=.047$ ). Figure $1 \mathrm{a}$ shows the separate slopes for I and CI, respectively. Subsequent conditional marginal effects at different levels of SDSQ showed that the difference between I and CI was significant at $\mathrm{P} \leq .05$ for values of SDSQ $>3$ and significant

A

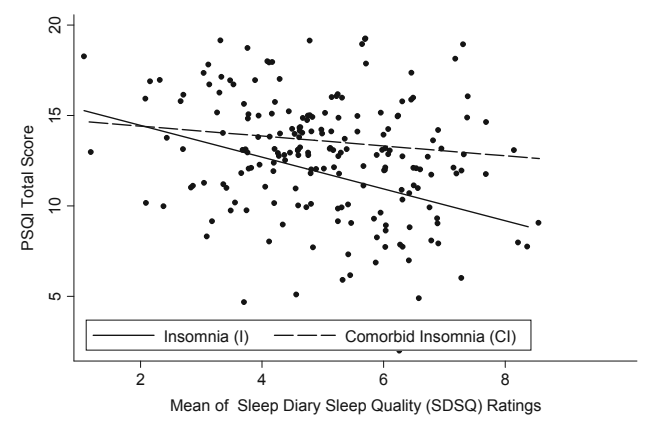

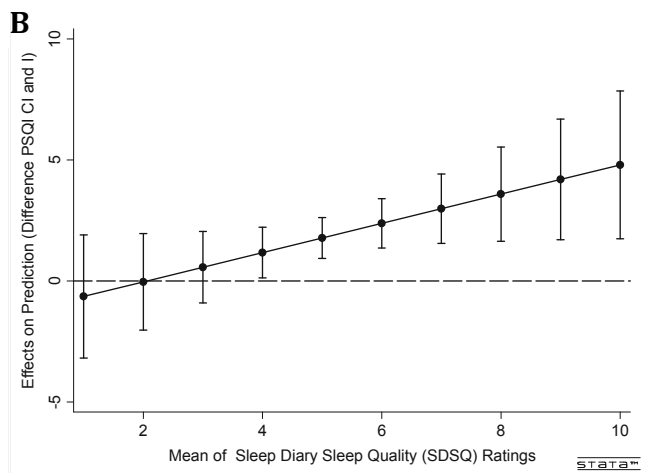

$\overline{5 T \exists T \Xi^{m+1}}$

Figure 1| A Scatterplot of the association between PSQI global score and sleep diary sleep quality (SDSQ), by insomnia subgroup (I=Insomnia without psychiatric comorbidity, CI= Insomnia with psychiatric comorbidity $)^{1}$

${ }^{1}$ the interaction between SDSQ rating is statistically significant $(\beta=-.51, P=.047)$

B Conditional marginal effects plus confidence intervals ${ }^{2}$

${ }^{2}$ the difference between I and CI is significant for values of SDSQ $>3$ 
at $\mathrm{P} \leq .01$ for values of SDSQ $>4$; Figure $1 \mathrm{~b}$ shows the conditional marginal effects and confidence intervals.

When including the recently remitted patients in I rather than CI $(n=34)$ CI, SDSQ predicted PSQI score $(\beta=-0.24, \mathrm{P}=.001)$, but there was no significant interaction between diagnostic group and SDSQ $(\beta=0.25, P=.33)$.

\section{The contribution of anxiety and depression}

\section{PSQI}

Diagnostic group (I vs. CI) significantly predicted PSQI score $(\beta=0.28, P<.001)$, explaining $7.6 \%$ of the variance (base model). That is, CI scored significantly higher on the PSQI than I. After adding BAI scores as predictor to the model $(\beta=0.38, P<.001)$, the explained variance increased by $12.3 \%$ to $20.0 \%\left(\mathrm{~F}_{1,192}=29.54, \mathrm{P}<.001\right) ; \beta$ for diagnostic group dropped to 0.14 and $\mathrm{P}=.05$. Also adding BDI mean scores as predictor to the model $(\beta=0.03, P=.69$ for BDI; $\beta=0.36, P<.001$ for BAI $)$ did not significantly add to the explained variance $\left(\mathrm{F}_{1,191}=0.16, \mathrm{P}=.69\right) ; \beta$ for diagnostic group dropped to 0.13 and was not significant anymore $(\mathrm{P}=.08)$. The results remained similar when excluding those patients diagnosed with an anxiety disorder $(n=40$, see supplementary material, part A).

When including the recently remitted patients in I rather than $\mathrm{CI}(\mathrm{n}=34)$, diagnostic group (I vs. CI) predicted PSQI score $(\beta=0.22, P=.002)$, explaining $4.6 \%$ of the variance. After adding BAI mean scores to the model $(\beta=0.41, P<.001)$, the explained variance increased by $14 \%$ to $18.4 \%\left(\mathrm{~F}_{1,192}=32.32, \mathrm{P}<.001\right)$, and the association between PSQI and diagnostic group disappeared $(\beta=0.03, P=.67)$. Also adding BDI mean scores as predictor to the model $(\beta=0.07, P=.37$ for BDI; $\beta=0.39, P<.001$ for BAI) did not significantly add to the explained variance $\left(\mathrm{F}_{1,191}=0.85, \mathrm{P}=.37\right) ; \beta$ for diagnostic group dropped to 0.01 and the association between PSQI and diagnostic group disappeared $(\mathrm{P}=$.89). The results remained similar when excluding those patients diagnosed with an anxiety disorder ( $n=40$; see supplementary material, part B).

\section{SDSQ}

When repeating the same analyses with SDSQ instead of PSQI score, a different picture emerged. Diagnostic group (I vs. CI) did not predict SDSQ $(\beta<0.01, P=.95)$ in the first place. That is, there was no difference in sleep quality between I and CI. After adding BAI mean scores to the base model $(\beta=-0.15, P=.05)$, explained variance increased by $1.9 \%\left(\mathrm{~F}_{1,206}=3.9, \mathrm{P}=.02\right)$ and diagnostic still showed no association with SDSQ $(\beta=0.06$, $\mathrm{P}=.44)$. Also adding BDI mean scores as predictor to the model $(\beta=-0.13, P=.13$ for 
BDI, $\beta=-0.10, P=.24$ for $B A I$,) did not significantly add to the explained variance $\left(\mathrm{F}_{1,205}=2.34, \mathrm{P}=.13\right)$.

When including the recently remitted patients in I instead of CI $(n=34)$, diagnostic group did not predict SDSQ $(\beta=-0.07, P=.29)$. Furthermore, neither BAI mean score $(\beta=-0.12, P=.13)$, nor BDI mean score $(\beta=-0.10, P=.24)$ were significant predictors of SDSQ.

\section{Discussion}

The present study investigated a retrospective measure of subjective sleep quality (the PSQI) in relation to a prospective measure (the SDSQ) in insomnia patients with differential psychiatric background.

As hypothesized, there was a stronger correlation between the PSQI score and the SDSQ in insomnia patients without a psychiatric comorbidity. Likewise, the association between the PSQI score, and sleep quality as measured by the sleep diary, was moderated by diagnostic status. That is, the association between the retrospective (PSQI-derived) sleep quality ratings and the prospective (sleep diary-derived) sleep quality ratings was weaker in insomnia patients with a comorbid psychiatric condition. These findings confirm the notion that psychiatric patients may be more biased in their retrospective ratings than individuals without psychiatric symptoms [19]. Additionally, psychiatric diagnostic status predicted the PSQI score, indicating that insomnia patients with a psychiatric comorbidity reported significantly worse sleep quality on the PSQI. However, this difference was weakened when adding anxiety to the model and it disappeared when the recently remitted patients were excluded. In a sensitivity analysis excluding all patients with an anxiety disorder, the results remained similar, indicating that the observed difference between the insomnia groups on the retrospective PSQI-sleep quality ratings may be partly accounted for by anxiety (and to a lesser extent also by depression).

In contrast to the PSQI, there was no difference in sleep quality between the two insomnia groups on the prospective sleep diary-derived sleep quality ratings. Depression and anxiety did not add to the predictive value of psychiatric diagnostic status in explaining sleep diary sleep quality ratings. Thus, a prospective sleep quality rating may tap into a construct seemingly independent of psychiatric status. In contrast, the PSQI may be detecting anxiety and distress in addition to sleep quality; as Backhaus and colleagues [4] suggest, there may be some bias introduced by the PSQI relative to the sleep diary possibly due to the long retrospective recall. Why this bias appears to be stronger for those with psychiatric comorbidity remains to be elucidated. 
Speculatively, a general memory deficit associated with psychopathology [33] or mood-congruent memory processes [34] may play a role.

In general, the reliability and validity data of the PSQI would not suggest that the PSQI is a poor measure; instead, this study and others suggest that the PSQI could benefit from a clarification of what it actually measures. Given that the PSQI is likely to be used in those with current or past comorbid Axis I disorders, it is important to consider that the PSQI may reflect a form of sleep-related distress which has to be further defined. Future studies including e.g. the Dysfunctional Beliefs and Attitudes Scale (DBAS) should shed more light on this. The finding that particularly anxiety explained much of the variation in the models above may provide some support for the hyperarousal theory of insomnia [35].

If the PSQI reflects sleep-related distress more than sleep quality per se, then we might refine the recommendation of the Standardization of Assessment Workgroup [36] to use the PSQI as an insomnia symptom outcome measure. Indeed, the PSQI assesses symptoms other than insomnia (e.g., nightmares) - thus a measure that focuses on insomnia symptoms only may be a better alternative. One such alternative from the Buysse et al. paper [36] is the Insomnia Severity Index [37]; further study would determine if this measure, or others like it, captures insomnia symptom severity or if it is confounded as well.

The present findings do not limit the utility of the PSQI as an outcome measure; however, it suggests some caution in interpretation when used as an index of sleep disturbance unless there is no history of past mental illness.

Although this study was conducted in a large, well-screened sample of people with insomnia from both research respondents and clinician-referred recruitment sources, some limitations exist. The sample reflected the presumed clinical characteristics and gender distribution of an insomnia population, however most participants were higher educated Caucasian or African Americans, thus potentially limiting the generalizability to the larger insomnia population. Related to that, it would be interesting to further subdivide the insomnia groups, calling for future research with even larger samples. Furthermore, while subjective sleep quality assessed by the PSQI represents a composite score, sleep quality assessed by the sleep diary was based on a single item. As such, it may be argued that both measures reflect different aspects of subjective sleep quality, which are not yet defined. More research into the construct of subjective sleep quality is evidently required.

In conclusion, the present study demonstrated in a large well-characterized clinical sample of those with insomnia that: (1) patients with psychiatric comorbidity may be more biased in their retrospective sleep quality ratings than those without and (2) the PSQI, possibly due to its retrospective nature, may reflect sleep-related distress 
to some degree, whereas the sleep diary based prospective sleep quality ratings may tap into a less confounded construct of sleep quality. Those who use the PSQI should consider this confound when using the measure in those with a history of Axis I disorders - the most common group of people with insomnia [38, 39]. This information is particularly germane in light of the omission of distinction between primary and comorbid insomnias in the new DSM 5 [40].

\section{Clinical Points}

- A Consensus Committee for the Standardization of Insomnia Assessment practices recommended the Pittsburgh Sleep Quality Index (PSQI) as a tool to assess for global sleep disturbance [36].

- If an index of sleep quality is desired, the PSQI score may reflect sleep-related distress rather than sleep quality per se, particularly in the presence of psychopathology. Thus, the use of prospective sleep diaries may be preferred for this reason. 


\section{References}

1. Harvey AG, Stinson K, Whitaker KL, Moskovitz D, Virk H. The subjective meaning of sleep quality: a comparison of individuals with and without insomnia. Sleep. 2008;31(3):383.

2. Akerstedt T, Hume K, Minors D, Waterhouse J. The subjective meaning of good sleep, an intraindividual approach using the Karolinska Sleep Diary. Percept Mot Skills. 1994;79(1):287-96.

3. Buysse DJ, Reynolds CF, 3rd, Monk TH, Berman SR, Kupfer DJ. The Pittsburgh Sleep Quality Index: a new instrument for psychiatric practice and research. Psychiatry Res. 1989;28(2):193-213.

4. Backhaus J, Junghanns K, Broocks A, Riemann D, Hohagen F. Test-retest reliability and validity of the Pittsburgh Sleep Quality Index in primary insomnia. J Psychosom Res. 2002;53(3):737-40.

5. Beck SL, Schwartz AL, Towsley G, Dudley W, Barsevick A. Psychometric evaluation of the Pittsburgh Sleep Quality Index in cancer patients. J Pain Symptom Manage. 2004;27(2):140-8.

6. Doi Y, Minowa M, Uchiyama M, Okawa M, Kim K, Shibui K, et al. Psychometric assessment of subjective sleep quality using the Japanese version of the Pittsburgh Sleep Quality Index (PSQI-J) in psychiatric disordered and control subjects. Psychiatry Res. 2000;97(2-3):165-72.

7. Fictenberg N, Putnam S, Mann N, Zafonte R, Millard A. Insomnia screening in postacute traumatic brain injury: utility and validity of the Pittsburgh Sleep Quality Index. Am J Phys Med Rehabil. 2001;80(5):339.

8. Beaudreau SA, Spira AP, Stewart A, Kezirian EJ, Lui L-Y, Ensrud K, et al. Validation of the Pittsburgh Sleep Quality Index and the Epworth Sleepiness Scale in older black and white women. Sleep Med. 2012;13(1):36-42.

9. Maglione JE, Ancoli-Israel S, Peters KW, Paudel ML, Yaffe K, Ensrud KE, et al. Depressive Symptoms and Subjective and Objective Sleep in Community-Dwelling Older Women. J Am Geriatr Soc. 2012;60(4):635-43.

10. Paudel ML, Taylor BC, Diem SJ, Stone KL, Ancoli-Israel S, Redline S, et al. Association Between Depressive Symptoms and Sleep Disturbances in Community-Dwelling Older Men. J Am Geriatr Soc. 2008;56(7):1228-35.

11. Atalay H. Comorbidity of insomnia detected by the Pittsburgh sleep quality index with anxiety, depression and personality disorders. Isr J Psychiatry Relat Sci. 2011;48(1):54.

12. Li Y, Zhang S, Zhu J, Du X, Huang F. Sleep disturbances are associated with increased pain, disease activity, depression, and anxiety in ankylosing spondylitis: a case-control study. Arthritis Res Ther. 2012;14(5):R215.

13. Jevtović S, Gregurek R, Kalenić B, Brajković L, Braš M, Lončar M, et al. Correlation of sleep disturbances, anxiety and depression in Croatian war veterans with posttraumatic stress disorder. Coll Antropol. 2011;35(1):175-81.

14. Calkins AW, Hearon BA, Capozzoli MC, Otto MW. Psychosocial Predictors of Sleep Dysfunction: The Role of Anxiety Sensitivity, Dysfunctional Beliefs, and Neuroticism. Behav Sleep Med. 2013;11(2):133-43.

15. Buysse DJ, Hall ML, Strollo PJ, Kamarck TW, Owens J, Lee L, et al. Relationships between the Pittsburgh Sleep Quality Index (PSQI), Epworth Sleepiness Scale (ESS), and clinical/polysomnographic measures in a community sample. J Clin Sleep Med. 2008;4(6):563.

16. Grandner MA, Kripke DF, Yoon IY, Youngstedt SD. Criterion validity of the Pittsburgh Sleep Quality Index: Investigation in a non-clinical sample. Sleep Biol Rhythms. 2006;4(2):129-39.

17. Calhoun PS, Wiley M, Dennis MF, Means MK, Edinger JD, Beckham JC. Objective evidence of sleep disturbance in women with posttraumatic stress disorder. J Trauma Stress. 2007;20(6):1009-18. 
18. Sánchez-Ortuño MM, Edinger JD. Internight sleep variability: its clinical significance and responsiveness to treatment in primary and comorbid insomnia. J Sleep Res. 2012;21(5):527-34.

19. Ebner-Priemer UW, Kuo J, Welch SS, Thielgen T, Witte S, Bohus M, et al. A valence-dependent group-specific recall bias of retrospective self-reports: A study of borderline personality disorder in everyday life. J Nerv Ment Dis. 2006;194(10):774-9.

20. Edinger JD, Wyatt JK, Stepanski EJ, Olsen MK, Stechuchak KM, Carney CE, et al. Testing the reliability and validity of DSM-IV-TR and ICSD-2 insomnia diagnoses. Results of a multitrait-multimethod analysis. Arch Gen Psychiatry. 2011;68(10):992-1002.

21. Folstein MF, Folstein SE, McHugh PR. 'Mini-mental state'. A practical method for grading the cognitive state of patients for the clinician. J Psychiatr Res. 1975;12(3):189-98.

22. American Academy of Sleep Medicine. International Classification of Sleep Disorders, 2nd edition. Darien, IL: American Academy of Sleep Medicine; 2005.

23. Beck AT, Epstein N, Brown G, Steer RA. An inventory for measuring clinical anxiety: psychometric properties. J Consult Clin Psychol. 1988;56(6):893-7.

24. Kabacoff RI, Segal DL, Hersen M, Van Hasselt VB. Psychometric properties and diagnostic utility of the Beck Anxiety Inventory and the State-Trait Anxiety Inventory with older adult psychiatric outpatients. J Anxiety Disord. 1997;11(1):33-47.

25. Carney CE, Moss TG, Harris AL, Edinger JD, Krystal AD. Should we be anxious when assessing anxiety using the Beck Anxiety Inventory in clinical insomnia patients? J Psychiatr Res. 2011;45(9):1243-9.

26. Beck AT, Steer RA, Carbin MG. Psychometric properties of the Beck Depression Inventory: Twentyfive years of evaluation. Clin Psychol Rev. 1988;8(1):77-100.

27. Aalto A-M, Elovainio M, Kivimäki M, Uutela A, Pirkola S. The Beck Depression Inventory and General Health Questionnaire as measures of depression in the general population: a validation study using the Composite International Diagnostic Interview as the gold standard. Psychiatry Res. 2012;197(1):163-71.

28. Richter P, Werner J, Heerlein A, s e, Kraus A, Sauer H. On the validity of the Beck Depression Inventory. Psychopathology. 1998;31(3):160-8.

29. Carney CE, Ulmer C, Edinger JD, Krystal AD, Knauss F. Assessing depression symptoms in those with insomnia: an examination of the beck depression inventory second edition (BDI-II). J Psychiatr Res. 2009;43(5):576-82.

30. First MB, Gibbon M, Spitzer RL, Williams JB. Structured Clinical Interview for DSM-IV-TR Axis I Disorders, Research Version, Patient Edition (SCID-I/P). New York: Biometrics Research, New York State Psychiatric Institute; 2002.

31. American Academy of Sleep Medicine. The AASM manual for the scoring of sleep and associated events: rules, terminology and technical specifications. Westchester, IL: American Academy of Sleep Medicine; 2007.

32. StataCorp. Stata Statistical Software: Release 12. College Station, TX: StataCorp LP; 2011.

33. Millan MJ, Agid Y, Brüne M, Bullmore ET, Carter CS, Clayton NS, et al. Cognitive dysfunction in psychiatric disorders: characteristics, causes and the quest for improved therapy. Nat Rev Drug Discov. 2012;11(2):141-68.

34. Kihlstrom JF, Eich E, Sandbrand D, Tobias BA. Emotion and memory: Implications for self-report. In: Stone A, Bachrach C, Jobe J, Kurtzman HC, VS, editors. The science of self-report: Implications for research and practice. Mahwah, NJ: Lawrence Erlbaum Associates, Inc.; 2000. p. 81-100.

35. Riemann D, Spiegelhalder K, Feige B, Voderholzer U, Berger M, Perlis M, et al. The hyperarousal model of insomnia: a review of the concept and its evidence. Sleep Med Rev. 2010;14(1):19-31. 
36. Buysse DJ, Ancoli-lsrael S, Edinger JD, Lichstein KL, Morin CM. Recommendations for a standard research assessment of insomnia. Sleep. 2006.

37. Morin CM, Belleville G, Bélanger L, Ivers H. The insomnia severity index: psychometric indicators to detect insomnia cases and evaluate treatment response. Sleep. 2011;34(5):601.

38. Buysse DJ, Reynolds CF, Kupfer DJ, Thorpy MJ, Bixler E, Manfredi R, et al. Clinical diagnoses in 216 insomnia patients using the International Classification of Sleep Disorders (ICSD), DSM-IV and ICD10 categories: a report from the APA/NIMH DSM-IV Field Trial. Sleep. 1994;17(7):630-7.

39. Edinger JD, Hoelscher TJ, Webb MD, Marsh GR, Radtke RA, Erwin CW. Polysomnographic assessment of DIMS: empirical evaluation of its diagnostic value. Sleep. 1989;12(4):315-22.

40. American Psychiatric Association. DSM 5. Washington, DC: American Psychiatric Association; 2013. 


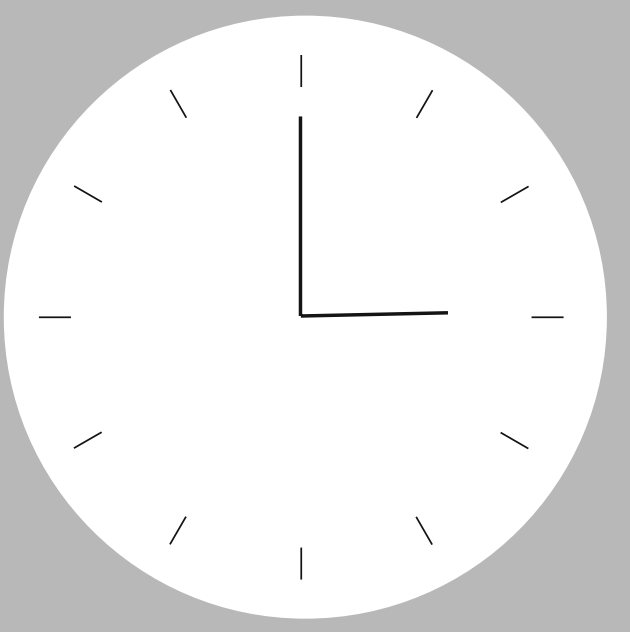

Chapter 3 


\section{Day-to-day associations between subjective sleep and affect in regard to future depression in a population-based female sample}

De Wild-Hartmann, JA,

Wichers, $M$,

Van Bemmel, AL,

Derom, C,

Thiery, E, Jacobs, $\mathrm{N}$, Van Os, J,

Simons, CJP 


\section{Abstract}

Background: Poor sleep is a risk factor for depression, however little is known about the underlying mechanisms.

Aim: Disentangling potential mechanisms by which sleep may be related to depression by zooming down to the 'micro-level' of within-person daily life patterns of subjective sleep and affect using the experience sampling method (ESM).

Methods: A population-based twin sample consisting of 553 women underwent a 5-day baseline ESM protocol assessing subjective sleep and affect together with four follow-up assessments of depression.

Results: Sleep was associated with affect during the next day, especially positive affect. Daytime negative affect was not associated with subsequent night-time sleep. Baseline sleep predicted depressive symptoms across the follow-up period.

Conclusion: The subtle, repetitive impact of sleep on affect on a daily basis, rather than the subtle repetitive impact of affect on sleep, may be one of the factors on the pathway to depression in women. 


\section{Introduction}

Sleep and affect are closely intertwined. This link is most evident in depression, where a large body of epidemiological studies has shown that sleep disturbances appear to be a risk factor for- as well as a symptom of- depression [e.g. 1, 2, for an overview see 3].

Longitudinal cohort studies investigating the association between sleep disturbances and depression (with years between the assessments) are very suited to demonstrating unbiased associations, but lend themselves less to unravel the underlying mechanisms contributing to these associations. To identify principles underlying the link between sleep and depression, the focus should be narrowed down to the daily associations of sleep and affect.

The experience sampling method, an ambulatory diary technique assessing variables of interest prospectively and repeatedly across the day for a period of time, represents a suitable approach to zoom into the daily within-person associations between subjective sleep and affect $[4,5]$. In addition, its prospective character allows for the examination of directions of daily sleep-affect associations, an aspect which is, with two exceptions $[6,7]$, largely disregarded.

The purpose of the present study was to disentangle potential mechanisms by which sleep may be related to depression, by (1) zooming down to the 'micro-level' of within-person daily life patterns of subjective sleep and affect using the ESM and (2) zooming out to the 'macro level' of subjective sleep and affect by investigating the association between baseline sleep and future depression in a female population-based sample.

\section{Methods}

\section{Sample}

The sample comprised 621 women (577 twins and 44 non-twin sisters) aged 18-61 years (mean 28 years). Participants were recruited from the East-Flanders Prospective Twin Survey (EFPTS) [8,9] and from birth registers of Flemish municipalities. The EFPTS is a population-based survey that started in 1964, registering prospectively all multiple births within East Flanders. Although most participants were twins, the current study did not require twin methodology. Originally, the study was designed to assess heritability of stress-sensitivity in daily life, and given evidence for qualitative differences in the type of environmental stressors that are associated with depression 
in men and women $[10,11]$, the sample was female only. The project was approved by the local medical ethics committee and all participants gave their written consent.

\section{Experience Sampling Method}

The ESM was used to assess daily life momentary affective states (Figure 1). The ESM is a validated, structured diary technique to assess individuals in their daily living environment $[12,13]$. Participants received a digital wristwatch and a set of ESM selfassessment forms collated in a booklet for each day. The wristwatch was programmed to emit a signal ('beep') at an unpredictable moment in each of ten 90-minute time blocks between 07:30 and 22:30 on 5 consecutive days. After each beep, participants were required to stop their activity and fill out the ESM self-assessment forms. All self-assessments were rated on 7-point Likert scales.

In addition to the self-assessments after each beep, participants were asked to complete a sleep questionnaire comprising an evening and morning part. The morning part had to be filled in immediately upon awakening and the evening part immediately prior to sleep (see below).

Trained research assistants with ample experience in momentary assessment techniques explained the ESM procedure to the participants during an initial briefing session, and participants completed an ESM practice form to confirm that they understood the 7-point Likert scale. Participants could call a telephone number in case they had questions or problems during the ESM sampling period. Participants were told to complete their reports immediately after the beep, thus minimising memory distortion, and to record the time at which they completed the form. To check whether the participants had completed the form within 15 min of the beep, the time at which participants indicated they completed the report was compared with the actual time of the beep. All reports not filled in within $15 \mathrm{~min}$ after the beep were excluded from the analysis, since previous work [13] has shown that reports completed after this interval are less reliable and consequently less valid. In addition, previous work has shown that participants who have valid reports for at least a third of all measurements can be included since their missing data do not distort the results, whereas measures of individuals with fewer than $30 \%$ of completed reports are less reliable [13].

\section{Procedure}

The study consisted of five parts: a baseline part $\left(\mathrm{T}_{0}\right)$, in which the 5-day ESM study took place, and four follow-up assessments $\left(\mathrm{T}_{1}-\mathrm{T}_{4}\right)$. The average period between the interview assessments was 134 days for the period $T_{0}-T_{1}, 91$ days for the period $T_{1}-T_{2}$, 116 days for the period $T_{2}-T_{3}$ and 91 days for the period $T_{3}-T_{4}$. 


\section{Measures of Affect}

Using the ESM procedure at baseline as described above, participants rated their mood states by using ten adjectives on a 7-point Likert scale, ranging from 1 (not) to 7 (very). Factor analysis identified two mood states: positive affect and negative affect. Positive affect comprised the weighted average of ratings on 'cheerful', 'content', 'energetic' and 'enthusiastic'; negative affect comprised the weighted average of ratings on 'insecure,', 'lonely', 'anxious', 'low', 'guilty' and 'suspicious'.

\section{Sleep Measurements}

Subjective sleep was assessed by means of a sleep diary. A sleep diary is a way of prospectively self-monitoring sleep and is regarded as the gold standard for subjective sleep assessment [14]. Furthermore, it allows specific investigation of within-person daily life patterns of subjective sleep and affect, the main aim of the current study.

Each morning, participants rated subjective sleep variables pertaining to the previous night: Sleep quality on a 7-point Likert scale ranging from 1 (not at all) to 7 (very well), sleep onset latency (time taken to fall asleep, in minutes), and number of awakenings. Furthermore, participants reported the (clock-) time of awakening and getting up. Each evening, participants recorded their bedtime, enabling estimation of total time in bed (time in minutes between time to bed and getting up). In order to estimate total sleep time, the variable sleep period was generated, reflecting time in minutes between reported sleep time and awakening.

\section{Depressive symptomatology}

The Structured Clinical Interview for DSM-IV Axis I Disorders ([SCID-1; 15] was administered at baseline $\left(\mathrm{T}_{0}\right)$ and at the fourth follow-up $\left(\mathrm{T}_{4}\right)$. The SCID-I is a diagnostic instrument to assess the presence of DSM-IV Axis I disorders and was used to obtain current and lifetime diagnosis of major depressive disorder. In addition to the SCID-I, subclinical depressive symptomatology was assessed at baseline and at each follow-up using the Symptom Checklist-90-Revised (SCL-90-R) [16]. The SCL-90-R is a widely used 90 -item self-report questionnaire measuring general psychological distress. For the analyses, the SCL-90-R depression subscale was used, consisting of 13 items, rated on a 5-point Likert scale.

\section{Other measures}

During every daily affect rating within the ESM protocol, participants were asked about previous alcoholic or food intake (yes/no) and level of physical exercise (7-point Likert scale) since the last beep. 
Furthermore, participants completed the Neuroticism-Extraversion subscale of the Eysenck Personality Scale [17] and rated their somatic health on a 5-point Likert scale (1=very well, $5=$ bad) at baseline.

\section{Analysis Plan}

Two sets of analyses were conducted. The first investigated the day-to-day associations between sleep and affect, using data from the baseline ESM study. The second set of analyses investigated the longitudinal associations between baseline measures of sleep and depressive symptomatology at the follow-up assessments.

\section{ESM data associations between sleep and affect}

The baseline ESM data-set has a hierarchical structure, due to within-person clustering: repeated measurements (level 1) are nested within individuals (level 2) and individuals are nested within twin pairs (level 3). That is, observations from the same participant are more similar than observations from different participants, and observations within a twin pair are more similar than between twin pairs. As nesting of data violates the assumption of independent residuals, multilevel regression analysis was used that takes clustering (in this case within participants and within twin pairs) into account [18].

Associations between (1) subjective sleep and ESM measures of affect the next day, and between (2) ESM daytime affect and subsequent sleep, were separately calculated using the XTMIXED command in STATA (version 11 for Windows) (see Figure 1). The first model included sleep as a predictor of affect the next day and was additionally corrected for food and alcoholic intake, physical exercise and age. In this model, no aggregation took place and all data points were used (i.e. ten affect ratings per day for each individual). The second model included affect as a predictor of subsequent sleep

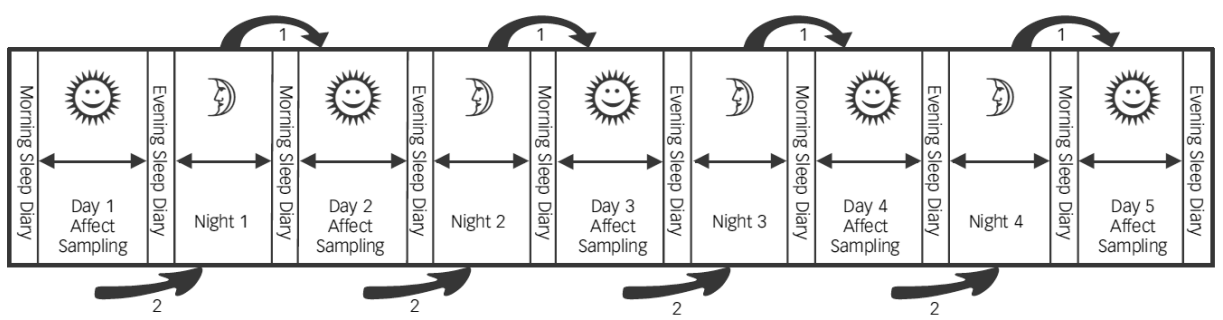

Figure 1 | Schematic overview of the study protocol. For the duration of 5 consecutive days, participants rated positive and negative affect items ten times a day and filled in sleep questionnaires in the morning and evening. This design allows for the investigation of the association between sleep and subsequent daytime affect (arrow 1 in the figure), as well as affect during the day and subsequent sleep (arrow 2 in the figure). 
and was additionally corrected for food- and alcoholic intake as well as physical exercise during the day. In this model, day aggregates of the independent variable (affect) were used (i.e. the mean of multiple measures of affect per day for each individual), as the dependent variable (sleep) was only measured once a day. Thus, in this model, repeated measurements over multiple days were clustered within participants and participants within twin pairs. Six day-of-the-week dummy variables were included in both models to account for daily variation (reference category Sunday). As we were only interested in the within-person component of the regression estimation, predictor variables were centred at the participant level. Regression coefficients were standardised with the aid of the STATA command ESTADD BETA. All regression analyses were controlled for age.

\section{Baseline sleep and follow-up depressive symptoms}

The associations between baseline subjective sleep and follow-up SCL-90-R depressive symptoms were analysed using multilevel regression analysis (XTMIXED), as multiple follow-up measurements $\mathrm{T}_{1}-\mathrm{T}_{4}$ (level 1) were clustered within participants (level 2), who were part of twin pairs (level 3). That is, the four follow-up measurements of depressive symptomatology $\left(\mathrm{T}_{1}-\mathrm{T}_{4}\right)$ were regressed on mean scores of the separate sleep variables. For the association between sleep at baseline and follow-up DSM-IV diagnosis of depression as response variable, multilevel logistic regression analyses were conducted using STATA command XTLOGIT, as participants are clustered within twin pairs. Participants with a current or lifetime diagnosis of major depression according to DSM-IV were excluded and analyses were controlled for age, baseline SCL-90-R depressive symptoms, trait neuroticism and somatic health. Regression coefficients were standardised with the aid of the STATA command ESTADD BETA.

\section{Results}

\section{Sample}

The total sample consisted of 621 White female participants, of whom 610 participated in the ESM procedure. Thirty-one women were excluded because they had fewer than 17 valid ESM self-reports or missing reports. A total of 26 participants were excluded because they fulfilled DSM-IV criteria for a major depressive episode at baseline, resulting in 553 participants with valid ESM measures at baseline. See Table 1 for a summary of demographic variables, sleep variables and depressive symptoms at baseline. The number of participants varied slightly across variables owing to partial missing data (Table 1). 
Table 1 | Sample Characteristics

\begin{tabular}{|c|c|c|c|}
\hline & Mean & SD & $\mathbf{N}$ \\
\hline \multicolumn{4}{|c|}{ Demographics } \\
\hline Age & 27.77 & 7.86 & 551 \\
\hline Education $^{a}$ & 3.26 & 1.02 & 552 \\
\hline \% Employed & 61.20 & & 551 \\
\hline$\%$ Married & 35.96 & & 551 \\
\hline \multicolumn{4}{|c|}{ Sleep characteristics } \\
\hline Sleep quality ${ }^{\mathrm{b}}$ & 5.26 & 1.46 & 553 \\
\hline Sleep onset latency ${ }^{c}$ & 21.40 & 26.85 & 553 \\
\hline Sleep period $^{\mathrm{d}}$ & 471.03 & 87.07 & 531 \\
\hline Number of awakenings & 1.5 & 1.76 & 553 \\
\hline \multicolumn{4}{|c|}{ Affect } \\
\hline Positive affect ${ }^{\mathrm{e}}$ & 3.57 & 1.00 & 541 \\
\hline Negative affect ${ }^{\mathrm{e}}$ & 0.82 & 0.35 & 553 \\
\hline \multicolumn{4}{|c|}{ Depressive symptoms } \\
\hline SCL-90-R baseline ${ }^{f}$ & 1.41 & 0.45 & 548 \\
\hline SCL-90-R follow-up ${ }^{g}$ & 1.41 & 0.50 & 440 \\
\hline$\%$ SCID depression $\mathrm{T}_{4}{ }^{\mathrm{h}}$ & 2.7 & & 362 \\
\hline
\end{tabular}

${ }^{\text {a }}$ Assessed on 4-point scale: $1=$ primary school; $4=$ university degree

${ }^{\mathrm{b}}$ Rated on a 7-point Likert scale: $1=$ very bad $7=$ very well

${ }^{c}$ time needed to fall asleep in min

${ }^{\mathrm{d}}$ in minutes, time between falling sleep and awakening (without considering nightly awakenings)

${ }^{\mathrm{e}}$ Weighted average

${ }^{\mathrm{f}}$ rated on 5-point Likert Scale

${ }^{g}$ mean aggregated Symptom Check List (SCL-90-R) follow-up score

${ }^{\mathrm{h}}$ Percentage of participants fulfilling DSM-IV criteria for major depressive disorder at $\mathrm{T}_{4}$

For the longitudinal part of the study, that is, the association between baseline sleep and future depression, 82 participants were additionally excluded because they fulfilled the DSM-IV criteria for current or lifetime diagnosis of depression, resulting in 471 participants. Data with respect to follow-up SCL-90-R depressive symptoms were present for 423 participants at $\mathrm{T}_{1}, 417$ at $\mathrm{T}_{2}, 392$ at $\mathrm{T}_{3}$ and 383 at $\mathrm{T}_{4}$. For 440 participants, there was at least one follow-up assessment of the SCL-90-R. Thirtyone participants dropped out for the entire follow-up period. They did not differ significantly in terms of baseline sleep quality $(\mathrm{t}=-0.39, \mathrm{P}=0.70)$ or baseline depressive symptomatology ( $\mathrm{t}=0.73, \mathrm{P}=0.47)$. Data with respect to follow-up SCID-I current depressive episode at $\mathrm{T}_{4}$ were present for 362 participants. Drop-out for the SCID-I at 
$\mathrm{T}_{4}$ was not associated with baseline sleep quality $(\mathrm{t}=-0.69, \mathrm{p}=0.48)$ or baseline depressive symptomatology $(\mathrm{t}=-1.26, \mathrm{p}=0.21)$.

\section{Subjective sleep as a predictor for affect the next day}

\section{Positive affect}

There was a significant association between all sleep variables and positive affect the next day. Sleep quality and sleep period showed a positive linear association with positive affect $(\beta=0.06, p<0.001$ and $\beta=0.02, p=0.011$ respectively), whereas number of awakenings and sleep latency showed a negative association $(\beta=-0.01, p=0.009$ and $\beta=-0.01, p=0.049$ respectively). The association between sleep quality and PA yielded the highest effect size (Figure 2).

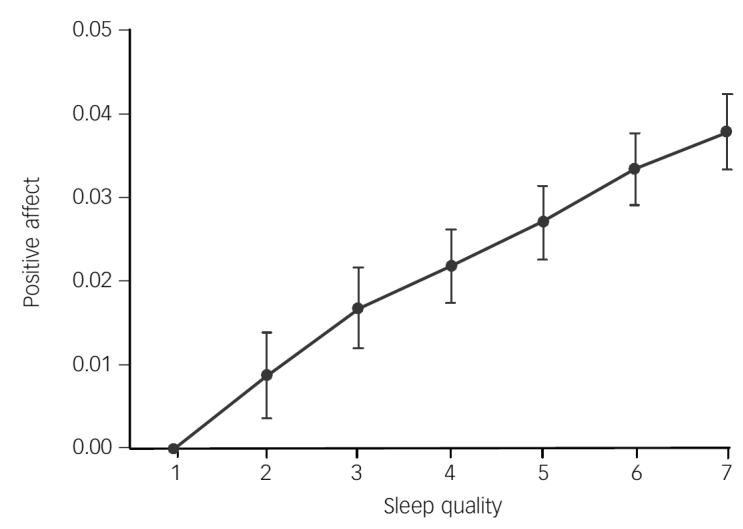

Figure 2 | Effect sizes of subjective sleep quality as reported upon awakening on average positive affect during the day: increase of positive affect per category of sleep quality (1= very bad, $7=$ very good) relative to reference category sleep quality $=1$.

\section{Negative affect}

There was a significant negative association between sleep quality and negative affect $(\beta=-0.03, p<0.001)$ and a significant positive association between sleep latency and negative affect $(\beta=0.01, p=0.028)$, but not between negative affect and sleep period $(\beta<0.01, p=0.532)$, or number of awakenings $(\beta<0.01, p=0.828)$. 


\section{Affect during the day as a predictor for sleep}

\section{Positive Affect}

Sleep quality was negatively associated with prior daytime positive affect $(\beta=-0.05$, $\mathrm{p}=0.008)$. Sleep latency $(\beta<-0.01, \mathrm{p}=0.826)$, sleep period $(\beta<-0.01, \mathrm{P}=0.889)$ and number of awakenings $(\beta=0.03, p=0.095)$ showed no significant association with prior positive affect.

\section{Negative affect}

Sleep quality $(\beta=0.01, p=0.556)$, sleep latency $(\beta=-0.01, p=0.481)$, sleep period $(\beta<-$ $0.01, p=0.808)$ and number of awakenings $(\beta<-0.01, p=0.807)$ were not significantly associated with prior negative affect.

\section{Baseline subjective sleep and follow-up depressive symptoms}

With the exception of sleep latency, all sleep variables were significantly associated with follow-up depressive symptoms in the expected direction. Sleep quality as well as sleep period was negatively associated with future depressive symptoms $(\beta=-0.10$, $p<0.001$ and $\beta=-0.07, p=0.020$ ). Number of awakenings was positively associated with future depressive symptoms at follow-up $(\beta=0.09, p=0.004)$. There was no significant association between sleep latency and future depressive symptoms $(\beta=0.02$, $\mathrm{p}=0.535$ ). In a sensitivity analysis, only including participants with no depressive symptoms at baseline on the SCL-90-R (scoring 1 'not at all' on all the items of the SCL-90-R depression subscale), the association between sleep quality and depressive symptoms at follow-up was significant $(\beta=-0.27, \mathrm{P}<0.001)$.

Sleep variables that were significantly associated with SCL-90-R depressive symptoms at follow-up (sleep quality, number of awakenings, sleep period), were further analysed to examine whether they were also predictive for a DSM-IV diagnosis of depression at $\mathrm{T}_{4}$. These analyses revealed that baseline sleep quality, number of awakenings and sleep period were not significantly associated with a diagnosis of major depression at follow-up (odds ratio (OR) $0.20(\mathrm{P}=0.194), \mathrm{OR}=1.52(\mathrm{P}=0.255)$ and $\mathrm{OR}=1.00(\mathrm{P}=0.736)$ respectively $)$.

\section{Discussion}

The present study demonstrated a close association between subjective sleep and affect in a female population-based sample, both at the micro-level of daily associations as well as at the macro-level of longitudinal associations. Sleeping worse in terms 
of lower sleep quality and/or longer sleep latency was associated with individually reduced positive affect and increased negative affect the next day and was also predictive for the development of depressive symptomatology, even in a sample excluding participants with any experience of depressive symptomatology at baseline. Contrary to prior expectation, the association between sleep and affect did not appear to be bidirectional, as subjective sleep was associated with subsequent rather than prior affect. Thus, measures of sleep were good predictors of subsequent daytime affect, whereas measures of affect (with the exception of the association between positive affect and sleep quality, which may constitute a chance finding) did not predict subsequent sleep. Notably, negative affect did not have an impact on subsequent sleep.

\section{Uni-versus bidirectional associations}

There appears to be only one other study that investigated the bidirectional associations between adult sleep and affect in daily life, however using a different approach. Talbot and colleagues [6] examined the associations between total wake time during the night and daytime mood. They used a single-point affect measurement - that is, immediate pre-sleep mood and immediate post-sleep mood - and did not consider later or earlier periods during the day. In the present study, affect was prospectively and repeatedly sampled across the entire day using ESM. Furthermore, the sample of Talbot and colleagues was not population-based, but included patients with insomnia $(n=34)$, bipolar disorder $(n=49)$ and healthy controls $(n=52)$. In most of their analyses, group status moderated the effect between sleep and mood. In line with the present study, their results do not seem to support a bidirectional association between sleep and mood in healthy controls, but only in the two diagnostic groups. Furthermore, in accordance with the present results, it seemed that in healthy controls, sleep has more of an impact on positive affect than on negative affect the next day.

The finding of bidirectional associations between sleep and mood in the insomnia and bipolar groups in contrast to the healthy controls [6], may be related to differences in sleep- and affect related physiological and cognitive processes in healthy individuals compared with psychiatric populations. Harvey [19] hypothesised a bidirectional link between sleep and affect in psychiatric disorders, as disturbance in mood may interfere with night-time sleep and sleep may interfere with daytime affect regulation, leading to a mutually maintaining process. Based on the current results it may be argued that in the general population, (perceived) night-time sleep may interfere with daytime affect regulation, but disturbance in mood is not great enough to lead to (perceived) night-time sleep interference.

The result that negative affect during the day does not appear to have an impact on subsequent sleep contrasts with prior expectations and a number of studies 
showing that pre-sleep affect influences sleep [20], even in healthy participants. However, most of these studies experimentally induced negative affect or stress, thus not representing the natural situation. The apparent lack of impact of prior negative affect on subjective sleep on a daily basis may be very important when considering the evolution of depression on a macro-level. That is, it seems that the subtle and repetitive impact of sleep on daily affect, rather than subtle and repetitive impact of NA on sleep, may be one of the factors on the causal pathway to depression.

\section{Positive affect versus negative affect}

Negative affect and positive affect were differentially associated with sleep variables, as associations were stronger and more consistent for sleep and positive affect, in particular for sleep quality and positive affect. This finding is in line with recent investigations, all pointing towards a stronger role for positive affect in sleep-affect regulations [4, 21-23]. A possible explanation for this finding may lie in the construct of positive and negative affect. Positive affect is hypothesised to be a reward-oriented motivational system, attracting the individual to engage with the environment, whereas negative affect is hypothesised to represent the 'threat system', which reacts in response to hazards $[24,25]$. In contrast to negative affect, positive affect is found to be subject to circadian rhythmicity throughout the 24-hour cycle, being highest during the afternoon and lowest during the second half of the night, possibly priming the individual for activity during daytime when the probability of reward is high. Negative affect is not found to demonstrate such rhythmicity, possibly as the individual has to be able to react to an (unpredictable) threat at any time [25-27]. Given these findings, a stronger modulation of positive affect may be anticipated [4], possibly via interactions of circadian and sleep-wake dependent processes [28].

It has been shown that the experience of positive affect can act as a buffer against negative reactivity and may thereby enhance emotional resilience against depression $[29,30]$. Based on the data at hand, it can be argued that sleep disturbances may reduce the experience of positive affect in daily life, leading to an increased negative reactivity and enhanced probability of developing depression in the longer term. However, more research is needed to unravel the precise mechanisms by which sleep may affect the regulation of affect.

\section{Clinical significance}

The associations between subjective sleep and affect in daily life, as well as the associations between baseline sleep and follow-up depressive symptomatology using a dimensional scale, were statistically significant. There was no significant association between baseline sleep and the dichotomous measure 'DSM-IV diagnosis of depres- 
sion at last follow-up'. The difference in the results between the dimensional measure of depressive symptoms (based on SCL-90-R) and the dichotomous measure of the presence of a diagnosis of depression (based on the SCID-I) may be power-related. The SCID-I was available for fewer participants than the SCL-90 and is, in contrast to the SCL-90-R, only administered at one time point $\left(\mathrm{T}_{4}\right)$. Furthermore, the present sample is not a clinical sample, but constitutes a population-based sample of relatively healthy females. The SCL-90-R may be a more sensitive instrument for the present population than the SCID-I.

Generally, effect sizes of around 0.2 are considered relevant but low, and those around 0.8 high [31]. In the current study, effect sizes were small. However, the results from the ESM study were derived from data reflecting average increase or decrease in positive/negative affect at repeated moments in daily life, thus representing a daily repetitive pattern of positive/negative affect change in association with a person's subjective sleep during each single day. Therefore, effect sizes reported in this study, although very small, cumulatively may well be clinically relevant.

\section{Limitations}

Some methodological limitations are apparent. Most important, sleep was not assessed objectively by means of polysomnography, but by self-reports, leading to two possible concerns. First, extended research has focused on the potential divergence of subjective and objective sleep data [32]. This showed that generalisation from subjective to objective sleep is not necessarily possible. However, inaccurate self-report of sleep variables appears to be especially present in patients with disturbed sleep or patients with depression $[32,33]$, whereas the current study focused on healthy individuals. Furthermore, the self-monitoring of sleep by means of a sleep diary can be regarded as one particular perspective of sleep, which does not necessarily agree with objective measurements, but which is nonetheless an important perspective. The diagnosis of insomnia, for instance, is based on reports of subjective, and not necessarily objective, sleep difficulties. Second, as with all self-reports, mood-congruent bias (i.e. mood upon awakening may colour the sleep quality rating) or a negative appraisal style that explains the association between sleep and depressive symptoms (rather than sleep per se) cannot be conclusively ruled out. Future studies should include objective methods that can complement and validate self-report sleep data, i.e. by including actigraphy. Nevertheless, the association between subjective sleep and affect and subjective sleep and depression is clinically as important as the association between objective sleep and affect.

Furthermore, it has been suggested that problems may arise in the ESM procedure as it depends on the compliance of participants $[34,35]$. During the collection of the 
data, no electronic devices were readily available to substitute the paper-and-pencil diary method. However, compliance levels were investigated in a subsample of the present sample, where participants were asked to take, during the ESM procedure, saliva samples at each of the ten unpredictable moments during the 5 consecutive days [10]. Participants recorded collection times, unaware that compliance with the sampling protocol was being investigated by means of electronic monitoring devices. Results showed that adherence was high (over 90\%) and inclusion of the inaccurately timed samples did not distort the data [10]. Therefore, results from the ESM procedure in this report can be considered valid.

Finally, the sample consisted of relatively highly educated, female participants. Since sleep [36, 37], as well as its relation to affect [38], has been found to differ by gender and socioeconomic status, generalisation of the present results to male or lower educated samples is not necessarily possible. However, one study focusing on the association between affect and sleep [39] could not identify gender differences.

To conclude, the present study may shed light on the mechanisms by which sleep may be related to depression in women by investigating the association between subjective sleep and affect at a momentary day-to-day (micro) level. The subtle, repetitive impact of sleep on affect on a daily basis, especially on positive affect, may be one of the factors on the pathway to depression.

\section{Funding}

This research was supported by the Netherlands Organisation for Scientific Research; the Fund for Scientific research, Flanders and Twins, a non-profit association for scientific research in multiple births (Belgium) (to the East-Flanders Prospective Survey). We thank all twins for their co-operation. M. Wichers was supported by the Netherlands Organisation for Scientific Research (NWO, VENI Grant Nr. 916.76.147) and by ZON-MW (Grant Nr. 171001002). 


\section{References}

1. Ohayon MM, Roth T. Place of chronic insomnia in the course of depressive and anxiety disorders. J Psychiatr Res. 2003;37(1):9-15.

2. Cho HJ, Lavretsky H, Olmstead R, Levin MJ, Oxman MN, Irwin MR. Sleep disturbance and depression recurrence in community-dwelling older adults: a prospective study. Am J Psychiatry. 2008;165(12):1543-50.

3. Baglioni C, Battagliese G, Feige B, Spiegelhalder K, Nissen C, Voderholzer U, et al. Insomnia as a predictor of depression: a meta-analytic evaluation of longitudinal epidemiological studies. J Affect Disord. 2011;135(1-3):10-9.

4. Bower B, Bylsma LM, Morris BH, Rottenberg J. Poor reported sleep quality predicts low positive affect in daily life among healthy and mood-disordered persons. J Sleep Res. 2010;19(2):323-32.

5. Zohar D, Tzischinsky 0, Epstein R, Lavie P. The effects of sleep loss on medical residents' emotional reactions to work events: a cognitive-energy model. Sleep. 2005;28(1):47-54.

6. Talbot LS, Stone S, Gruber J, Hairston IS, Eidelman P, Harvey AG. A test of the bidirectional association between sleep and mood in bipolar disorder and insomnia. J Abnorm Psychol. 2012;121(1):39-50.

7. Cousins JC, Whalen DJ, Dahl RE, Forbes EE, Olino TM, Ryan ND, et al. The bidirectional association between daytime affect and nighttime sleep in youth with anxiety and depression. J Pediatr Psychol. 2011;36(9):969-79.

8. Derom CA, Vlietinck RF, Thiery EW, Leroy FO, Fryns JP, Derom RM. The East Flanders Prospective Twin Survey (EFPTS). Twin Res Hum Genet. 2006;9(6):733-8.

9. Loos R, Derom C, Vlietinck R, Derom R. The East Flanders Prospective Twin Survey (Belgium): a population-based register. Twin Res. 1998;1(4):167-75.

10. Jacobs N, Nicolson NA, Derom C, Delespaul P, van Os J, Myin-Germeys I. Electronic monitoring of salivary cortisol sampling compliance in daily life. Life Sci. 2005;76(21):2431-43.

11. Kendler KS, Thornton LM, Prescott CA. Gender differences in the rates of exposure to stressful life events and sensitivity to their depressogenic effects. Am J Psychiatry. 2001;158(4):587-93.

12. Csikszentmihalyi M, Larson R. Validity and reliability of the Experience-Sampling Method. J Nerv Ment Dis. 1987;175(9):526-36.

13. Delespaul P. Assessing schizophrenia in daily life. The experience sampling method. Maastricht: Maastricht University Press; 1995.

14. Carney CE, Buysse DJ, Ancoli-Israel S, Edinger JD, Krystal AD, Lichstein KL, et al. The consensus sleep diary: standardizing prospective sleep self-monitoring. Sleep. 2012;35(2):287-302.

15. First MB, Gibbon M, Spitzer RL, Williams JB. Structured Clinical Interview for DSM-IV-TR Axis I Disorders, Research Version, Patient Edition (SCID-I/P). New York: Biometrics Research, New York State Psychiatric Institute; 2002.

16. Derogatis LR, Rickels K, Rock AF. The SCL-90 and the MMPI: a step in the validation of a new selfreport scale. Br J Psychiatry. 1976;128:280-9.

17. Eysenck H, Eysenck S. Manual of the Eysenck personality scales. London, UK: Hodder \& Stoughton; 1991.

18. Snijders T, Bosker R. Multilevel analysis: An introduction to basis and advanced multilevel modeling. London: SAGE publications Ltd; 1999.

19. Harvey AG. Insomnia, Psychiatric Disorders, and the Transdiagnostic Perspective. Curr Dir Psychol Sci. 2008;17(5):299-303.

20. Vandekerckhove M, Weiss R, Schotte C, Exadaktylos V, Haex B, Verbraecken J, et al. The role of presleep negative emotion in sleep physiology. Psychophysiology. 2011;48(12):1738-44. 
21. Paterson JL, Dorrian J, Ferguson SA, Jay SM, Lamond N, Murphy PJ, et al. Changes in structural aspects of mood during 39-66 h of sleep loss using matched controls. Appl Ergon. 2011;42(2):196201.

22. Dagys N, McGlinchey EL, Talbot LS, Kaplan KA, Dahl RE, Harvey AG. Double trouble? The effects of sleep deprivation and chronotype on adolescent affect. J Child Psychol Psychiatry. 2011;53(6):6607.

23. Talbot LS, McGlinchey EL, Kaplan KA, Dahl RE, Harvey AG. Sleep deprivation in adolescents and adults: changes in affect. Emotion. 2010;10(6):831-41.

24. Murray G, Allen NB, Trinder J. Mood and the circadian system: investigation of a circadian component in positive affect. Chronobiol Int. 2002;19(6):1151-69.

25. Murray G, Nicholas CL, Kleiman J, Dwyer R, Carrington MJ, Allen NB, et al. Nature's clocks and human mood: the circadian system modulates reward motivation. Emotion. 2009;9(5):705-16.

26. Clark LA, Watson D, Leeka J. Diurnal variation in the positive affects. Motiv Emot. 1989;13(3):20534.

27. Watson D, Wiese D, Vaidya J, Tellegen A. The two general activation systems of affect: Structural findings, evolutionary considerations, and psychobiological evidence. J Pers Soc Psychol. 1999;76(5):820.

28. Boivin DB, Czeisler CA, Dijk DJ, Duffy JF, Folkard S, Minors DS, et al. Complex interaction of the sleep-wake cycle and circadian phase modulates mood in healthy subjects. Arch Gen Psychiatry. 1997;54(2):145-52.

29. Wichers M, Jacobs N, Derom C, Thiery EW, Van Os J. Depression: Too much negative affect or too little positive affect? Twin Res. 2007;10:19-20.

30. Wichers MC, Myin-Germeys I, Jacobs N, Peeters F, Kenis G, Derom C, et al. Evidence that moment-tomoment variation in positive emotions buffer genetic risk for depression: a momentary assessment twin study. Acta Psychiatr Scand. 2007;115(6):451-7.

31. Cohen J. Statistical power analysis for the behavioral sciences. 2nd ed. Hillsdale, NJ: Erlbaum; 1988.

32. Armitage R, Trivedi M, Hoffmann R, Rush AJ. Relationship between objective and subjective sleep measures in depressed patients and healthy controls. Depress Anxiety. 1997;5(2):97-102.

33. Tang NK, Harvey AG. Altering misperception of sleep in insomnia: behavioral experiment versus verbal feedback. J Consult Clin Psychol. 2006;74(4):767-76.

34. Broderick JE, Arnold D, Kudielka BM, Kirschbaum C. Salivary cortisol sampling compliance: comparison of patients and healthy volunteers. Psychoneuroendocrinology. 2004;29(5):636-50.

35. Kudielka BM, Broderick JE, Kirschbaum C. Compliance with saliva sampling protocols: electronic monitoring reveals invalid cortisol daytime profiles in noncompliant subjects. Psychosom Med. 2003;65(2):313-9.

36. Grandner MA, Patel NP, Gehrman PR, Xie D, Sha D, Weaver T, et al. Who gets the best sleep? Ethnic and socioeconomic factors related to sleep complaints. Sleep Med. 2010;11(5):470-8.

37. Krishnan V, Collop NA. Gender differences in sleep disorders. Curr Opin Pulm Med. 2006;12(6):3839.

38. Berry DT, Webb WB. State measures and sleep stages. Psychol Rep. 1983;52(3):807-12.

39. McCrae CS, McNamara JP, Rowe MA, Dzierzewski JM, Dirk J, Marsiske M, et al. Sleep and affect in older adults: using multilevel modeling to examine daily associations. J Sleep Res. 2008;17(1):4253. 



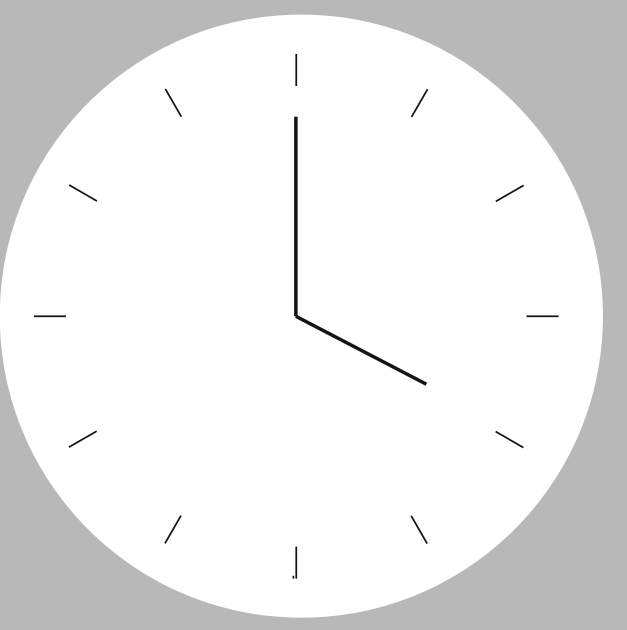

Chapter 4 


\title{
The serotonin transporter 5-HTTLPR polymorphism in the association between sleep quality and affect
}

\author{
Hartmann, JA, \\ Wichers, $\mathrm{M}$, \\ Van Bemmel, AL, \\ Derom, C, \\ Thiery, E, \\ Jacobs, N, \\ Van Os, J, Simons, CJP
}




\section{Abstract}

Background: A link between sleep and affect is well-known. Serotonin (5-HT) is associated with the regulation of affective as well as sleep-related processes. A functional polymorphism in the serotonin transporter gene (5-HTTLPR) has been associated with serotonergic functioning. The present study investigated whether allelic variation of this gene moderates the association between nighttime subjective sleep quality and affect the following day.

Method: A population-based sample of 361 ethnically homogenous adult female twins underwent a five day protocol based on the experience sampling method (ESM), assessing momentary negative affect, positive affect, and subjective sleep quality repeatedly and prospectively.

Results: There was a significant interaction between sleep quality and genotype in predicting positive affect the next day: carriers of one $(n=167)$ or two $S$-alleles $(n=78)$ had a significantly steeper slope compared to LL carriers $(\mathrm{n}=116)\left(\chi^{2}=4.16, \mathrm{p}=.042\right.$ and $\chi^{2}=3.90, \mathrm{p}=.048$ respectively).

Conclusion: The association between subjective sleep quality and positive affect the next day varied as a function of 5-HTTLPR: it was stronger in carriers of at least one copy of the S-allele compared to homozygous L-carriers, supporting a link between sleep and affect regulation, in which serotonin may play a role. However, these results are preliminary and require replication.

Key words: 5-HTTLPR; subjective sleep quality; positive affect; negative affect; experience sampling methodology; daily life 


\section{Introduction}

The neurotransmitter serotonin (5-hydroxytryptamine, 5-HT) is associated with a number of important behavioural and physiological processes, including the regulation of affect and sleep [1-6]. A significant link between sleep and affect has been proposed for decades, i.e. poor or short sleep is associated with affective dysregulation the next day [7] and in the longer term predicts the onset of depression [8,9]. The serotonergic system may modulate the observed association between sleep and affect, given that wakefulness or acute sleep restriction is associated with elevated serotonergic activity [4], while chronic sleep restriction induces changes in serotoninreceptor sensitivity [10].

The serotonin transporter (5-HTT), encoded by the SLC6A4 gene, plays an essential role in regulating 5-HT activity by clearing released serotonin from the synaptic cleft. A variable number of tandem repeats in the 5' promotor region (5-HTTLPR) of SLC6A4 has been shown to influence transcriptional activity. The short (S) allele of 5-HTTLPR is associated with reduced transcriptional activity compared to the long (L) allele, resulting in differential 5-HTT expression and function [11]. A spectrum of phenotypes, typically related to anxiety, neuroticism and depression, has been linked to the 5-HTTLPR genotypes [2, 11-13]. Furthermore, 5-HTTLPR has been associated with primary insomnia [14] and sleep quality $[15,16]$.

Previously, we showed that subjective sleep quality was associated with momentary affect during the next day using the experience sampling method (ESM) [17]. If 5-HTTLPR has an effect on serotonergic function, and if serotonergic function modulates the association between sleep and affect, it may be hypothesized that 5-HTTLPR variants impact the association between sleep and affect differentially. As such, we investigated whether the previously identified association between sleep and affect was moderated by 5-HTTLPR genotype.

\section{Experimental procedures}

\section{Sample}

Participants were taking part in a general population twin study on gene-environment interaction in affective disorders. This population-based survey has prospectively recorded all multiple births (inclusion when at least one of the children weighted minimal $500 \mathrm{~g}$ or, when unknown, with a gestational age of minimal 22 weeks) in the province of East-Flanders since 1964 [18]. Given important sex-differences in aetiology and expression of common mental disorders [19], only women were selected. Of 
623 women, 131 refused genotyping, and of the 492 consenting individuals, 384 sent back samples suitable for DNA analysis. Of the 384 individuals, 361 completed the experience sampling protocol (see below). The sample of 361 at baseline included 343 twins and 18 of their sisters. Of the 343 twins, 224 were monozygotic (109 pairs and 6 single twins), 118 dizygotic (45 pairs and 28 single twins) and 1 was of unknown zygosity. All participants were white and all four grandparents were of Belgian origin. The project was approved by the Local Committee of Medical Ethics and all participants gave their written consent.

\section{Measures}

\section{ESM}

The experience sampling method was used to assess daily life momentary affective states. ESM is a validated, structured diary technique to assess participants in their daily living environment. Participants received a digital wrist watch and a set of ESM self-assessment forms collated in a booklet for each day. The wrist watch was programmed to emit a signal (beep) at an unpredictable moment in each of ten 90 min time blocks between 07:30 and 22:30 on five consecutive days. After each beep, participants were required to stop their activity and fill out the ESM self-assessment forms. For a detailed description of the method, see references [20-22].

\section{Affect}

Using the ESM procedure, participants rated their mood states during the day by using 10 adjectives on a 7-point Likert scale, ranging from 1 (not) to 7 (very). Factor analysis identified two affect states: positive affect (PA) and negative affect (NA). PA comprised the weighted average on ratings of 'cheerful', 'content', 'energetic' and 'enthusiastic'; NA the weighted average of ratings on 'insecure', 'lonely', 'anxious', 'low', 'guilty' and 'suspicious'.

\section{Sleep quality}

Subjective sleep quality was assessed by means of a sleep diary. A sleep diary is a way of prospectively self-monitoring sleep and is regarded as the gold standard for subjective sleep assessment [23]. Based on previous work investigating the day-to-day associations between self-reported sleep and PA and NA in this sample [17], the sleep quality item of the sleep diary was chosen for further exploration as results demonstrated the strongest association between previous nights' subjective sleep quality and next day affect. Each morning, participants rated their sleep quality pertaining to the previous night on a 7-point Likert scale ranging from 1 (not at all) to 7 (very 
well). The scale was reversed so that 'very good sleep' was the reference category and higher scores represent worse sleep quality.

\section{Depressive symptomatology}

The Structured Clinical Interview for DSM-IV Axis I Disorders [SCID-I; 24] was administered to obtain current and lifetime diagnosis of major depressive disorder.

\section{Neuroticism}

Neuroticism was assessed using the neuroticism-extraversion subscale of the Eysenck Personality Scale [25].

\section{Genotyping}

Placental tissue for DNA analysis was available from 156 participants, blood samples from 14, and buccal cell samples from 208 using a sterile swab specifically designed for the collection of buccal cell samples for DNA testing (Omni Swabs; Whatman plc, Brentford, England). GenomicDNA was isolated using the QIAampDNAMini Kit (Qiagen, Westburg, Leusden, the Netherlands) according to the appropriate protocol for each sample type. For every monozygotic twin in the sample with genotypic data, the same genotypic data were included for the co-twin, assuming that both twins had identical genotypes. For detailed information regarding the 5-HTTLPR genotype analysis, see the work of Jacobs et al. [26].

\section{Statistical methods}

To take the 3-level grouping structure into account (repeated measurements nested within individuals nested within twin pairs), multilevel regression analysis (XTMIXED in STATA 12 for Windows) was used to investigate the hypothesis that 5-HTTLPR genotype moderated the association between nightly sleep quality on affect during the subsequent day. Thus, the two-way interaction between sleep quality and genotype was the parameter of interest. Genotype was conservatively dummy-coded, with LL as reference category. All associations were controlled for age and neuroticism and were repeated under the exclusion of participants with a lifetime diagnosis of depression. The post-estimation command MARGINS was used to calculate the effect of sleep quality on affect separately for the three allelic groups. 


\section{Results}

Sample characteristics are shown in Table 1. Frequencies for the three 5-HTTLPR genotypes (32\% LL, 49\% SL and 19\% SS) were in Hardy-Weinberg equilibrium $\left(\chi^{2}=.04\right.$, $\mathrm{p}=.85)$, using only one twin per twin pair $(\mathrm{n}=206)$. There was no main effect of genotype on sleep ( $b=-.11, \mathrm{p}=.169,95 \%$ CI $[-.259, .045])$, on positive affect $(b=.04, \mathrm{p}=.470$, $95 \%$ CI $[-.067, .145])$ or on negative affect $(b=.01, \mathrm{p}=.449,95 \%$ CI $[-.018, .041])$.

Table 1 | Sample Characteristics of the three 5-HTTLPR genotypes

\begin{tabular}{|c|c|c|c|c|}
\hline & $\mathbf{L L}$ & LS & SS & Total \\
\hline $\mathrm{N}$ & 116 & 167 & 78 & 361 \\
\hline Age & $28(7.5)$ & $28(7.4)$ & $26(7.6)$ & $28(7.5$, range18-46) \\
\hline \multicolumn{5}{|l|}{ Education } \\
\hline College & $84(72 \%)$ & $101(60 \%)$ & $51(65 \%)$ & $236(65 \%)$ \\
\hline Sec School & $30(26 \%)$ & $63(38 \%)$ & $24(31 \%)$ & $117(32 \%)$ \\
\hline Prim School & $2(2 \%)$ & $3(2 \%)$ & $3(4 \%)$ & $8(3 \%)$ \\
\hline Positive affect ${ }^{a}$ & $3.6(1.0)$ & $3.6(1.0)$ & $3.6(1.0)$ & $3.6(\mathrm{SD}, 1.0)$ \\
\hline Negative affect ${ }^{a}$ & $.81(.33)$ & $.80(.35)$ & $.86(.38)$ & $.82(\mathrm{SD}, .35)$ \\
\hline Sleep quality ${ }^{\mathrm{b}}$ & $2.9(1.5)$ & $2.8(1.5)$ & $2.6(1.5)$ & $2.8(\mathrm{SD}, 1.5)$ \\
\hline MDD current ${ }^{\mathrm{c}}$ & $9(7.8 \%)$ & $7(4.2 \%)$ & $3(4.0 \%)$ & $19(5.3 \%)$ \\
\hline MDD past ${ }^{\mathrm{d}}$ & $20(17.2 \%)$ & $28(16.8 \%)$ & $12(15.4 \%)$ & $60(16.6 \%)$ \\
\hline Neuroticism ${ }^{\mathrm{e}}$ & $.43(.27)$ & $.44(.29)$ & $.5(.24)$ & $.45(\mathrm{SD}, .27)$ \\
\hline
\end{tabular}

$\mathrm{MDD}=$ major depressive disorder

${ }^{a}$ Weighted average

${ }^{\mathrm{b}}$ Rated on 7-point Likert scale

${ }^{\mathrm{c}}$ Number of participants currently fulfilling DSM-IV criteria for major depressive disorder

${ }^{\mathrm{d}}$ Number of participants fulfilling DSM-IV criteria for major depressive disorder in the past

${ }^{\mathrm{e}}$ Between 0 and 1

\section{Positive affect}

Multilevel regression analysis yielded a significant two-way interaction between allelic variation and sleep quality for the LL vs. SS comparison $(b=-.03, \mathrm{p}=.048,95 \%$ CI $[-.066,-.003])$ as well as the LL vs. SL comparison ( $b=-.03, \mathrm{p}=.04195 \%$ CI [-.055, -.001]) indicating that allelic variation moderated the association between sleep quality and positive affect. As shown in Figure 1, carriers of one or two S-alleles had a significantly steeper slope compared to LL carriers $\left(\chi^{2}=4.16, p=.042\right.$ and $\chi^{2}=3.90$, $\mathrm{p}=.048$ respectively). The slopes of homozygotic S-carriers did not differ significantly from that of heterozygotic S-carries $\left(\chi^{2}=.1, \mathrm{p}=.754\right)$. Results remained similar when excluding those participants with a lifetime diagnosis of depression $(n=79)$ : there 
was a significant two-way interaction between allelic variation and sleep quality for the LL vs. SS comparison ( $b=-.04, \mathrm{p}=.021,95 \%$ CI $[-.08,-.006])$ as well as the LL vs. SS comparison ( $b=-.03, \mathrm{p}=.036,95 \%$ CI [-.06, -.002]). That is, carriers of one or two S-alleles had a significantly steeper slope compared to LL carriers $\left(\chi^{2}=4.40, \mathrm{p}=.036\right.$ and $\chi^{2}=5.35, \mathrm{p}=.021$ respectively), while the slopes of homozygotic S-carriers did not differ from heterozygotic S-carriers $\left(\chi^{2}=.36, \mathrm{p}=.55\right)$.

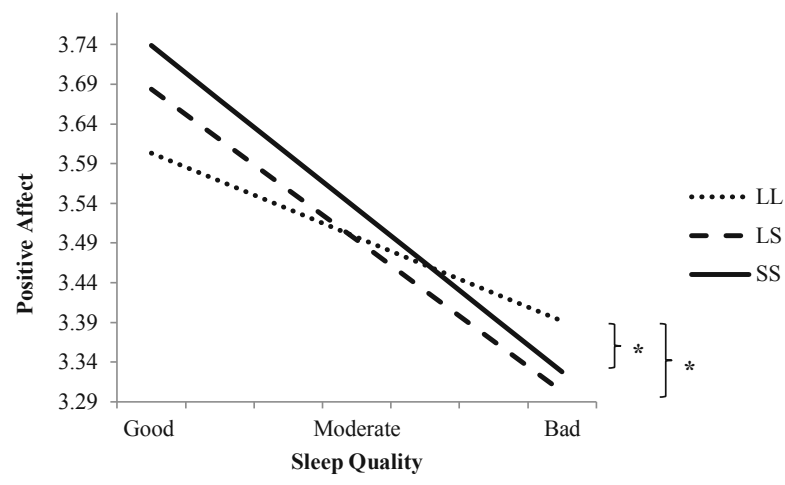

Figure 1 | Association between 5-HTTLPR genotype, sleep quality and positive affect. Slopes of SS- and LS-carriers differ significantly from LL-carriers.

\section{Negative Affect}

Multilevel regression analysis yielded no significant interaction between allelic variation and sleep quality for the LL vs. SS comparison $(b=.01, \mathrm{p}=.119,95 \%$ CI [-.003, $.023]$ ) nor for the LL vs. SL comparison ( $b=.001, \mathrm{p}=.845,95 \%$ CI [-.009, .011]). Results remained similar when patients with a lifetime diagnosis of depression were excluded $(n=79)$ : there was no significant interaction between allelic variation and sleep quality for the LL vs. SS comparison $(b=.01, \mathrm{p}=.085,95 \%$ CI $[-.001, .025]$.$) nor for the LL$ vs. SL comparison ( $b=.001, \mathrm{p}=.820,95 \%$ CI $[-.009, .012])$.

\section{Discussion}

The present study is the first to show that 5-HTTLPR allelic variation interacts with sleep quality to predict positive affect the next day. The association between sleep quality and positive affect the next day was stronger in carriers of at least one copy of the S-allele compared to LL carriers, supporting the notion of a significant link be- 
tween sleep and affect regulation, in which serotonin may play a role. These findings seemed robust as the exclusion of participants with a lifetime diagnosis of depression did not change the conclusions.

In this study, variation in 5-HTTLPR was not directly associated with subjective sleep quality, which is in line with the work by Brummett et al. [16] investigating the association between 5-HTTLPR, subjective sleep quality and chronic stress. They reported that 5-HTTLPR genotype was not related to subjective sleep quality as a main effect, but only in the presence of chronic stress. In contrast, a related study [15] identified a direct association between 5-HTTLPR and sleep quality; however, this effect was only observed in males, and the present sample included females only.

Similar to work of Deuschle et al. [14], demonstrating that the S-allele was significantly more prevalent in patients with primary insomnia, and the study by Brummett and colleagues [16], showing that the S-allele was associated with poorer sleep quality in the presence of chronic stress, it appeared that it is the S-allele which shows the stronger association between previous nights' sleep quality and next day affect.

There was no significant interaction between sleep quality and genotype in the case of NA, which is consistent with our previous study in this sample [17] showing that it is particularly momentary PA that is connected to previous nights' sleep quality.

Two important limitations should be considered. First, sleep quality in this study was not assessed objectively by means of polysomnography, but by prospective self-reports. As it is well-known that subjective and objective sleep measures do not necessarily concur, no generalization can be made to objectively assessed sleep. Furthermore, other causes of disturbed sleep, such as sleep apnea or period limb movement disorder could not be excluded, which would have been preferred given no screening for sleep disorders took place. There is some evidence that sleep apnea may be associated with 5-HTTLPR [27]. However, this effect was only identified in men, and therefore may not apply in the present female sample; moreover, as sleep apnea appeared to be associated with the L-allele of 5-HTTLPR, it may not account for the present findings. The second limitation pertains to the sample, which was female only. As there is evidence for sex-specific genetic effects on sleep [i.e. 15, 27], a direct extrapolation to the male population is not possible. Replication of the present findings as well as a further exploration of the current research question in a sample including both sexes and alternative measures of sleep quality, is desired.

\section{Role of Funding Source}

This research was supported by the Netherlands Organisation for Scientific Research; the Fund for Scientific Research, Flanders and Twins, a non-profit association for 
scientific research in multiple births (Belgium) (to the East-Flanders Prospective Survey).

M. Wichers was supported by the Netherlands Organisation for Scientific Research (NWO, VENI Grant Nr. 916.76.147) and by ZON-MW (Grant Nr. 171001002).

The funding sources had no further role in study design, data collection, data analysis, data interpretation, manuscript writing or submission process. 


\section{References}

1. Adrien J. Neurobiological bases for the relation between sleep and depression. Sleep Med Rev. 2002;6(5):341-51.

2. Canli T, Lesch KP. Long story short: the serotonin transporter in emotion regulation and social cognition. Nat Neurosci. 2007;10(9):1103-9.

3. Cools R, Roberts AC, Robbins TW. Serotoninergic regulation of emotional and behavioural control processes. Trends Cogn Sci. 2008;12(1):31-40.

4. Monti JM. Serotonin control of sleep-wake behavior. Sleep Med Rev. 2011;15(4):269-81.

5. Reid S, Barbui C. Long term treatment of depression with selective serotonin reuptake inhibitors and newer antidepressants. BMJ. 2010;340:c1468.

6. Landolt H-P, Meier V, Burgess HJ, Finelli LA, Cattelin F, Achermann P, et al. Serotonin-2 receptors and human sleep: effect of a selective antagonist on EEG power spectra. Neuropsychopharmacology. 1999;21(3):455-66.

7. Dinges DF, Pack F, Williams K, Gillen KA, Powell JW, Ott GE, et al. Cumulative sleepiness, mood disturbance, and psychomotor vigilance performance decrements during a week of sleep restricted to 4-5 hours per night. Sleep. 1997;20(4):267-77.

8. Baglioni C, Battagliese G, Feige B, Spiegelhalder K, Nissen C, Voderholzer U, et al. Insomnia as a predictor of depression: a meta-analytic evaluation of longitudinal epidemiological studies. J Affect Disord. 2011;135(1-3):10-9.

9. Ohayon MM, Roth T. Place of chronic insomnia in the course of depressive and anxiety disorders. J Psychiatr Res. 2003;37(1):9-15.

10. Roman V, Walstra I, Luiten PG, Meerlo P. Too little sleep gradually desensitizes the serotonin $1 \mathrm{~A}$ receptor system. Sleep. 2005;28(12):1505-10.

11. Lesch KP, Bengel D, Heils A, Sabol SZ, Greenberg BD, Petri S, et al. Association of anxietyrelated traits with a polymorphism in the serotonin transporter gene regulatory region. Science. 1996;274(5292):1527-31.

12. Caspi A, Sugden K, Moffitt TE, Taylor A, Craig IW, Harrington H, et al. Influence of life stress on depression: moderation by a polymorphism in the 5-HTT gene. Science. 2003;301(5631):386-9.

13. Serretti A, Calati R, Mandelli L, De Ronchi D. Serotonin transporter gene variants and behavior: a comprehensive review. Curr Drug Targets. 2006;7(12):1659-69.

14. Deuschle M, Schredl M, Schilling C, Wust S, Frank J, Witt SH, et al. Association between a serotonin transporter length polymorphism and primary insomnia. Sleep. 2010;33(3):343-7.

15. Barclay NL, Eley TC, Mill J, Wong CC, Zavos HM, Archer SN, et al. Sleep quality and diurnal preference in a sample of young adults: associations with 5HTTLPR, PER3, and CLOCK 3111. Am J Med Genet B Neuropsychiatr Genet. 2011;156B(6):681-90.

16. Brummett BH, Krystal AD, Ashley-Koch A, Kuhn CM, Zuchner S, Siegler IC, et al. Sleep quality varies as a function of 5-HTTLPR genotype and stress. Psychosom Med. 2007;69(7):621-4.

17. de Wild-Hartmann JA, Wichers M, van Bemmel AL, Derom C, Thiery E, Jacobs N, et al. Day-today associations between subjective sleep and affect in regard to future depression in a female population-based sample. Br J Psychiatry. 2013;202:407-12.

18. Derom C, Thiery E, Peeters H, Vlietinck R, Defoort P, Frijns JP. The East Flanders Prospective Twin Survey (EFPTS): An Actual Perception. Twin Res Hum Genet. 2013;16(1):58-63.

19. Fanous A, Gardner CO, Prescott CA, Cancro R, Kendler KS. Neuroticism, major depression and gender: a population-based twin study. Psychol Med. 2002;32(4):719-28. 
20. Csikszentmihalyi M, Larson R. Validity and reliability of the Experience-Sampling Method. J Nerv Ment Dis. 1987;175(9):526-36.

21. De Vries M. The Experience of psychopathology: investigating mental disorders in their natural settings. Cambridge: Cambridge University Press; 1992.

22. Delespaul P. Assessing schizophrenia in daily life. The experience sampling method. Maastricht: Maastricht University Press; 1995.

23. Carney CE, Buysse DJ, Ancoli-Israel S, Edinger JD, Krystal AD, Lichstein KL, et al. The consensus sleep diary: standardizing prospective sleep self-monitoring. Sleep. 2012;35(2):287-302.

24. First MB, Gibbon M, Spitzer RL, Williams JB. Structured Clinical Interview for DSM-IV-TR Axis I Disorders, Research Version, Patient Edition (SCID-I/P). New York: Biometrics Research, New York State Psychiatric Institute; 2002.

25. Eysenck H, Eysenck S. Manual of the Eysenck personality scales. London, UK: Hodder \& Stoughton; 1991.

26. Jacobs N, Kenis G, Peeters F, Derom C, Vlietinck R, van Os J. Stress-related negative affectivity and genetically altered serotonin transporter function: evidence of synergism in shaping risk of depression. Arch Gen Psychiatry. 2006;63(9):989-96.

27. Yue W, Liu H, Zhang J, Zhang X, Wang X, Liu T, et al. Association study of serotonin transporter gene polymorphisms with obstructive sleep apnea syndrome in Chinese Han population. Sleep. 2008;31(11):1535-41. 


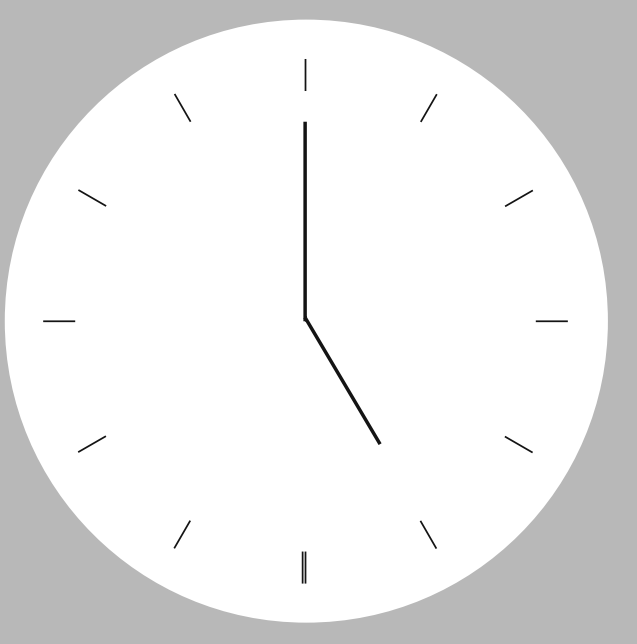

Chapter 5 


\title{
Diurnal variation of affect: a comparison among depression, psychosis, and controls
}

\author{
Hartmann, JA, \\ Simons, CJP, \\ Viechtbauer, $\mathrm{W}$, \\ Lieverse, $\mathrm{R}$, \\ Menne-Lothmann, C, \\ Kramer, I, \\ Peeters, F, \\ MERGE, \\ Myin-Germeys, I, \\ Wichers, M
}




\begin{abstract}
Background: In healthy individuals, positive (PA) and negative affect (NA) appear to differ in the way they dynamically unfold over the day. While PA shows a quadratic diurnal variation, NA remains stable across the day. There are indications for a deviant diurnal variation of PA and NA in depression; however, the evidence is preliminary and the specificity for depression unclear. The aim of the current study is therefore to systematically characterize and compare the diurnal variation of PA and NA in depression, psychosis and the general population.
\end{abstract}

Methods: A naturalistic design comprising a pooled sample of 1537 participants derived from twelve experience-sampling studies, consisting of repeated daily assessments of NA and PA over five to six days. Three groups (depression, psychosis, control) were formed based on their initial diagnostic status. Multilevel modelling was used to predict NA and PA by ten conservatively dummy-coded time-points per group; subsequently, coefficients were compared across groups.

Results: Time of day significantly predicted PA in all three groups, showing a diurnal variation comparable to an inverted U. The depression group differed significantly from the control group at time-point $10(\mathrm{z}=3.10, p<.001)$, demonstrating a weaker decrease of PA at the end of the day ( $\sim 21: 45 \mathrm{~h})$. Time of day significantly predicted NA during two (psychosis), three (control), or five time-points (depression). In the depression group, NA decreased significantly more than the control group from approximately $15: 45 \mathrm{~h}$ onwards ( $\mathrm{z}$ values ranging from $2.35(p=.019)$ to $5.22(p<.001)$ ).

Conclusion: The present study demonstrated a deviant diurnal variation for both PA and NA in depression: The typical decline of PA towards the night, observable in the control population, was weakened in depression. Furthermore, NA showed a stronger diurnal variation in depression as visible in a clear decrease of NA over the day. These differential patterns seemed to be specific for depression and may reflect an altered endogenous rhythmicity. 


\section{Introduction}

Human mood can be defined by the interaction of two largely independent systems: positive affect (PA) and negative affect (NA) [1]. High levels of PA are associated with mood states such as enthusiasm, cheerfulness, or excitement. Broadly, PA can be conceptualized as the affective representative of the behavioural approach system (BAS), a system regulating active engagement with the environment, reflecting the reward-oriented part of the dual system structure governing behavioural approach and withdrawal [1-3]. In contrast, high levels of NA are associated with mood states such as anxiety, guilt, or distress and can be conceptualized as the affective representative of the behavioural inhibition system (BIS). The BIS reflects the threat-oriented counterpart to the BAS and is responsible for behavioural withdrawal in the presence of aversion [1-3].

In both laboratory-controlled [3, 4] and real-life settings [2-7], PA and NA have been demonstrated to differ in the way they dynamically unfold over the day, referred to as diurnal mood variation (DMV). PA shows a quadratic variation ('inverted u-curve') when considering the waking portion (usual daytime) of the 24-hour cycle, with the lowest levels observed during the morning and evening (see Figure 1). When the entire 24-hour cycle is considered (day and night), PA shows a sinusoidal curve, with lowest levels during the late night and highest levels during the day. It has been argued that the DMV observed in PA reflects the action of an endogenous (i.e. circadian) rhythm, stimulating the individual to actively engage with the environment during the day when the likelihood of reward is higher than during the night [2, 3]. In contrast to PA, NA remains relatively stable across the 24-hour cycle [2-4, 8]. The lack of an apparent systematic rhythmicity in NA has been ascribed to the unpredictability of threat (i.e. the individual has to be able to react to an aversive situation at any time) $[2-4,8]$.

In depression, there is evidence for a shifted or weakened circadian rhythmicity [9], possibly also reflected in a deviant DMV of PA [8]. On a behavioural level, a diminished or shifted diurnal variation of PA could imply that potentially rewarding situations

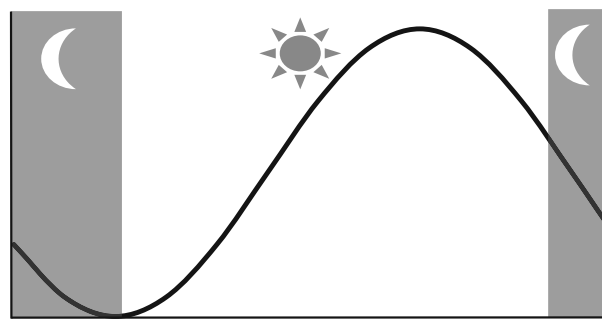

Figure 1 | Schematic of the course of positive affect across the day 
during the day are not approached (as observed in anhedonia) [10] or it may interfere with sleep-related processes. Furthermore, a clear 'morning worst' pattern is often clinically reported in depression and represents one of the defining criteria for the diagnosis of the melancholic subtype of major depressive disorder (MDD) according to the DSM-IV [11]. This 'morning-worst' pattern may be reflected in a differential, potentially less stable, unfolding of NA across the day. An understanding of the DMV in depression may give important insights into its endophenotype, however only two studies have prospectively addressed DMV in depression.

Murray and colleagues [8] compared the DMV of PA in a sample of women varying in depressive symptoms, identifying an attenuated quadratic variation for the group high in depressive symptoms. However, their sample comprised participants with non-clinical depression only. In another study, Peeters and colleagues [12] compared the DMV of PA between healthy individuals and patients fulfilling DSM-IV criteria for MDD, identifying a linear increase (rather than quadratic course) of PA over the day in the depressed patients. Moreover, NA appeared to show a linear decrease in depressed patients, a pattern absent in healthy controls. However, their study was based on a small sample only. Furthermore, there is no evidence that the observed deviant diurnal variation of PA and NA observed in depression is specific for MDD. The aim of the present study was to (a) confirm previous preliminary findings concerning the diurnal variation of PA and NA in depression in a very unique sample of over 1500 individuals representing different diagnostic groups and (b) investigate whether possible abnormalities in diurnal variation of affect are specific to depression.

This is the first time that an ambulatory assessment approach has been used to compare DMV between different diagnostic groups.

\section{Methods}

\section{Sample}

The sample consisted of participants pooled from twelve independent studies using an identical study design, i.e. the Experience Sampling Method (ESM, see below). Based on their initial diagnostic status, participants were classified in the following groups: (i) a depression group, (ii) a psychosis group, and (iii) a general population/ control group. The latter group consisted of healthy controls, female twins from the general population, and individuals selected to be low in schizotypy (hereafter referred to as 'control group'). The depression group included individuals diagnosed with major depression, either with a current episode or a past episode with residual symptoms (i.e. Hamilton Depression Rating Scale score $>7$ ). The psychosis group in- 
cluded patients with a diagnosis of non-affective psychosis. Table 1 gives an overview of the exact derivation of the participants together with a reference to the original study descriptions.

Table 1 | Participant status and reference to the original

\begin{tabular}{|c|c|c|c|c|}
\hline $\begin{array}{l}\text { Status } \\
\text { present paper }\end{array}$ & $\begin{array}{l}\text { Study } \\
\text { ID }\end{array}$ & $\mathrm{N}$ & Original Status & Reference \\
\hline \multirow[t]{8}{*}{ Controls } & 2 & 24 & Healthy Control & Barge-Schaapveld et al. [13] \\
\hline & 3 & 27 & Healthy Control & Van der Steen et al., in prep. \\
\hline & 4 & 39 & Healthy Control & Peeters et al. [12] \\
\hline & 6 & 50 & Healthy Control & Myin-Germeys et al. [14] \\
\hline & 8 & 84 & Healthy Control & Collip et al. [15] \\
\hline & 9 & 50 & Healthy Control & Collip et al., in prep. \\
\hline & 10 & 600 & General population female twins & Wichers et al. [16] \\
\hline & 11 & 38 & Low schizotypy & Thewissen et al. [17] \\
\hline \multirow[t]{4}{*}{ Depression } & 2 & 65 & MDD & Barge-Schaapveld et al. [13] \\
\hline & 4 & 45 & MDD, current episode & Peeters et al. [12] \\
\hline & 7 & 129 & MDD, past episode, HDRS $>7$ & Geschwind et al. [18] \\
\hline & 12 & 101 & MDD, current or past episode, HDRS $>7$ & Kramer et al. [19] \\
\hline \multirow[t]{6}{*}{ Psychosis } & 1 & 27 & Non-affective psychosis & Lataster et al. [20] \\
\hline & 5 & 18 & Non-affective psychosis & Bak et al. [21] \\
\hline & 6 & 44 & Non-affective psychosis & Myin-Germeys et al. [14] \\
\hline & 8 & 70 & Non-affective psychosis & Collip et al. [15] \\
\hline & 9 & 47 & Non-affective psychosis & Collip et al., in prep. \\
\hline & 11 & 79 & Non-affective psychosis & Thewissen et al. [17] \\
\hline Total & & 1537 & & \\
\hline
\end{tabular}

HDRS = Hamilton Depression Rating Scale

\section{Experience Sampling Method (ESM)}

ESM is a validated, structured diary technique to assess individuals in their daily living environment. It is a momentary assessment method providing repeated in-themoment micro-measurements of affect and context across the waking day (07:30 until 22:30) in a prospective and ecologically valid manner [22-24]. It has been previously used to study the dynamics of mood [25-27].

In all but one studies (study ID 12), participants received a digital wristwatch and a set of ESM self-assessment forms collated in a booklet for each day. In one of the studies (Study ID 12), the booklet was replaced by an electronic ESM device ('PsyMate'). The wristwatch, respectively the electronic ESM device, was programmed to emit 
a signal ('beep') at an unpredictable moment in each of ten 90-minute time blocks between 07:30 and 22:30 on five days (study ID 1,10, and 12) or six (all other studies) days. After each beep, participants were required to stop their activity and fill out the ESM self-assessment booklets, or digitally complete the questionnaire shown on the device display. All self-assessments concerning mood states were rated on 7-point Likert scales.

To minimize memory distortion, participants were instructed to complete their reports immediately after the beep. In the paper-and-pencil version, participants had to record the clock time at which they filled in the form. This time was, after the completion of the ESM protocol, compared to the actual beep time and reports filled in later than 15 minutes after the beep were removed. In the electronic version, the self-assessments were no longer available for completion after 15 minutes.

\section{Measures}

\section{Positive Affect}

The combined dataset consisted of the repeated responses (10 times a day for 5 or 6 days, equalling a maximum of 50 respectively 60 responses per individual) of every participant to the item 'I feel cheerful', rated on a 7-point Likert scale. Cheerful is an item that has been shown to load very high on the factor 'Positive affect' $[28,29]$ and has been previously used as an indicator for PA [30]. Furthermore, it was an item which was consistently available in every ESM protocol across all twelve studies.

\section{Negative Affect}

As for PA, the dataset consisted of the repeated responses $(10$ times a day for 5 or 6 days, equalling a maximum of 50 respectively 60 responses per individual) of every participant to the items 'I feel lonely', 'I feel guilty' and 'I feel anxious'. These items consistently load high on the factor 'Negative Affect' [25, 28, 29] and were available across all studies.

\section{Analyses}

The data set had a hierarchical structure, due to within-person clustering: repeated measurements (level 1) are nested within individuals (level 2). Observations within one participant are more similar than those across participants. As nesting of data typically violates the assumption of independent residuals, multilevel regression analysis was used that takes clustering into account [31]. All analyses were performed using STATA 12 [32]. 
In order to investigate the diurnal variation of PA and NA in the three different diagnostic groups, three separate regression models were fitted in which affect (either PA or NA) was predicted by time. 'Time' refers to a dummy-coded variable running from 1 to 10 (corresponding to the 10 beep moments per day) for every ESM day. By treating time conservatively as a dummy variable, no linear, quadratic or cubic trends were 'forced' onto the data. After the regressions, the statistical difference of the coefficients for time (i.e. change in affect per time point relative to the reference category time point 1 ) for the patient groups vs. the control group was assessed by the following formula: $\mathrm{z}=(\mathrm{B} 1-\mathrm{B} 2) / \sqrt{ }\left(\operatorname{seB} 1^{\wedge} 2+\mathrm{seB} 2^{\wedge} 2\right)$. The multilevel models, fitted via maximum likelihood, included random intercepts for participant and day and were fitted with an autoregressive residual structure. To account for the inclusion of twins in the control group, this model also included a random intercept for twin. As a random slope for time would not increase the model fit as assessed by AIC and BIC, the more parsimonious model was adapted. All analyses were controlled for age and gender.

\section{Results}

\section{Sample}

After removal of invalid subjects and invalid beeps, the combined dataset consisted of 1,537 participants derived from 12 studies who responded to a total number of 66,580 beeps. On average, participants responded to 38.44 beeps in studies consisting of five ESM days (i.e. study 1, 8 and 12) and to 47.71 beeps in studies consisting of six ESM days (all other studies). The control group included 912 participants, the depression group consisted of 340 participants, and the psychosis group consisted of 285 participants.

Table 2 provides an overview of demographic characteristics of the different diagnostic groups of the sample.

\section{Positive Affect}

The diagnostic groups differed significantly in their mean level of PA $\left(\mathrm{F}_{(2,1536)}=360.86\right.$, $p<.001$ ). The mean levels of PA (see Table 2) in the control group were significantly higher than the levels in the psychosis $\left(\chi^{2}(1)=49.04, p<.001\right)$ and depression group $\left(\chi^{2}(1)=721.69, p<.001\right)$. The psychosis group showed higher levels than the depression group $\left(\chi^{2}(1)=235.24, p<.001\right)$.

Table 2 shows the multilevel estimates for the absolute PA level per time point per diagnostic group. PA levels were lowest in the morning, rose to peak in the afternoon 
Table 2 | Sample characteristics and multilevel estimates for PA and NA

\begin{tabular}{|c|c|c|c|}
\hline $\begin{array}{l}\text { Sample Characteristics/ } \\
\text { Multilevel estimates }\end{array}$ & Control & Depression & Psychosis \\
\hline \multicolumn{4}{|l|}{ Sample characteristics } \\
\hline $\mathrm{N}$ & 910 & 340 & 285 \\
\hline Age (SD) & $31.13(10.86)$ & $44.42(10.23)$ & $33.84(16.67)$ \\
\hline Female (\%) & 776 (85.09) & $228(67.06)$ & $93(32.63)$ \\
\hline \multicolumn{4}{|l|}{ Education } \\
\hline \multicolumn{4}{|l|}{ Employed (\%) } \\
\hline Mean level PA (SD) & $4.78(1.38)$ & $3.04(1.68)$ & $4.30(1.67)$ \\
\hline Mean level NA (SD) & $1.19(.52)$ & $2.01(1.21)$ & $1.76(1.08)$ \\
\hline \multicolumn{4}{|l|}{ Multilevel estimates $^{a}$} \\
\hline \multicolumn{4}{|l|}{ (Absolute) PA during } \\
\hline$\sim$ 08:15 Beеp $1(\mathrm{~B}, \mathrm{SE})$ & $4.35(.13)$ & $2.03(.35)$ & $3.77(.16)$ \\
\hline 09:45 Веep $2(\mathrm{~B}, \mathrm{SE})$ & $4.61(.13)$ & $2.28(.35)$ & $4.01(.16)$ \\
\hline 11:15 Веер $3(\mathrm{~B}, \mathrm{SE})$ & $4.69(.13)$ & $2.42(.35)$ & $4.19(.16)$ \\
\hline$\sim$ 12:45 Веер $4(\mathrm{~B}, \mathrm{SE})$ & $4.76(.13)$ & $2.43(.35)$ & $4.14(.16)$ \\
\hline$\sim$ 14:15 Beep $5(\mathrm{~B}, \mathrm{SE})$ & $4.73(.13)$ & $2.43(.35)$ & $4.19(.16)$ \\
\hline$\sim$ 15:45 Веер $6(\mathrm{~B}, \mathrm{SE})$ & $4.73(.13)$ & $2.45(.35)$ & $4.25(.16)$ \\
\hline 17:15 Веep 7 (B, SE) & $4.71(.13)$ & $2.45(.35)$ & $4.21(.16)$ \\
\hline$\sim$ 18:45 Веер $8(\mathrm{~B}, \mathrm{SE})$ & $4.73(.13)$ & $2.48(.35)$ & $4.14(.16)$ \\
\hline$\sim 20: 15$ Beep $9(\mathrm{~B}, \mathrm{SE})$ & $4.70(.13)$ & $2.46(.35)$ & $4.12(.16)$ \\
\hline$\sim$ 21:45 Веер $10(\mathrm{~B}, \mathrm{SE})$ & $4.54(.13)$ & $2.38(.35)$ & $4.01(.16)$ \\
\hline \multicolumn{4}{|l|}{ (Absolute) NA during } \\
\hline$\sim$ 08:15 Beеp $1(\mathrm{~B}, \mathrm{SE})$ & $1.31(.048)$ & $2.78(.271)$ & $1.82(.122)$ \\
\hline$\sim$ 09:45 Веер 2 (B, SE) & $1.31(.048)$ & $2.80(.271)$ & $1.82(.122)$ \\
\hline 11:15 Веер 3 (B, SE) & $1.30(.048)$ & $2.78(.271)$ & $1.81(.122)$ \\
\hline$\sim$ 12:45 Веер $4(\mathrm{~B}, \mathrm{SE})$ & $1.30(.048)$ & $2.74(.271)$ & $1.80(.122)$ \\
\hline$\sim$ 14:15 Веep $5(\mathrm{~B}, \mathrm{SE})$ & $1.29(.048)$ & $2.75(.271)$ & $1.79(.121)$ \\
\hline$\sim$ 15:45 Веер $6(\mathrm{~B}, \mathrm{SE})$ & $1.28(.048)$ & $2.69(.271)$ & $1.76(.121)$ \\
\hline$\sim$ 17:15 Веер 7 (B, SE) & $1.29(.048)$ & $2.68(.271)$ & $1.80(.121)$ \\
\hline$\sim$ 18:45 Веер $8(\mathrm{~B}, \mathrm{SE})$ & $1.28(.048)$ & $2.68(.271)$ & $1.76(.121)$ \\
\hline$\sim$ 20:15 Веер $9(\mathrm{~B}, \mathrm{SE})$ & $1.29(.048)$ & $2.62(.271)$ & $1.81(.121)$ \\
\hline 21:45 Веер 10 (B, SE) & $1.29(.048)$ & $2.63(.271)$ & $1.83(.122)$ \\
\hline
\end{tabular}

$\mathrm{B}=$ unstandardized regression coefficient

$\mathrm{SE}=$ Standard Error

${ }^{\mathrm{a}}$ In contrast to what is depicted in the Figures 2 and 3 ( change scores), the multilevel estimates here represent the estimated absolute values of NA and PA 
and subsequently decreased throughout the evening/night in all groups. The time of the peak varied between time point 4 (corresponding to an approximate clock time of $12: 45 \mathrm{~h}$ (healthy controls)), time point 6 (corresponding to an approximate clock time of 15:45h (psychosis group)) and time point 8 (corresponding to an approximate clock time of 18:45h (depression group)). Figure 2 shows the multilevel estimates for the change of PA per time point per diagnostic group, relative to the reference category time point 1 , together with the approximate clock time. As such, all groups show a 0 at time point 1 . It is important to note that this figure does not display the absolute differences between the groups, but the changes in PA relative to time point 1 . The dummy-coded variable time (corresponding to the ten beep moments per day) was a significant predictor of PA ( $p<.001$; for B's and SE's see Figure 2) during all time points in all three groups. Post-hoc z-tests for the equality of the coefficients across the models (i.e. change in PA per time point relative to the reference category time
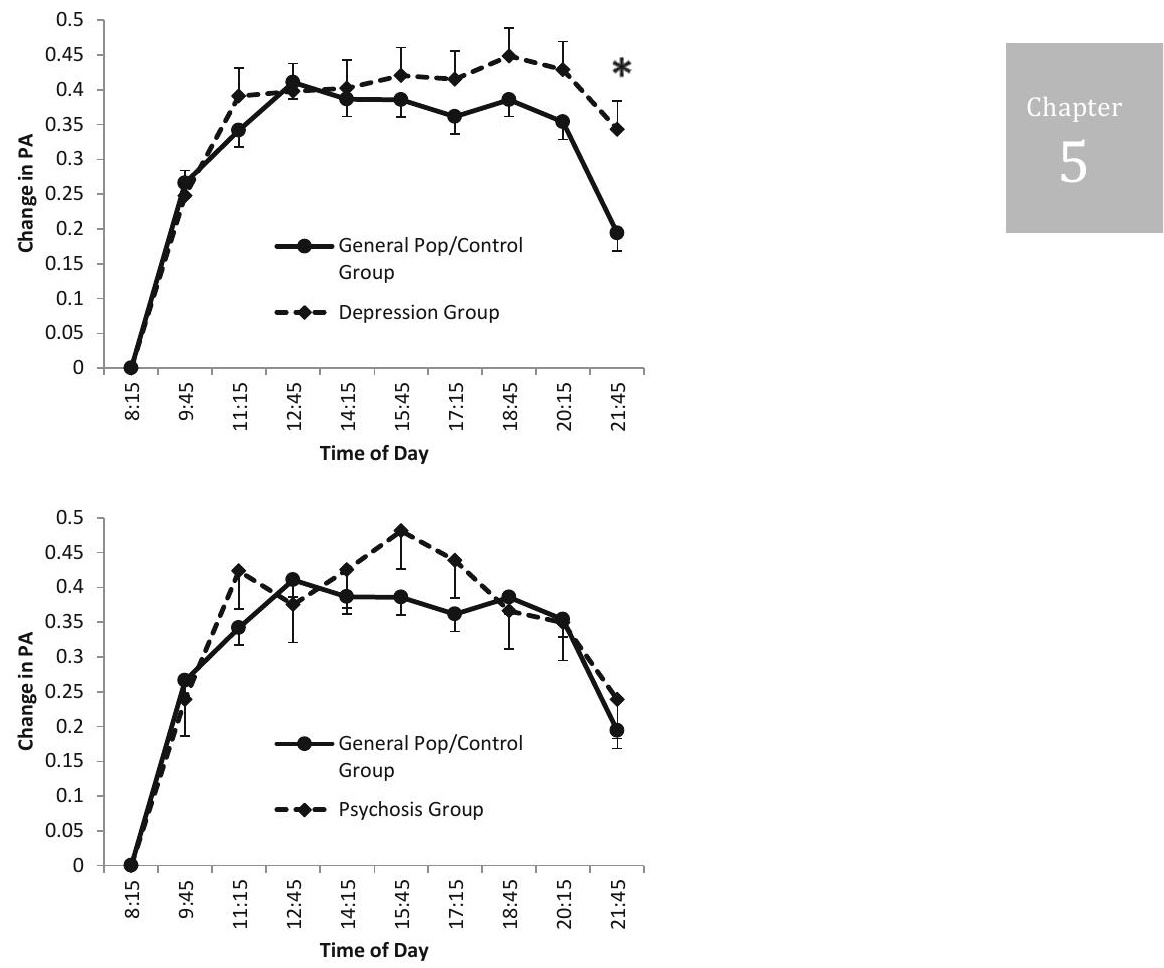

Figure 2 | Multilevel estimates (regression coefficient (B) and standard error (SE)) for change of positive affect (PA) across the day, with time point 1 as reference. Top: Depression group versus control group. The groups differ significantly at the last time point (see text). Bottom: Psychosis group versus control group. The groups do not differ significantly at any of the time points. Clock time is only approximate and corresponds to the quasi-random beep moments (1-10) per day. 
point 1) in patient groups vs. the control group showed that there was a significant difference between the coefficients of the control group and the depression group at the last time point. That is, around a clock time of 20:45h, the depression group showed a higher increase of PA (relative to reference time point 1 ) compared to the control group (i.e. time point 10: $\mathrm{z}=3.10, p<.001$ ).

\section{Negative Affect}

The diagnostic groups differed significantly in their mean level of $N A\left(F_{(2,1536)}=242.14\right.$ $p<.001$ ). The mean levels of NA (see Table 2 ) in the control group were significantly lower than the levels in the depression $\left(\chi^{2}(1)=413.03, p<.001\right)$ and psychosis group $\left(\chi^{2}(1)=177.73, p<.001\right)$. The psychosis group showed lower levels than the depression group $\left(\chi^{2}(1)=23.18, p<.001\right)$.

Table 2 displays the multilevel estimates for the mean NA levels per time point per diagnostic group. Figure 3 shows the multilevel estimates for the change of NA per time point per diagnostic group, relative to the reference category time point 1 , together with the approximate clock time. As such, all groups start at 0 at time point 1. It is important to note that this figure does not display the absolute differences between the groups, but the changes in NA relative to time point 1.

The regression models revealed a more or less stable course of NA for the control group: With the exception of small effects at time point $6(\sim 15: 45 \mathrm{~h} ; \mathrm{B}=-.03, p=.005)$, $8(\sim 18: 45 \mathrm{~h} ; \mathrm{B}=-.03, p=.002)$ and $9(\sim 20: 15 \mathrm{~h}, \mathrm{~B}=-.02, p=.025)$ the dummy-coded variable time (corresponding to the ten beep moments per day) was not a significant predictor of NA (for B's and SE's see Figure 3). A similar pattern was observable for the psychosis group: With the exception of time point $6(\sim 15: 45 \mathrm{~h}, \mathrm{~B}=-.06, p=.043)$ and $8(\sim 18: 45 \mathrm{~h}, \mathrm{~B}=-.06, p=.029)$, time was not a significant predictor of NA. The depression group showed a different pattern: From time point $6(\sim 15: 45 \mathrm{~h})$, the time points were highly significant predictors of NA (B's ranging from -.09 (time point 6) to -.17 (time point 9), all $p<.001$ (see also Figure 3). Post-hoc z-tests for the equality of the coefficients across the models (i.e., change in NA per time point relative to the reference category time point 1 ) in patient groups vs. the control group showed the following: While there were no differences between the control group and psychosis group, the coefficients from the depression group differed significantly from those of the control group on time point $6(\sim 15: 45 \mathrm{~h}, \mathrm{z}=2.35, p=.019)$, time point $7(\sim 17: 15 \mathrm{~h}$, $\mathrm{z}=3.00, p=.003)$, time point $8(\sim 18: 45 \mathrm{~h}, \mathrm{z}=2.51, p=.012)$, time point $9(\sim 18: 15 \mathrm{~h}, \mathrm{z}=$ $5.22, p<.001)$, and time point $10(\sim 21: 45 \mathrm{~h}, \mathrm{z}=4.92, p<.001)$. That is, from approximately 15:45h onward, the depression group showed a larger decrease of NA as the control group. 

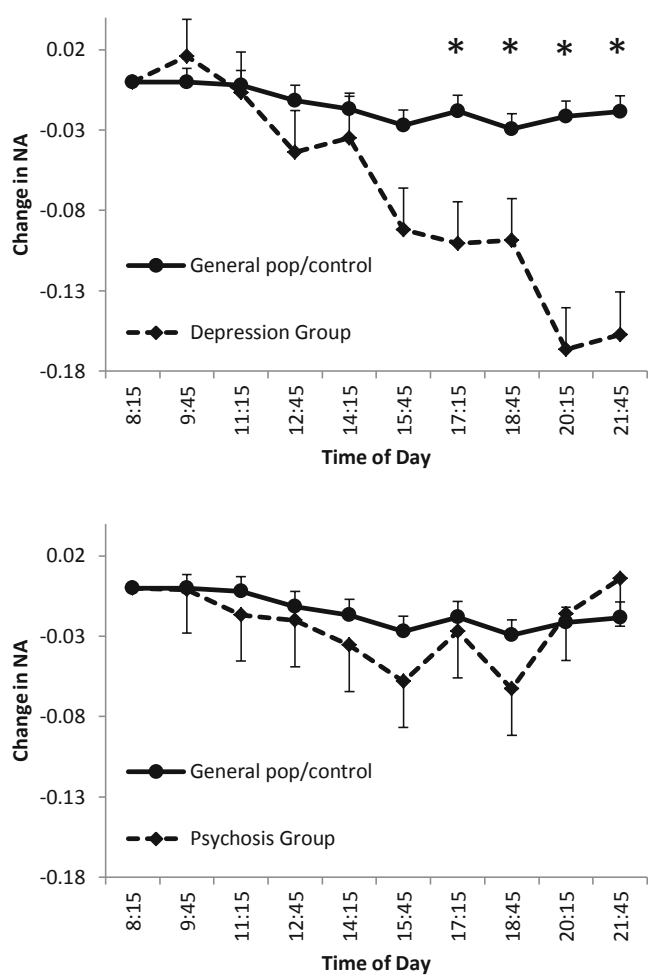

Figure 3 | Multilevel estimates (regression coefficient (B) and standard error (SE)) for change of negative affect (NA) across the day, with time point 1 as reference. Top: Depression group versus control group. The groups differ significantly between time point 6 and 10 (see manuscript text). Bottom: Psychosis group versus control group. The groups do not differ significantly at any of the time points. Clock time is only approximate and corresponds to the ten quasi-random beep moments per day.

\section{Discussion}

The present study investigated the diurnal variation of PA and NA in an ambulatory, real-time design in a very large sample consisting of three different diagnostic groups: patients with a DSM-IV diagnosis of major depression, patients with a DSM-IV diagnosis of psychosis, and individuals from the general population/healthy controls. Our results confirmed the presence of a clear DMV in PA and a more stable course for NA in healthy individuals, while patients diagnosed with major depression exhibited an altered diurnal variation for both NA and PA. These deviant mood variations appeared to be specific to depression as it was not observed in the psychosis group. To our knowledge, this is the first time that DMV was investigated in patients with psychosis. 


\section{Positive Affect}

As apparent from the plots of PA change across the day, all three diagnostic groups showed a daily PA variation approximately resembling an inverted $U$. That is, lowest levels of PA in the morning, a peak in the afternoon, followed by a fall during the evening or night. All ten time points, corresponding to the ten beep moments of each ESM day, were significant predictors of PA in all groups. As such, the three groups roughly showed the expected DMV for PA. However, the group with patients diagnosed with depression showed significantly different PA variations compared to the control group. Visual inspection of the plots revealed that the peak of PA appeared to occur at different time points in these groups. As expected, the highest PA in the control group was observed at approximately 12:45h, while the depression group appeared to peak around six hours later, at approximately $18: 45 \mathrm{~h}$ in the evening. Additionally, there was a significant difference in the course of PA between the depression- and control group at the last time point, indicating that the fall of PA in the second part of the day is attenuated in the depressed patients.

These observations are consistent with the theory that human beings have their highest levels of PA during midday, and that this function seems to be dysregulated (i.e. shifted) in patients with depression. Although based on the current study design, no conclusions can be drawn about the origin of the observed differences in depressed and healthy individuals, the present findings fit well within the theory of PA being the result of a bio-behavioural approach system. This may be partly driven by an endogenous circadian oscillator, which may be disturbed in depression [8]. Indeed, it has been proposed that circadian abnormalities are etiologically linked to depression, such as in the phase-shift hypothesis (mood disturbances are associated with a phase advance/delay of the circadian rhythm, [e.g., 33, 34]) and the reduced amplitude hypothesis (mood disturbances are associated with an attenuated circadian amplitude [e.g., 35, 36]).

In concrete terms, an attenuated PA rhythm (i.e. reduced amplitude) could behaviourally translate into decreased levels of motivation and goal-directed activities. From a clinical perspective, blunted PA could be linked to the experience of anhedonia [10], i.e. the loss of interest and the reduced ability to experience pleasure [37]. Anhedonia, in a clinically relevant form, is observed in almost half of depressed patients [38] and is a symptom which is particularly difficult to treat [39]. In a similar vein, a shifted PA rhythm (i.e. phase delay) may be associated with (i) low levels of PA and motivation during times requiring high engagement in goal-directed activities (i.e. during daytime) and (ii) higher levels of PA and motivation during times requiring disengagement with the environment (i.e. evening/night), potentially interfering with sleep-related processes. 
Conversely, the psychosis group did not significantly differ from the control group at any of the time points. However, this group showed a later peak of PA at approximately 15:45h (see also below).

\section{Negative Affect}

Time was a significant predictor of NA at three out of ten time points in the control group. Accordingly, time appeared to be associated with the course of NA (albeit only towards the end of the day). This contrasts with our hypothesis, predicting no association between NA and time of day. However, compared to the depression group, the control group showed a rather stable course across the day. In the depression group, time was a significant predictor of NA during all ten time points, showing a clear decrease of NA across the day. From approximately 17:15h, the depression group significantly differed from the control group in change of NA. The finding of a clear diurnal variation in the depression group replicated the observation from a smaller study in depression $(n=47)$, identifying a linear decrease of NA across the day, which was absent in healthy controls [12]. The authors of this study asserted that the heightened diurnal variation of NA may be indicative of an overactive BIS system. Indeed, an overactive BIS system may account for higher levels of NA in general (as also observed in the present study), however it does not necessarily explain why there is such a variation (i.e. decrease) in NA across the day. Why should a threat response system, like BIS, in depression be more reactive during the morning than evening hours? Evidently, more research, possibly under more controlled circumstances and consideration of physiological variables, is warranted to better understand the diurnal variation of NA in depression. At the very least, it can be stated that the findings reported here are congruent with the 'morning worst' patterns observed in clinical practice.

\section{Specificity for depression}

The present study showed that the altered diurnal variation of PA and NA seems to be markedly specific for depression. The psychosis group showed a diurnal course of affect comparable to the control group, with the exception of the PA peak timing, placed between that of the control- and the depression group. As such, they may be some form of alterations in PA periodicity as well, however to a far lesser extent than in depression. Indeed, there is recent evidence for circadian disruption in psychosis as well [40]. However, before firm conclusions can be drawn, the present findings should await replication from studies with a more rigorously controlled design. If these findings hold true and altered diurnal variation of affect is indeed specific for depression or depressive symptoms, it could help to better understand and charac- 
terize the endophenotype of depression, potentially informing new, or augmenting existing, chronotherapeutic treatment strategies [41].

\section{Limitations}

A number of limitations should be noted. Due to data pooling and the general designs of the studies, only a few variables were available across all studies to control for potential confounding in the analyses. Although age and gender were available and included, a number of other important factors, such as sleep , medication or environmental factors, could not be incorporated. The lack of a control for the previous night's sleep parameters warrants special circumspection. It has been shown that mood is affected by a complex, non-additive interaction of both circadian influences and wake-dependent effects (i.e. the duration of prior wakefulness) [42]. As such, it is highly conceivable that the groups may have differed in their wake-dependent processes, leading (in interaction with circadian phase) to a differential course of PA and NA the next day. Future studies should preferentially take previous night's sleep parameters into consideration.

The measurement of PA was based on a single item (i.e. cheerful). However, this item has been previously used as single indicator of PA [30] and has been shown to consistently load very high on the factor PA $[28,29]$. In contrast to NA, which requires several items due to little variation, PA generally exhibits high levels of variation and thus, may be captured by a single item.

Finally, it could be argued that the weaker diurnal variation of NA across the day in the control group is due to a floor effect or too little variation, since levels of NA tended to be very low in this group. However, as the psychosis group, with general higher levels and variation of NA, showed a course comparable to that of the control group, this possibility is less likely. 


\section{References}

1. Watson D. Intraindividual and interindividual analyses of positive and negative affect: their relation to health complaints, perceived stress, and daily activities. J Pers Soc Psychol. 1988;54(6):1020.

2. Watson D, Wiese D, Vaidya J, Tellegen A. The two general activation systems of affect: Structural findings, evolutionary considerations, and psychobiological evidence. J Pers Soc Psychol. 1999;76(5):820.

3. Murray G, Nicholas CL, Kleiman J, Dwyer R, Carrington MJ, Allen NB, et al. Nature's clocks and human mood: the circadian system modulates reward motivation. Emotion. 2009;9(5):705-16.

4. Murray G, Allen NB, Trinder J. Mood and the circadian system: investigation of a circadian component in positive affect. Chronobiol Int. 2002;19(6):1151-69.

5. Clark LA, Watson D, Leeka J. Diurnal variation in the positive affects. Motiv Emot. 1989;13(3):20534.

6. Porto R, Duarte L, Menna-Barreto L. Circadian variation of mood: comparison between different chronotypes. Biol Rhythm Res. 2006;37(5):425-31.

7. Hasler BP, Mehl MR, Bootzin RR, Vazire S. Preliminary evidence of diurnal rhythms in everyday behaviors associated with positive affect. J Res Pers. 2008;42(6):1537-46.

8. Murray G. Diurnal mood variation in depression: a signal of disturbed circadian function? J Affect Disord. 2007;102(1-3):47-53.

9. Wirz-Justice A. Diurnal variation of depressive symptoms. Dialogues Clin Neurosci. 2008;10(3):337.

10. Hasler BP, Allen JJ, Sbarra DA, Bootzin RR, Bernert RA. Morningness-eveningness and depression: preliminary evidence for the role of the behavioral activation system and positive affect. Psychiatry Res. 2010;176(2-3):166-73.

11. American Psychiatric Association. Diagnostic and Statistical Manual of Mental Disorders (DSM-IVTR). Washington, DC2000.

12. Peeters F, Berkhof J, Delespaul P, Rottenberg J, Nicolson NA. Diurnal mood variation in major depressive disorder. Emotion. 2006;6(3):383.

13. Barge-Schaapveld DQ, Nicolson NA. Effects of antidepressant treatment on the quality of daily life: An experience sampling study. J Clin Psychiatry. 2002.

14. Myin-Germeys I, van Os J, Schwartz JE, Stone AA, Delespaul PA. Emotional reactivity to daily life stress in psychosis. Arch Gen Psychiatry. 2001;58(12):1137-44.

15. Collip D, Nicolson NA, Lardinois M, Lataster T, van Os J, Myin-Germeys I. Daily cortisol, stress reactivity and psychotic experiences in individuals at above average genetic risk for psychosis. Psychol Med. 2011;41(11):2305-15.

16. Wichers M, Schrijvers D, Geschwind N, Jacobs N, Myin-Germeys I, Thiery E, et al. Mechanisms of gene-environment interactions in depression: evidence that genes potentiate multiple sources of adversity. Psychol Med. 2009;39(07):1077-86.

17. Thewissen V, Bentall RP, Lecomte T, van Os J, Myin-Germeys I. Fluctuations in self-esteem and paranoia in the context of daily life. J Abnorm Psychol. 2008;117(1):143-53.

18. Geschwind N, Peeters F, Drukker M, van Os J, Wichers M. Mindfulness training increases momentary positive emotions and reward experience in adults vulnerable to depression: a randomized controlled trial. J Consult Clin Psychol. 2011;79(5):618-28.

19. Kramer I, Simons CJ, Hartmann JA, Menne-Lothmann C, Viechtbauer W, Peeters F, et al. A therapeutic application of the experience sampling method in the treatment of depression: a randomized controlled trial. World Psychiatry. 2014;13(1):68-77. 
20. Lataster J, Myin-Germeys I, Wichers M, Delespaul PAEG, van Os J, Bak M. Psychotic exacerbation and emotional dampening in the daily life of patients with schizophrenia switched to aripiprazole therapy: a collection of standardized case reports. Ther Adv Psychopharmacol. 2011;1(5):145-51.

21. Bak M, Delespaul P, Krabbendam L, Huistra K, Walraven W, Van Os J. Capturing coping with symptoms in people with a diagnosis of schizophrenia: introducing the MACS-24. Int J Methods Psychiatr Res. 2009;18(1):4-12.

22. Csikszentmihalyi M, Larson R. Validity and reliability of the Experience-Sampling Method. J Nerv Ment Dis. 1987;175(9):526-36.

23. Delespaul P. Assessing schizophrenia in daily life. The experience sampling method. Maastricht: Maastricht University Press; 1995.

24. Myin-Germeys I, Oorschot M, Collip D, Lataster J, Delespaul P, van Os J. Experience sampling research in psychopathology: opening the black box of daily life. Psychol Med. 2009;39(9):1533-47.

25. de Wild-Hartmann JA, Wichers M, van Bemmel AL, Derom C, Thiery E, Jacobs N, et al. Day-today associations between subjective sleep and affect in regard to future depression in a female population-based sample. Br J Psychiatry. 2013;202:407-12.

26. Wichers M. The dynamic nature of depression: a new micro-level perspective of mental disorder that meets current challenges. Psychol Med. 2014;44(07):1349-60.

27. Bylsma LM, Rottenberg J. Uncovering the dynamics of emotion regulation and dysfunction in daily life with ecological momentary assessment. Emotion regulation and well-being. New York: Springer; 2011. p. 225-44.

28. Jacobs N, Menne-Lothmann C, Derom C, Thiery E, van Os J, Wichers M. Deconstructing the familiality of variability in momentary negative and positive affect. Acta Psychiatr Scand. 2013;127(4):318-27.

29. Wichers M, Peeters F, Geschwind N, Jacobs N, Simons C, Derom C, et al. Unveiling patterns of affective responses in daily life may improve outcome prediction in depression: a momentary assessment study. J Affect Disord. 2010;124(1):191-5.

30. Totterdell P. Effects of depressed affect on diurnal and ultradian variations in mood in a healthy sample. Chronobiol Int. 1995;12(4):278-89.

31. Snijders T, Bosker R. Multilevel analysis: An introduction to basis and advanced multilevel modeling. London: SAGE publications Ltd; 1999.

32. StataCorp. Stata Statistical Software: Release 12. College Station, TX: StataCorp LP; 2012.

33. Germain A, Kupfer DJ. Circadian rhythm disturbances in depression. Hum Psycopharm Clin Ex. 2008;23(7):571-85.

34. Lewy AJ, Sack RL, Singer CM, White DM, Hoban TM. Winter depression and the phase-shift hypothesis for bright light's therapeutic effects: history, theory, and experimental evidence. J Biol Rhythms. 1988.

35. Koorengevel KM, Beersma DG, den Boer JA, van den Hoofdakker RH. A forced desynchrony study of circadian pacemaker characteristics in seasonal affective disorder. J Biol Rhythms. 2002;17(5):46375.

36. Souêtre E, Salvati E, Belugou J-L, Pringuey D, Candito M, Krebs B, et al. Circadian rhythms in depression and recovery: evidence for blunted amplitude as the main chronobiological abnormality. Psychiatry Res. 1989;28(3):263-78.

37. Treadway MT, Zald DH. Reconsidering anhedonia in depression: lessons from translational neuroscience. Neurosci Biobehav Rev. 2011;35(3):537-55.

38. Pelizza L, Ferrari A. Anhedonia in schizophrenia and major depression: state or trait. Ann Gen Psychiatry. 2009;8(1):22. 
39. McCabe C, Mishor Z, Cowen PJ, Harmer CJ. Diminished neural processing of aversive and rewarding stimuli during selective serotonin reuptake inhibitor treatment. Biol Psychiatry. 2010;67(5):43945.

40. Wulff K, Dijk D-J, Middleton B, Foster RG, Joyce EM. Sleep and circadian rhythm disruption in schizophrenia. Br J Psychiatry. 2012;200(4):308-16.

41. Wirz-Justice A, Benedetti F, Berger M, Lam RW, Martiny K, Terman M, et al. Chronotherapeutics (light and wake therapy) in affective disorders. Psychol Med. 2005;35(07):939-44.

42. Boivin DB, Czeisler CA, Dijk DJ, Duffy JF, Folkard S, Minors DS, et al. Complex interaction of the sleep-wake cycle and circadian phase modulates mood in healthy subjects. Arch Gen Psychiatry. 1997;54(2):145-52. 

PART II

Experience Sampling Method as therapeutic tool 


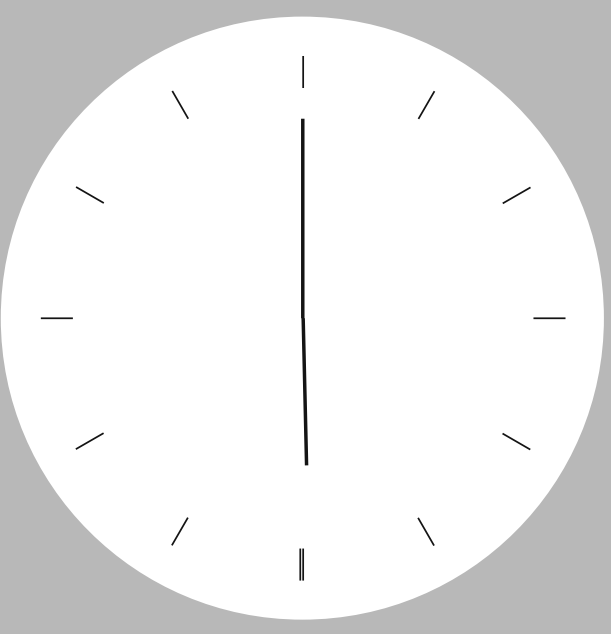

Chapter 6 


\title{
Translating assessments of the film of daily life into person-tailored feedback interventions in depression
}

\author{
Wichers, $M$, \\ Hartmann, JA, \\ Kramer, IMA, \\ Lothmann, C, \\ Peeters, F, \\ Van Bemmel, L, \\ Myin-Germeys, I, \\ Delespaul, Ph, \\ Van Os, J, \\ Simons, CJP
}



In a clinical overview - recently published in the Acta Psychiatrica Scandinavica Palmier-Claus et al.[1] advocate the use of ESM (experience sampling) in clinical practice. ESM has the power to uncover subtle and fine-grained patterns of affect and behaviour in the flow of daily life with relevance to relapse and recovery in depression $[2,3]$. Despite the recent rise in new mobile health interventions [4, 5], no study has yet tried to translate the film of daily life - as acquired with ESM - into person-tailored feedback on relevant patterns of emotions and behaviour in depression.

We report on a first, ongoing study in which depressed patients collect ESM data over a 6-week period and receive weekly verbal and graphical feedback on daily life contexts (social context, current activities, physical activity etc.) in relation to their momentary emotional responses. Also, they receive feedback on changes in relevant emotional and behavioural patterns over time (Figure 1). The aim is to give patients

A

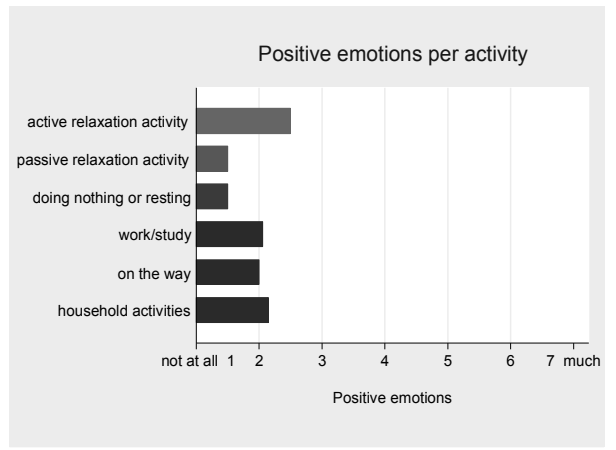

B

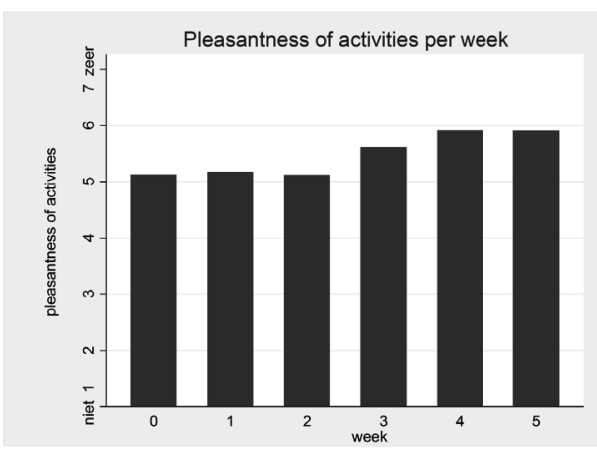

C

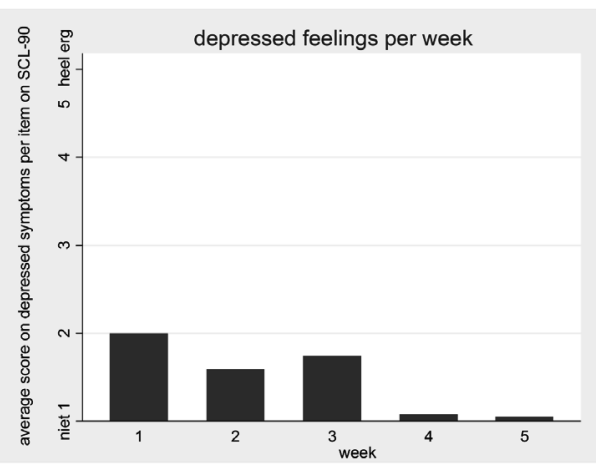

Figure 1 (a-c) | Data of a patient in the PsyMate intervention study. (a) Positive emotions experienced per type of activity in the beginning of the 6-week intervention period. (b) Appraised pleasantness of activities over the weeks of the intervention. (c) Average score on SCL-90 depression items over the weeks of the intervention (written permission of the patient was obtained to publish the data) 
more insight into functional and dysfunctional behaviours in daily life. For example, they could learn in which contexts they will experience most positive emotions. This may help patients to translate the black box of their depressive experience into manageable pieces of daily life behaviour that they can influence. In this study, patients are randomized into an experimental group, a pseudo-experimental group (ESM data collection, but no feedback) and a control group.

Applying ESM in clinical practice, although theoretically attractive, may have practical limitations. Continuous mood tracking is likely intensive, especially for depressed patients, who are characterized by low levels of motivation and energy. Therefore, the tolerability and desirability from the perspective of patients need to be examined. We present preliminary results of participants in the above-described study on the use of an ESM electronic monitoring device (the PsyMate) and the ESM-generated feedback (Table 1).

The sample consisted of 22 participants (12 male, 55\%), of whom one was excluded from further analysis. Severity of depression as assessed by the Hamilton Depression Rating Scale (HDRS) during the initial screening ranged from 8 to $26(\mathrm{M}=15.8, \mathrm{SD}=$ 4.3), indicating mild-to-moderate major depression.

Results showed that participants were not troubled (scale: 1-7) by the length of the questionnaire at each beep $(M=2.1)$ or by the sound the PsyMate produced when it beeped $(\mathrm{M}=2.4)$. The number of beeps per day was experienced as somewhat distressing $(M=3.4)$ and to some extent questions appeared difficult or not always very clear $(M=3.1)$. Participants rated the comprehensibility of the verbal, graphical and written feedback as good ( $M=5.6 ; M=6.0 ; M=5.6$ respectively). Subjects appreciation of having feedback in graphical form ranged from 5 (considerable) to 7 (very high) with a mean of 6.4. Additionally, participants responded that they had tried to implement the suggestions from the feedback into their daily lives $(M=5.8)$. Sixty per cent ( 3 of 5 ) responded that they would have liked to continue with the PsyMate. One subject reported having preferred other feed-back than the feedback given in the current intervention.

Thus, although some aspects of PsyMate's use are relatively demanding, most patients in the feedback condition indicated that they wished to continue using it. These preliminary results are promising for the future use of ESM in interventions. However, the current sample size is very small. The final results of this study and those of other future studies need to be awaited to assess how patients experience PsyMate interventions and whether the intervention, in combination with antidepressant medication or as an adjunct to psychotherapy, may improve treatment effectiveness. 
Table 1 | Descriptive statistics of the debriefing questionnaires

\begin{tabular}{|c|c|c|c|c|}
\hline & & $\begin{array}{l}\text { Means (min- max) } \\
\quad(\text { Scale 1-7) }\end{array}$ & $S D$ & $N$ (subjects) \\
\hline & Use of the PsyMate questionnaire & & & All groups \\
\hline \multirow[t]{3}{*}{ Use of PsyMate } & Was the text on screen well readable? & $6.1(4-7)$ & 1.1 & 21 \\
\hline & Was the PsyMate difficult to control? & $1.4(1-5)$ & 1.0 & 21 \\
\hline & $\begin{array}{l}\text { Questions in the PsyMate difficult or not } \\
\text { clear? }\end{array}$ & $3.1(1-6)$ & 1.7 & 21 \\
\hline \multirow[t]{4}{*}{$\begin{array}{l}\text { Acceptance } \\
\text { of PsyMate }\end{array}$} & $\begin{array}{l}\text { The use of the PsyMate was distressing with } \\
\text { respect to the total number of beeps per day }\end{array}$ & $3.4(1-6)$ & 1.6 & 21 \\
\hline & $\begin{array}{l}\text { The use of the PsyMate was distressing } \\
\text { with respect to the length of one beep } \\
\text { questionnaire }\end{array}$ & $2.1(1-5)$ & 1.3 & 21 \\
\hline & $\begin{array}{l}\text { The use of the PsyMate was intrusive with } \\
\text { respect to the sound of the beep }\end{array}$ & $2.4(1-7)$ & 2.0 & 21 \\
\hline & Feedback debriefing questionnaire & & & $\begin{array}{l}\text { Feedback } \\
\text { Condition }\end{array}$ \\
\hline \multirow{9}{*}{$\begin{array}{l}\text { Feedback } \\
\text { experience }\end{array}$} & The feedback was easy to understand & $5.6(4-6)$ & 0.9 & $5^{*}$ \\
\hline & $\begin{array}{l}\text { Did you want to get more specific advice } \\
\text { based on the feedback? }\end{array}$ & $3.4(1-5)$ & 1.5 & 5 \\
\hline & $\begin{array}{l}\text { It was pleasant to receive a summary of the } \\
\text { feedback }\end{array}$ & $6(5-7)$ & 0.7 & 5 \\
\hline & $\begin{array}{l}\text { The summary of the feedback was easy to } \\
\text { understand }\end{array}$ & $5.6(4-6)$ & 0.9 & 5 \\
\hline & $\begin{array}{l}\text { It was pleasant to receive feedback by } \\
\text { means of graphs }\end{array}$ & $6.4(6-7)$ & 0.5 & 5 \\
\hline & $\begin{array}{l}\text { The information in the graphs was easy to } \\
\text { understand }\end{array}$ & $6.0(6-6)$ & 0 & 5 \\
\hline & $\begin{array}{l}\text { I have tried to implement the suggestions } \\
\text { derived from the graphs in my daily life }\end{array}$ & $5.2(4-6)$ & 0.8 & 5 \\
\hline & $\begin{array}{l}\text { The amount of information of which I } \\
\text { received feedback was just fine }\end{array}$ & $5.2(4-6)$ & 0.8 & 5 \\
\hline & $\begin{array}{l}\text { The duration of the contact of the feedback } \\
\text { sessions was just fine }\end{array}$ & $5.8(5-6)$ & 0.4 & 5 \\
\hline
\end{tabular}

* Five patients randomized into the experimental condition had finished the six-week intervention period 


\section{References}

1. Palmier-Claus JE, Myin-Germeys I, Barkus E, Bentley L, Udachina A, Delespaul P, et al. Experience sampling research in individuals with mental illness: reflections and guidance. Acta Psychiatr Scand. 2011;123(1):12-20.

2. Wichers M, Barge-Schaapveld D, Nicolson N, Peeters F, De Vries M, Mengelers R, et al. Reduced stress-sensitivity or increased reward experience: the psychological mechanism of response to antidepressant medication. Neuropsychopharmacology. 2008;34(4):923-31.

3. Wichers M, Peeters F, Geschwind N, Jacobs N, Simons C, Derom C, et al. Unveiling patterns of affective responses in daily life may improve outcome prediction in depression: a momentary assessment study. J Affect Disord. 2010;124(1):191-5.

4. Depp CA, Mausbach B, Granholm E, Cardenas V, Ben-Zeev D, Patterson TL, et al. Mobile interventions for severe mental illness: design and preliminary data from three approaches. J Nerv Ment Dis. 2010;198(10):715.

5. Heron KE, Smyth JM. Ecological momentary interventions: incorporating mobile technology into psychosocial and health behaviour treatments. Br J Health Psychol. 2010;15(1):1-39. 



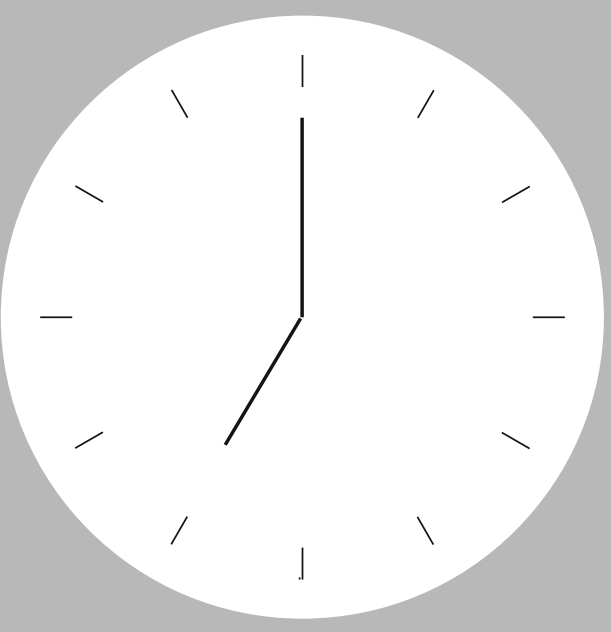

Chapter 7 


\title{
Personalized feedback on positive affect in daily life: a randomized controlled trial using the experience sampling method as intervention in depression
}

\author{
Hartmann, JA, \\ Wichers, $\mathrm{M}$, \\ Menne-Lothmann, C, \\ Kramer, IMA, \\ Viechtbauer, W, \\ Peeters, F, \\ Schruers, KRJ, \\ Van Bemmel, AL, \\ Myin-Germeys, I, \\ Delespaul, $\mathrm{Ph}$, \\ Van Os, J, \\ Simons, CJP
}




\section{Abstract}

Objectives: Positive affect (PA) plays a crucial role in the development, course, and recovery of depression. Recently, we showed that a therapeutic application of the experience sampling method (ESM), consisting of feedback focusing on PA in daily life, was associated with a decrease in depressive symptoms. The present study investigated whether the experience of PA increased during the course of this intervention.

Design: Multicentre parallel randomized controlled trial. An electronic random sequence generator was used to allocate treatments.

Settings: University, two local mental health care institutions, one local hospital

Participants: 102 pharmacologically treated outpatients with a DSM-IV diagnosis of major depressive disorder, randomized over three treatment arms.

Intervention: Six weeks of ESM self-monitoring combined with weekly PA-focused feedback sessions (experimental group); six weeks of ESM self-monitoring combined with six weekly sessions without feedback (pseudo-experimental group); or treatment as usual (control group).

Main outcome: The interaction between treatment allocation and time in predicting positive and negative affect (NA) was investigated in multilevel regression models.

Results: 102 patients were randomized (mean age 48.0, SD 10.2) of which 81 finished the entire study protocol. All 102 patients were included in the analyses. The experimental group did not show a significant larger increase in momentary PA during or shortly after the intervention compared to the pseudo-experimental or control groups $\left(\chi^{2}(2)=0.33, p=.846\right)$. The pseudo-experimental group showed a larger decrease in NA compared to the control group $\left(\chi^{2}(1)=6.29, p=.012\right)$.

Conclusion: PA-focused feedback did not significantly impact daily life PA during or shortly after the intervention. As the previously reported reduction in depressive symptoms associated with the feedback unveiled itself only after weeks, it is conceivable that the effects on daily life PA also evolve slowly and therefore were not captured by the experience sampling procedure immediately after treatment.

Trial registration: Trialregister.nl/trialreg/index.asp. Identifier: NTR1974 


\section{Introduction}

Research on the factor structure of human emotional responses has identified two different, yet related, affective dimensions: Positive (PA) and negative affect (NA). The rewardoriented PA dimension, reflecting affective states such as enthusiasm, cheerfulness, and contentment, is associated with behavioural approach or engagement with the environment; the threat-oriented NA dimension, reflecting affective states such as anxiety, loneliness, and guilt, is associated with behavioural avoidance or withdrawal $[1,2]$.

In depression, both negative and positive affective experience may be altered [1, 3 , 4]. Converging evidence suggests that particularly a deficiency in PA (linked to the concept of anhedonia) represent a core mechanism underlying depression [5]. Likewise, recent studies show that a high ability to experience PA, rather than NA, is predictive for the development, course, and recovery of depression [6-10]. This finding provides potential routes to novel treatments in depression, i.e., interventions aimed at increasing positive affective experience in daily life [11].

\section{Experience Sampling Methodology as Intervention}

The Experience Sampling Method (ESM) is a structured diary technique requiring individuals to repeatedly report their affective states and behaviour together with contextual information in the flow of daily life [12-14]. ESM has until recently been mainly used to assess subjects for research purposes. However, the replacement of paper-and-pencil based diaries by electronic sampling devices introduces the possibility of rapid analysis and availability of real life experiential data [15]. Electronically collected data thus can be used not only to monitor, but also to give feedback to the patient and professional caregiver with minimal delay, providing fine-grained, prospective information on affective patterns, behaviour and contextual influences in daily life $[16,17]$. Using ESM not merely as an instrument to monitor, but as a tool to intervene (referred to as ESM-I), may be promising for the development of new mHealth ('mobile health') therapies in depression [16-18].

\section{The present study}

The current randomized controlled trial (RCT) in a sample of depressed patients was designed to evaluate an intervention aimed at reducing depressive symptoms by enhancing PA in daily life using ESM-I. During the six-week intervention, selfcollected ESM data on momentary affective and behavioural responses was fed-back to the patient on a weekly basis. Given the potentially pivotal role of PA in the recovery of depression, the feedback focused on positive affective experience in daily life. The experimental feedback condition was compared to two other conditions: a 
pseudo-experimental condition in which the weekly feedback sessions were replaced by weekly meetings with the researcher without feedback, and a control condition without any meetings with the researcher during the intervention period.

Recently, we reported the results of this RCT with respect to its effectiveness in reducing depressive symptomatology [19]. It was demonstrated that the ESM-derived, PA-focused feedback was associated with a linear decrease in depressive symptoms in the six months following the intervention, a pattern not observed in the other two conditions [19]. As such, the intervention appeared to be effective in reducing depressive symptoms in the long run. However, the question remains as to whether the intervention, aimed at increasing PA in daily life, was indeed associated with a boost of momentary positive affective experience. The purpose of the present study is to shed light on the potential micro-mechanism by which PA-focused ESM-I may lead to a decrease in depressive symptoms. It was hypothesized that the experimental feedback condition, compared to the pseudo-experimental and control condition, would be associated with an increase in PA during and shortly after the intervention.

\section{Methods}

\section{Ethics statement}

The study was approved by the local ethics committee (Medical Ethics Committee of Maastricht University Medical Centre, azM/UM, \#NL26181.068.09/MEC09-03-013) and all participants provided written informed consent before their enrolment. The trial was registered at the Netherlands Trial Register (Identifier: NTR1974). The study was performed according to the declaration of Helsinki. The original protocols and a CONSORT checklist are provided (see Protocol S1, Checklist S1).

\section{Study Overview}

The multicentre trial was conducted between January 2010 and October 2012 in the following settings: Maastricht University, two local mental health care institutions, and a local hospital. Participant recruitment took place between January 2010 and February 2012 in mental health care institutions and through local advertisements.

Participants were considered eligible when they were between 18 and 65 years of age; diagnosed with a depressive episode according to DSM-IV [20] with current or residual symptoms (17-item Hamilton Depression Rating Scale (HDRS) score of $>7$ ); treated with antidepressants or mood stabilizers; and in possession of sufficient Dutch language skills. Participants were excluded if they met criteria for a non-affective psychotic disorder according to DSM-IV or if they reported a (hypo-) manic or mixed episode within the past month. 


\section{Procedure}

The recruitment process started with a short telephone interview conducted by a psychologist or psychiatrist to establish whether inclusion criteria were likely met. If so, potential participants were invited to a full screening on site. During the screening, the Structured Clinical Interview for DSM-IV Axis I Disorders (SCID-I) [20] and the HDRS [21] were administered. If admitted to the study, the participants underwent a fiveday ESM baseline assessment followed by randomization to either the experimental group, pseudo-experimental group or control group. Randomization with allocation ratio 1:1:1 was stratified with respect to duration of pharmacological treatment (use of a particular antidepressant for shorter vs. longer than 8 weeks prior to study entry) and the attendance of psychotherapy (yes/no). Allocation took place by drawing a sealed envelope (prepared by an independent research coordinator) with a number sequence produced by an electronic random sequence generator (www.random.org) in blocks of six. Due to the nature of the psychological treatment allocation was not blinded.

Participants allocated to the experimental group underwent a six-week ESM protocol consisting of a three- day ESM assessment period per week and, in addition to their treatment as usual (TAU), six weekly ESM-based feedback sessions (ESM-I). Participants allocated to the pseudo-experimental group followed the same protocol, but instead of receiving ESM-based feedback, this group engaged in a structured conversation with the researcher in the form of an HDRS interview during the weekly sessions. During the six-week ESM protocol of the experimental and pseudo-experimental groups, participants allocated to the control group received TAU only. Finally, all participants underwent a five-day ESM period after the six week intervention period (hereafter: post-assessment).

In summary, all three groups underwent a five-day ESM pre- and post-assessment. During the six week intervention period, the experimental and pseudo-experimental groups engaged in three days of ESM per week, combined with weekly feedback sessions (experimental group) or weekly structured conversations without feedback (pseudo-experimental group).

\section{Experience Sampling Method}

ESM is a validated, structured diary technique to assess participants in their daily living environment. It is a momentary assessment method providing repeated in-themoment micro-measurements of affect and context in a prospective and ecologically valid manner [12, 13, 22].

Participants received a dedicated mHealth electronic ESM device ('PsyMate'), emitting a signal ('beep') at a random moment in each of ten 90-minute time blocks 
between 07:30 am and 10:30 pm. The signal prompted participants to fill in selfassessments (7-point Likert scale ratings and forced-choice questions) automatically shown on the device display. To minimize memory distortion, participants were instructed to complete their reports immediately upon the signal; after 10 minutes, the self-assessments were no longer available for completion. The ESM procedure was explained in an initial briefing session and a practice run was performed to ensure that the participants understood the questions and the device.

\section{Intervention}

The experimental group received standardized ESM-derived feedback. Feedback sessions immediately followed the weekly ESM procedure. In these face-to-face sessions, feedback was provided by a psychologist or psychiatrist. The feedback on participants' momentary affective states in specific daily life contexts and the association with depressive symptoms was given graphically, presented by the researcher according to a standardized verbal protocol. A written summary based on a standardized template was provided to the participant as well as the attending clinician.

\section{Feedback structure}

Every feedback session consisted of two parts. In the first part, information with respect to experiences during the most recent week was presented. In the second part, this information was placed in the context of all previous weeks.

\section{Feedback content}

The feedback sessions consisted of information that was repeated each week, as well as variable feedback elements. Each week, information regarding the degree and distribution of PA experienced during the past week was presented, as well as graphs displaying the course of experienced PA across the weeks. Furthermore, the course of depressive feelings over the weeks was presented in each session and compared to the course of PA. The variable elements in the feedback procedure were divided over three modules. The first two weeks focused on daily activities and PA experienced during particular activities. The third and fourth week focused on daily events and PA associated with these events. The last two weeks focused on social interaction and associated PA. Variable elements were presented as described above for the fixed feedback information, zooming in on the most recent week followed by longitudinal information over the weeks. 


\section{Outcome Measures}

Primary outcome measures were PA and NA, derived as follows. During the ESM assessments as described above, participants rated their momentary mental states by rating adjectives on a 7-point Likert scale, ranging from 1 (not) to 7 (very). Withinperson factor analysis (principal component factors with oblique rotation) performed on these items that were centred per person and ESM-week, identified two factors with an eigenvalue $>1$, accounting for $46 \%$ of the variance: positive affect and negative affect. Positive affect comprised the average of ratings on 'cheerful', 'enthusiastic', 'relaxed' and 'satisfied' (with factor loadings >.6); negative affect comprised the average of ratings on 'lonely', 'anxious', 'guilty', and 'suspicious' (with factor loadings >.5).

\section{Statistical Analyses}

The data set had a hierarchical structure, due to within-person clustering: repeated measurements (level 1), nested within individuals (level 2). Observations within one participant are more similar than those across participants. As nesting of data typically violates the assumption of independent residuals, multilevel regression analysis was used that takes clustering into account [23]. All analyses were performed using STATA 12 [24].

In order to examine the effect of the feedback intervention on PA and NA, two sets of analyses were conducted. In the first set, the effects of the feedback intervention on change in PA and NA from pre- to post-assessment, relative to the two control groups, was examined. To this end, linear multilevel regression analyses (STATA command XTMIXED) were conducted to inspect the categorical by categorical interaction between treatment allocation (experimental vs. pseudo-experimental vs. control group) and time (pre- vs. post-assessment) as fixed effects. The multilevel models for PA and NA, fitted via restricted maximum likelihood, included a random intercept for participant and a random slope for time. The post-estimation commands MARGINS and TEST (providing Wald tests) were used to calculate and compare the effect of time on affect in the different groups.

In the second set of analyses, the effect of the feedback intervention on affect during the intervention period, relative to the pseudo-experimental group, was examined. Using multilevel regression analyses (STATA command XTMIXED) fitted via restricted maximum likelihood, the categorical by categorical interaction between treatment allocation (experimental vs. pseudo-experimental) and time (in weeks since start of the intervention) as fixed effects was examined; the model included a random intercept for participant and a random slope for time (intervention week 1-6). 


\section{Results}

\section{Participants}

A total of 309 patients underwent an initial screening by telephone, of which 102 were allocated at random to the experimental, pseudo-experimental or control groups (see Figure 1 for the participant flow through the study). At screening, the groups showed some differences in clinical features: Compared to the pseudo-experimental and control group, patients in the experimental group more often used lithium and displayed lower HDRS scores (Table 1); these differences were no longer significant at baseline (two weeks later, i.e., just before the start of the intervention, see also [19]). There were no large or significant differences in sociodemographic variables between the groups at baseline (Table 1).

Of the 102 randomized patients, 81 finished the ESM protocol (i.e., completed the ESM post-assessment). Treatment assignment was not associated with probability of finishing the ESM study protocol $\left(\chi^{2}(2)=1.49, p=.47\right)$ and number of attended intervention sessions did not differ between the experimental and pseudo-experimental groups $(\mathrm{F}(1,68)=1.66, \mathrm{p}=.20)$.

Previous work has shown that ESM assessments with less than $30 \%$ of filled out beeps are less reliable and consequently not valid [13]. Therefore, ESM periods (one period corresponding to one ESM 'week' in the protocol) with less than $30 \%$ of beeps completed were excluded from the analyses, leading to the exclusion of one baseline ESM period, four post ESM periods, and two periods during the intervention period (Figure 1).

\section{ESM Measures}

Participants completed 16,678 device entries in total. Of these, 83 observations $(<1 \%)$ were excluded as invalid because less than $30 \%$ of beeps for that ESM period were filled in. On average, participants responded to 39.7 (out of maximal 50) beeps during the 5-day ESM periods (pre-and post- assessment) and to 23.7 (out of maximal 30 ) during the 3-day periods (intervention). Figure 2 shows the individual PA series across the study protocol for one participant of each condition.

\section{Effects of the intervention on positive and negative affect from pre- to post-assessment}

\section{Positive affect}

(See Table 1 for the means for PA at baseline and after the intervention). As the raw data indicate, the experimental group increased on average .3 points on PA, the pseudo-experimental group increased by .1 points, and the control group by .2 points. Al- 


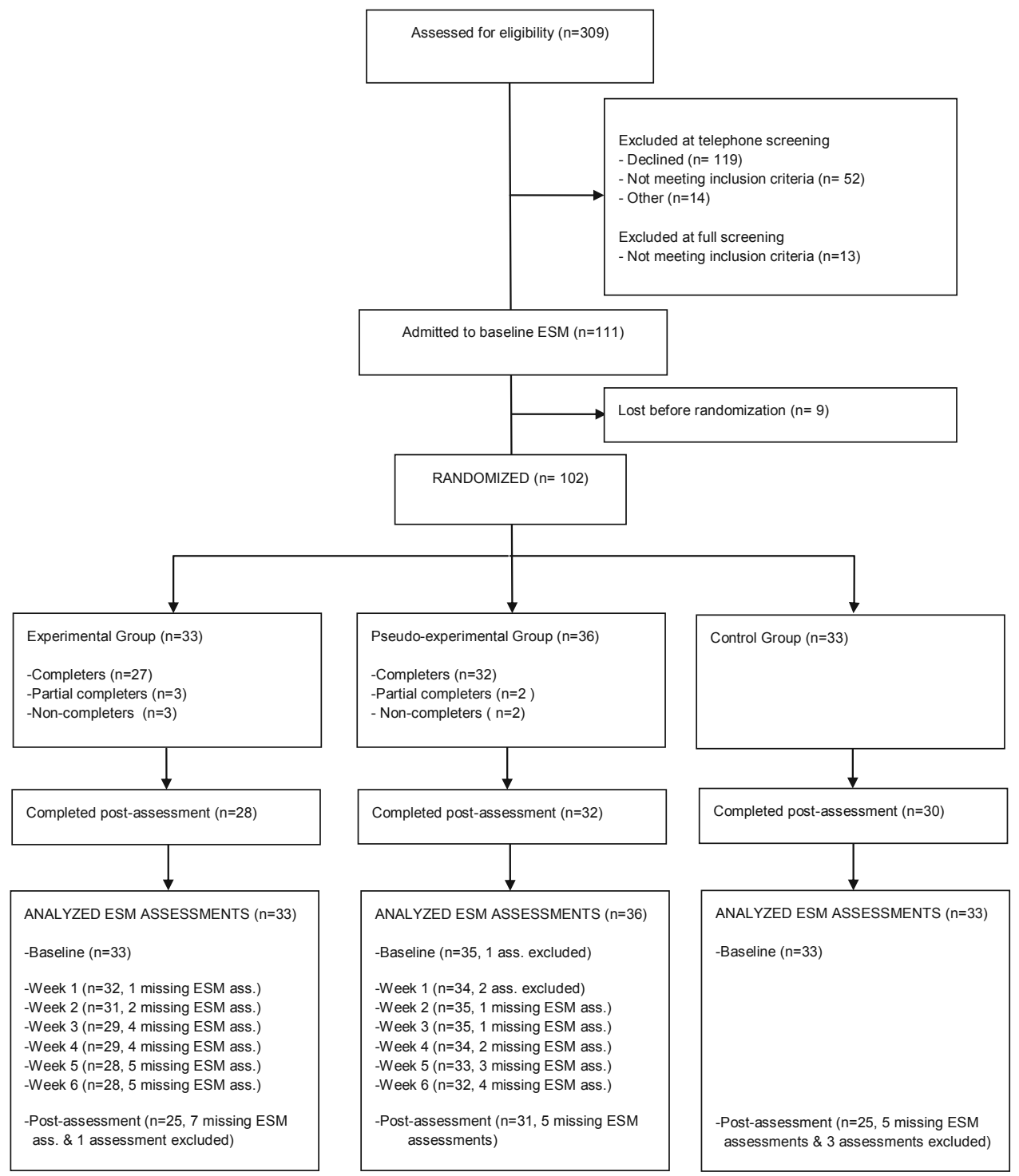

Figure 1 | Participant flow diagram. Completer: Participant who attended all six intervention sessions; Partial Completer: Participant who attended less than six intervention sessions but did not withdrew from the study; non-completer: Participant who attended less than six intervention sessions and withdrew from the study.ESM= Experience Sampling Method 
though the experimental group showed the largest increase in PA at mean level, there was no significant interaction between group (experimental, pseudo-experimental, control group) and time (pre- vs. post-assessment) $\left(\chi^{2}(2)=0.33, p=.846\right)$.

\section{Negative affect}

(See Table 1 for the means for NA at baseline and after the intervention). In contrast to $\mathrm{PA}$, there was a significant interaction between group (experimental, pseudo-experimental and control group) and time (pre- vs. post-assessment) $\left(\chi^{2}(2)=6.29, p=.043\right)$.

Table 1 | Sample characteristics

\begin{tabular}{|c|c|c|c|c|}
\hline & Experimental Group & $\begin{array}{l}\text { Pseudo-experimental } \\
\text { Group }\end{array}$ & Control Group & Total \\
\hline $\mathrm{N}$ & 33 & 36 & 33 & 102 \\
\hline Age (SD) & $48.7(10.2)$ & $46.7(9.6)$ & $48.9(10.9)$ & $48.0(10.2)$ \\
\hline $\operatorname{Sex}(M / F)$ & $17 / 16$ & $14 / 22$ & $15 / 18$ & $46 / 56$ \\
\hline \multicolumn{5}{|l|}{ Education } \\
\hline - $\quad$ Low $(\%)$ & $6(18.2)$ & $9(25.0)$ & $10(30.3)$ & $25(24.5)$ \\
\hline - $\quad$ Middle (\%) & $12(36.4)$ & $14(38.9)$ & $12(36.4)$ & $38(37.3)$ \\
\hline - $\quad$ High (\%) & $15(45.5)$ & $13(36.1)$ & $11(33.3)$ & $39(38.2)$ \\
\hline Full/ part time work (\%) & $13(39.4)$ & $10(27.8)$ & $12(36.4)$ & $35(34.3)$ \\
\hline Married (\%) & $12(36.4)$ & $16(44.4)$ & $17(51.5)$ & $45(44.1)$ \\
\hline PA pre-assessment (SD) & $3.4(1.3)$ & $3.3(1.3)$ & $3.2(1.0)$ & $3.3(1.2)$ \\
\hline PA post-assessment & $3.7(1.3)$ & $3.4(1.4)$ & $3.4(1.8)$ & $3.5(1.3)$ \\
\hline NA pre-assessment (SD) & $2.2(1.1)$ & $2.2(1.2)$ & $2.3(1.2)$ & $2.3(1.2)$ \\
\hline NA post-assessment & $2.1(1.4)$ & $2.0(1.2)$ & $2.3(1.3)$ & $2.2(1.3)$ \\
\hline Current psychotherapy & $4(14.8)$ & $4(13.3)$ & $2(7.4)$ & $10(11.76)$ \\
\hline \multicolumn{5}{|l|}{ Use of antidepressants ${ }^{a}$} \\
\hline - $\quad$ Maintenance (\%) & $28(84.9)$ & $30(83.3)$ & $25(75.8)$ & $83(81.4)$ \\
\hline - $\quad$ Acute phase (\%) & $5(15.2)$ & $6(16.7)$ & $8(24.2)$ & $19(18.6)$ \\
\hline HDRS Mean (SD) ${ }^{\mathrm{b}}$ & $14.1(4.5)$ & $16.2(4.8)$ & $17.0(4.3)$ & $15.8(4.6)$ \\
\hline \multicolumn{5}{|l|}{ Depressive episode $^{c}$} \\
\hline - $\quad$ Current (\%) & $19(57.6)$ & $24(66.7)$ & $25(75.8)$ & $68(66.7)$ \\
\hline - $\quad$ In past (\%) & $14(42.4)$ & $12(33.3)$ & $8(24.2)$ & $34(33.3)$ \\
\hline Bipolar disorder & $5(15.2)$ & $2(5.6)$ & $2(6.1)$ & $9(8.8)$ \\
\hline Use of lithium $(\%)^{\mathrm{d}}$ & $7(21.2)$ & $1(2.8)$ & $3(9.1)$ & $11(10.8)$ \\
\hline
\end{tabular}

${ }^{\text {a }}$ Maintenance=use of the antidepressant for $\geq 8$ weeks; new= use of antidepressant $<8$ weeks

${ }^{\mathrm{b}}$ HDRS (Hamilton Depression Rating Scale) score significantly different between groups at screening $(\mathrm{F}=3.64$; $p=.03)$

${ }^{\mathrm{c}}$ According to SCID (Structured Clinical Interview for DSM-IV-TR Axis I disorders)

${ }^{d}$ Use of lithium at screening significantly different between the groups $\left(\chi^{2}=6.23\right.$, Fisher's exact $\left.p=.049\right)$ 

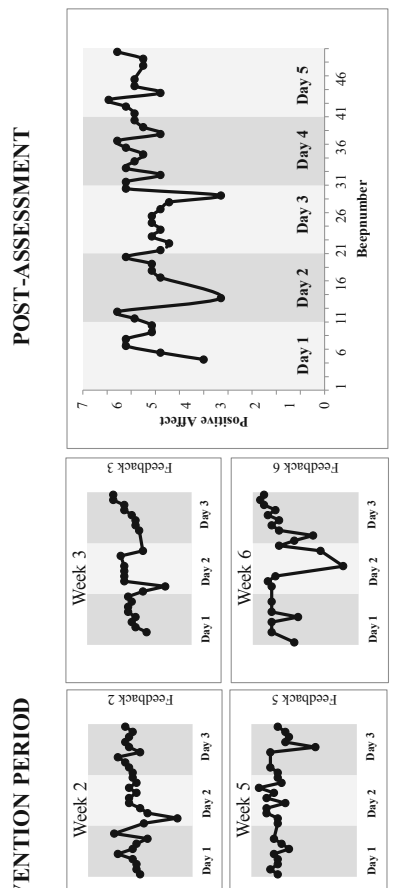

产
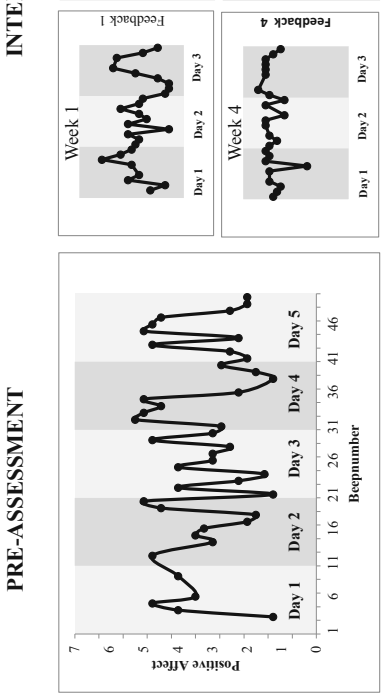

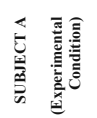
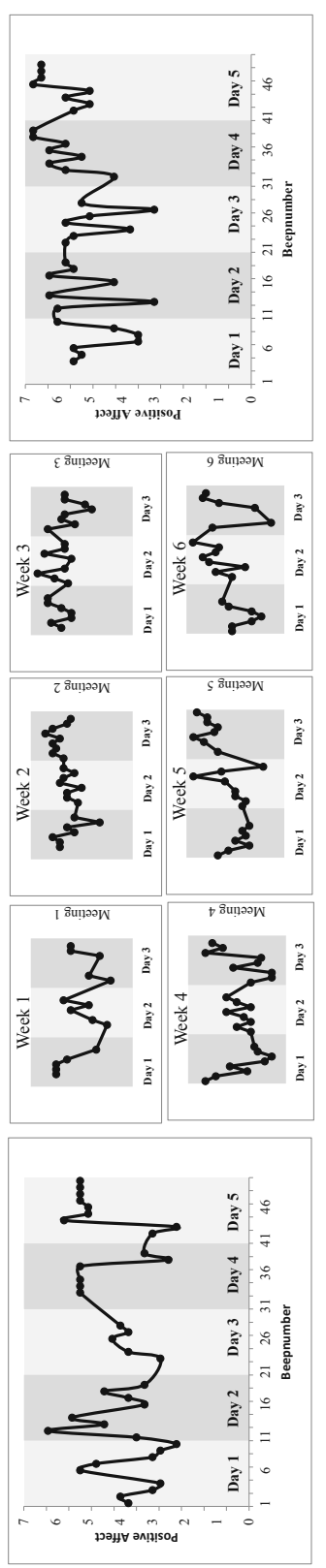

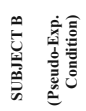

Чั.

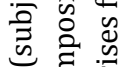
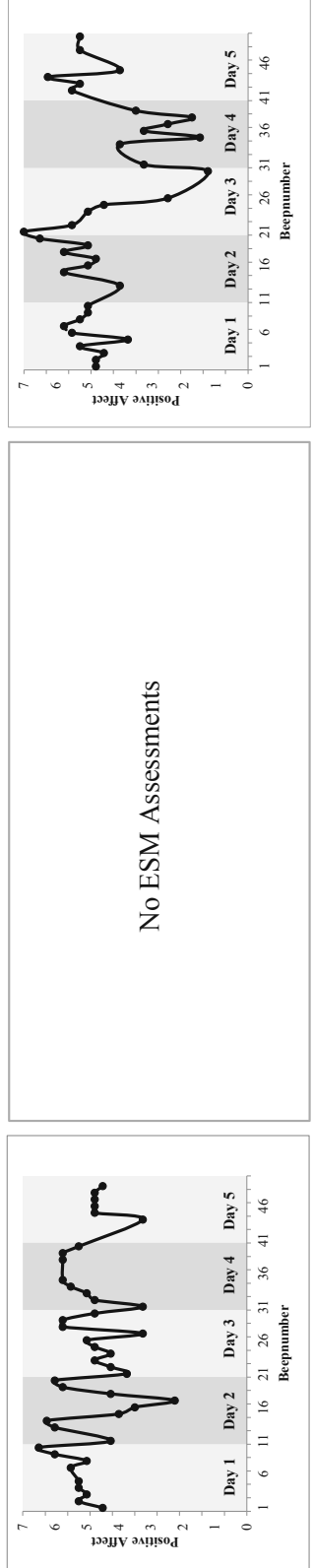

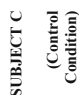

Chapter

F 웡

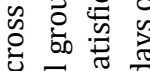

प्र

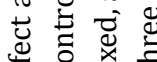

¿ँ

¿ ठ ए

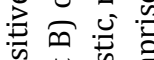

¿.

능

胥焉

覀要离

질

苛 吾

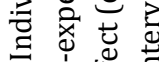

五递总

N $\overline{0}$ त

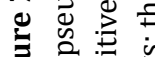

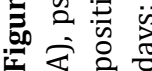


Adjusted predictions show that the control group was associated with an increase of NA from 2.28 to 2.47; the pseudo-experimental group was associated with a decrease of NA from 2.21 to 1.99; the experimental group was associated with a decrease of NA from 2.26 to 2.22 . The slopes between the pseudo-experimental group and control group differed significantly $\left(b=-0.40, \chi^{2}(1)=6.29, p=.012\right)$. There was no significant difference in slopes between participants in the pseudo-experimental group and the experimental group ( $\left.b=-0.22, \chi^{2}(1)=1.17, p=.279\right)$, or between participants in the experimental group and the control group $\left(b=-0.20, \chi^{2}(1)=1.85, p=.174\right)$.

A
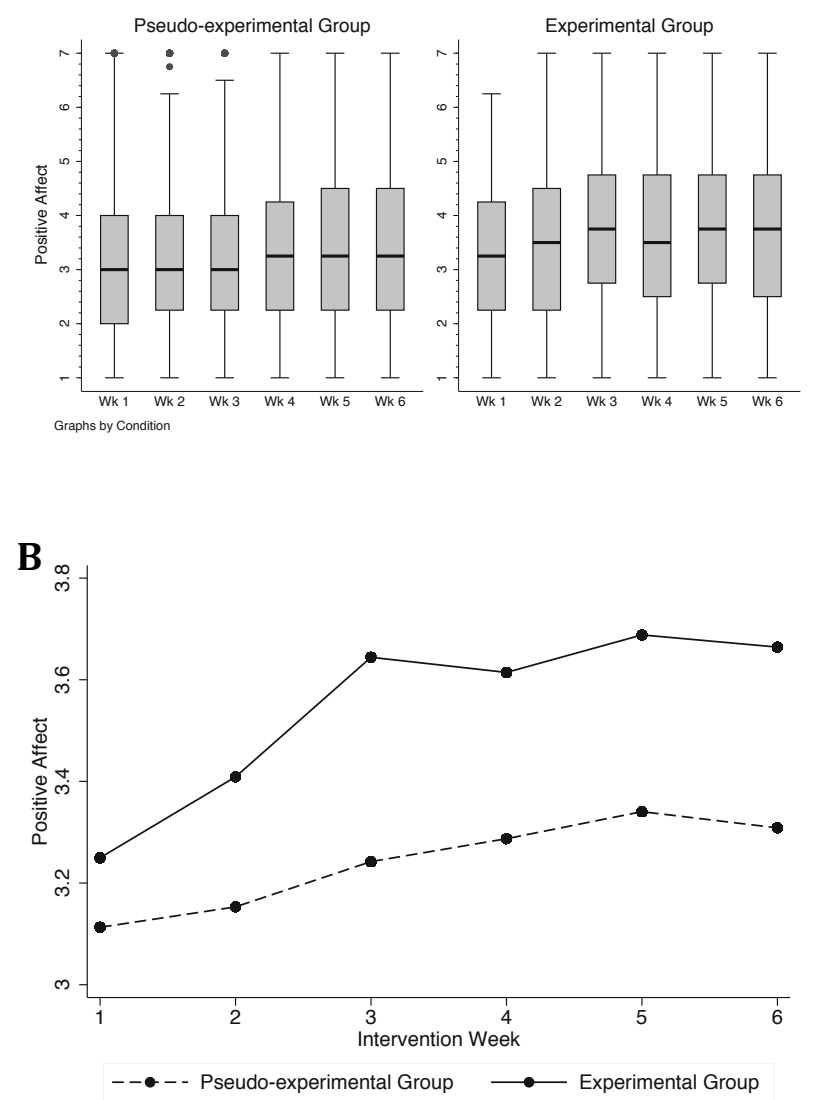

Figure 3 | A Box-Whisker plot of PA across the intervention period, by condition. The bottom and top of box indicate first (Q1) and third quartile (Q3), the band indicates the median; whiskers represent upper and lower adjacent values (within Q3+1.5(Q3-Q1) and Q1-1.5(Q3-Q1), respectively. B Means per week across intervention period, by condition 


\section{Effects of the intervention on positive and negative affect over the course of the intervention}

Figure 3 shows box-whisker diagrams and means for PA over the course of the intervention period for the experimental and pseudo-experimental group. Although a visual inspection of the medians and means suggests a slightly larger increase for PA in the experimental group than in the pseudo-experimental group, statistical modelling yielded no significant interaction between treatment allocation and intervention week ( 1 to 6$)\left(\chi^{2}(5)=0.24, p=.999\right)$ for positive affect. Likewise, there was no significant interaction between treatment allocation and intervention week (1-6) for negative affect $\left(\chi^{2}(5)=.50, p=.992\right)$.

\section{Discussion}

Building on evidence that PA may be a crucial system involved in phenotypic resilience in depression $[6,11]$ and capitalizing on recent technical developments making electronically collected ESM data readily available $[16,17]$, the present RCT focused on intervening at the level of positive affective experience in daily life by providing PAfocused feedback derived from self-collected ESM data (ESM-I). In an earlier analysis in the same sample, we showed that ESM-I was associated with a clinically relevant reduction of depressive symptoms commencing three weeks after the intervention [19]. In the present study, we zoomed in on the micro-level of every-day positive and negative affective experiences during the intervention, possibly shedding light on the mechanisms through which ESM-I may occasion a reduction in depressive symptomatology at the macro-level. That is, it was investigated if the PA-focused ESM-I was indeed associated with an increase in positive affective experience in daily life during and shortly after the intervention.

Although a first inspection of the raw data indicated the largest increase in PA from baseline to post-assessment for the experimental group compared to the pseudoexperimental and control groups, the analysis yielded no statistically significant differences in the change from pre- to post-test. Likewise, although a visual examination of the raw data during the intervention period suggested a larger increase in PA for the experimental group, the analysis yielded no statistically significant differences. What could account for these unexpected results? As visible from the boxplots for PA, there appeared to be a high degree of variance in this sample. It is conceivable that the signal could not be picked up against the amount of noise, and a larger sample would have been needed in order to detect the signal. Alternatively, the findings may relate to the period chosen during which ESM monitoring took place. Based on our previous 
report, the differences in depressive symptoms between the experimental group and control group became apparent three weeks after completion of the intervention and the differences grew stronger over time. However, ESM data on momentary PA was, due to patient burden, only available in the period during- and shortly (one week) after the intervention. It is possible that an increase in positive affective experience would only become visible after the measurement window of one week post-intervention. According to the broaden-and-build theory [25], experiencing PA may increase the focus of an individual, enabling him or her to pay more attention to rewarding events and to augment engagement in PA evoking activities, leading to the experience of even more positive affect. It may be that the development of such an emotional "upward spiral" may take some time to develop. The translation of receiving PA-focused feedback in the clinical setting to the actual exploration of PA-evoking activities in daily life, and eventually being able to activate the "upward spiral" of positive emotions, is probably a process of trial and error, which may take some time to evolve. It is possible that this process occurred after our ESM sampling window and therefore was not captured (see also the limitations section). Finally, an alternative possibility is that an increase in momentary PA is not the mechanism behind the observed reduction in depressive symptoms in the experimental group and that it is necessary to search for alternative mechanisms.

While the results indicated no significant change in NA levels in the experimental group during the intervention period, participants in the pseudo-experimental group showed a stronger decrease in NA from pre- to post-assessment compared to the control group. This is in line with our preceding paper, demonstrating that the pseudoexperimental group showed a reduction in depressive symptoms directly during the intervention period; however, this effect was not persistent as depressive symptoms in the pseudo-experimental group started to increase again during the follow-up period [19]. The decrease in NA may reflect a non-specific placebo response as patients may have thought that they were receiving the experimental intervention. Alternatively, the sessions with the researcher, during which the patient was able to talk about his or her depressive feelings during the previous week, may have resulted in the specific reduction of NA. Instead, it may be that merely the monitoring of affective responses, behaviour and context in daily life for the duration of six weeks may be associated with increased momentary emotional awareness, making ESM interesting for use in mindfulness-based therapies [26].

The generalizability of the trial results can be considered good as a very broad spectrum of depressed patients were included (i.e. patients deriving from both first-and second line treatment, patients suffering from current depressive episode or episode 
in the past with divergent symptom severity, patients with or without multiple comorbidities).

\section{Limitations}

The present RCT did not include a fourth treatment arm, that is, a pseudo-experimental group consisting of a six-week period of ESM self-monitoring only, without weekly contacts with the researcher. Therefore, it was not possible to separate the effect of self-monitoring from the effects of weekly contacts with the researcher. This treatment arm was not included since the primary goal of the present RCT was to investigate the effects of feedback based on ESM, and not the effects of ESM self-monitoring per se.

ESM was only performed over the course of the intervention and not during the 6-month follow-up periods. As such, data with respect to daily life momentary PA and NA were only available for the duration of the intervention period and the moments immediate before and after. In light of our previous results with regard to the effects of ESM-I on depressive symptoms, showing that the effect of ESM-I may take some weeks to evolve, it would have been instructive to also have ESM data available in the weeks after completion of the intervention. This would potentially have shed more light on the micro-mechanisms by which ESM-I did reduce depressive symptoms in the long term. It is a challenge for future ESM studies to identify the ideal time frames for ESM monitoring in order to fully investigate the mechanisms of interventions at the micro-level while minimizing patient burden.

\section{Acknowledgements}

M. W. was supported by the Netherlands Organization for Scientific Research (Aspasia Grant).The study was funded by the Dutch Health Research Council (ZON-MW grants nos. 171001002 and 91501003 ). The research leading to these results has received funding from the European Community's Seventh Framework Program under grant agreement no. HEALTH-F2-2009-241909 (Project EU-GEI). The authors thank all patients for participating and all collaborating mental health centers for their support in recruiting patients. They also thank W. Beuken and T. Driessen for administrative support, and P. Höhn, K. Akkermans, R. Diederen, K. Gielen, M. Hendriks and E. Pols for support in data acquisition.

\section{Declaration of interest}

The tool with which momentary assessments were performed (the PsyMate) is developed under the auspices of the Maastricht University technology transfer office, partially supported by unrestricted grants from Servier and Janssen-Cilag. 
J.v.O. is or has been an unrestricted research grant holder with, or has received financial compensation as an independent symposium speaker from, Eli Lilly, BMS, Lundbeck, Organon, Janssen-Cilag,GlaxoSmithKline, AstraZeneca, Pfizer, and Servier. 


\section{References}

1. Clark LA, Watson D, Mineka S. Temperament, personality, and the mood and anxiety disorders. J Abnorm Psychol. 1994;103(1):103-16.

2. Watson D, Wiese D, Vaidya J, Tellegen A. The two general activation systems of affect: Structural findings, evolutionary considerations, and psychobiological evidence. J Pers Soc Psychol. 1999;76(5):820.

3. Barge-Schaapveld DQ Nicolson NA, Berkhof J, deVries MW. Quality of life in depression: daily life determinants and variability. Psychiatry Res. 1999;88(3):173-89.

4. Myin-Germeys I, Peeters F, Havermans R, Nicolson NA, DeVries MW, Delespaul P, et al. Emotional reactivity to daily life stress in psychosis and affective disorder: an experience sampling study. Acta Psychiatr Scand. 2003;107(2):124-31.

5. Dunn BD. Helping depressed clients reconnect to positive emotion experience: current insights and future directions. Clin Psychol Psychother. 2012;19(4):326-40.

6. Geschwind N, Nicolson NA, Peeters F, van Os J, Barge-Schaapveld D, Wichers M. Early improvement in positive rather than negative emotion predicts remission from depression after pharmacotherapy. Eur Neuropsychopharmacol. 2011;21(3):241-7.

7. Wichers MC, Myin-Germeys I, Jacobs N, Peeters F, Kenis G, Derom C, et al. Evidence that moment-tomoment variation in positive emotions buffer genetic risk for depression: a momentary assessment twin study. Acta Psychiatr Scand. 2007;115(6):451-7.

8. Wichers MC, Barge-Schaapveld DQ, Nicolson NA, Peeters F, de Vries M, Mengelers R, et al. Reduced stress-sensitivity or increased reward experience: the psychological mechanism of response to antidepressant medication. Neuropsychopharmacology. 2009;34(4):923-31.

9. Wichers M, Kenis G, Jacobs N, Myin-Germeys I, Schruers K, Mengelers R, et al. The psychology of psychiatric genetics: evidence that positive emotions in females moderate genetic sensitivity to social stress associated with the BDNF Val-sup-6-sup-6Met polymorphism. J Abnorm Psychol. 2008;117(3):699-704.

10. Garland EL, Fredrickson B, Kring AM, Johnson DP, Meyer PS, Penn DL. Upward spirals of positive emotions counter downward spirals of negativity: insights from the broaden-and-build theory and affective neuroscience on the treatment of emotion dysfunctions and deficits in psychopathology. Clin Psychol Rev. 2010;30(7):849-64.

11. Geschwind N, Peeters F, Drukker M, van Os J, Wichers M. Mindfulness training increases momentary positive emotions and reward experience in adults vulnerable to depression: a randomized controlled trial. J Consult Clin Psychol. 2011;79(5):618-28.

12. Csikszentmihalyi M, Larson R. Validity and reliability of the Experience-Sampling Method. J Nerv Ment Dis. 1987;175(9):526-36.

13. Delespaul P. Assessing schizophrenia in daily life. The experience sampling method. Maastricht: Maastricht University Press; 1995.

14. Peeters F, Nicolson NA, Berkhof J, Delespaul P, deVries M. Effects of daily events on mood states in major depressive disorder. J Abnorm Psychol. 2003;112(2):203-11.

15. Ben-Zeev D. Mobile technologies in the study, assessment, and treatment of schizophrenia. Schizophr Bull. 2012;38(3):384-5.

16. Wichers M, Hartmann JA, Kramer IM, Lothmann C, Peeters F, van Bemmel L, et al. Translating assessments of the film of daily life into person-tailored feedback interventions in depression. Acta Psychiatr Scand. 2011;123(5):402-3. 
17. Wichers M, Simons CJ, Kramer IM, Hartmann JA, Lothmann C, Myin-Germeys I, et al. Momentary assessment technology as a tool to help patients with depression help themselves. Acta Psychiatr Scand. 2011;124(4):262-72.

18. Trull TJ, Ebner-Priemer U. Ambulatory assessment. Annu Rev Clin Psychol. 2013;9:151-76.

19. Kramer I, Simons CJ, Hartmann JA, Menne-Lothmann C, Viechtbauer W, Peeters F, et al. A therapeutic application of the experience sampling method in the treatment of depression: a randomized controlled trial. World Psychiatry. 2014;13(1):68-77.

20. First MB, Gibbon M, Spitzer RL, Williams JB. Structured Clinical Interview for DSM-IV-TR Axis I Disorders, Research Version, Patient Edition (SCID-I/P). New York: Biometrics Research, New York State Psychiatric Institute; 2002.

21. Hamilton M. A rating scale for depression. J Neurol Neurosurg Psychiatry. 1960;23:56-62.

22. Myin-Germeys I, Oorschot M, Collip D, Lataster J, Delespaul P, van Os J. Experience sampling research in psychopathology: opening the black box of daily life. Psychol Med. 2009;39(9):1533-47.

23. Snijders T, Bosker R. Multilevel analysis: An introduction to basis and advanced multilevel modeling. London: SAGE publications Ltd; 1999.

24. StataCorp. Stata Statistical Software: Release 12. College Station, TX: StataCorp LP; 2012.

25. Fredrickson BL. The role of positive emotions in positive psychology: The broaden-and-build theory of positive emotions. Am Psychol. 2001;56(3):218.

26. Telford C, McCarthy-Jones S, Corcoran R, Rowse G. Experience Sampling Methodology studies of depression: the state of the art. Psychol Med. 2012;42(6):1119-29 



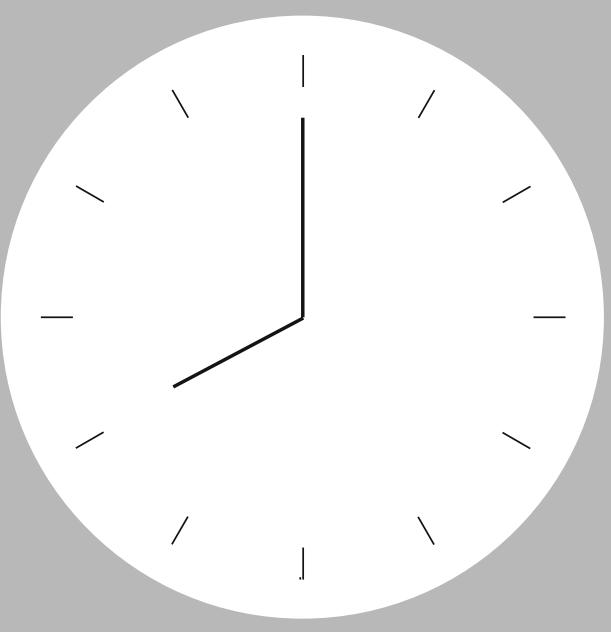

Chapter 8 


\title{
Effects of momentary self-monitoring on empowerment in a randomized controlled trial in patients with depression
}

\author{
Simons, CJP, \\ Hartmann, JA, \\ Kramer, I, \\ Menne-Lothmann, C, \\ Höhn, $\mathrm{P}$, \\ Van Bemmel, AL, \\ Myin-Germeys, I, \\ Delespaul, Ph, \\ Van Os, J, \\ Wichers, M
}




\begin{abstract}
Background: Interventions based on the experience sampling method (ESM-I) are ideally suited to provide insight in personal, contextualized affective patterns in the flow of daily life. The aim of the study was to examine whether ESM-I may increase experience of empowerment in patients with depression.
\end{abstract}

Method: Depressed out-patients ( $\mathrm{n}=102)$ receiving psychopharmacological treatment participated in a randomized controlled trial with three arms: (i) an experimental group receiving six weeks of add-on ESM self-monitoring combined with weekly feedback sessions, (ii) a pseudo-experimental group participating in six weeks of add-on ESM self-monitoring without feedback, and (iii) a control group (treatment as usual only). Patients were recruited in the Netherlands between January 2010 and February 2012. Self-report empowerment scores were obtained pre- and post-intervention.

Results: There was an effect of group $\times$ assessment period, indicating that the experimental $(\mathrm{B}=7.26, p=0.061, \mathrm{~d}=0.44$, statistically imprecise) and pseudo-experimental group $(B=11.19, p=0.003, d=0.76)$ increased more in reported empowerment compared to the control group. In the pseudo-experimental group, $29 \%$ of the participants showed a statistically reliable increase in empowerment score compared to $17 \%$ in the control group.

Conclusion: Add-on self-monitoring to complement standard antidepressant treatment may increase patients' feelings of empowerment. Providing ESM-derived feedback did not augment this effect.

Keywords: ecological momentary assessment; intervention study; personalized feedback; depressive disorder; empowerment 


\section{Introduction}

Electronic momentary assessment with the experience sampling method (ESM) allows for precise and prospective monitoring of emotions experienced in a daily life context. ESM consists of repeated assessments of affective experience and context in the flow of daily life [1-3]. These momentary assessments may reveal subtle repetitive and relevant patterns of experience in response to environmental and mental challenges [4]. Research employing ESM has shown the relevance of these patterns for the understanding of mental ill health [4-6], and highlights the relevance of focusing on moments of positive affective experiences in predicting resilience against psychopathology [7-9], and treatment response [10,11]. These momentary assessments may also be used at an individual level, as input for personalized feedback on dynamic patterns of emotions [12-15]. Evidence from existing studies suggests that combining antidepressant medication with psychotherapy may yield enhanced effects $[16,17]$. It can be argued that ESM-intervention (ESM-I) may enhance the effect of antidepressant psychopharmacological treatment as well, by providing a tool for environmental guidance to optimally support the facilitating effects of antidepressant drugs on plasticity and mood recovery [18]. That is, by transforming implicit, moment-to-moment emotional reactivity to explicit, visualized configurations, patients may increase their self-awareness of, and control over, daily life dynamics that may impact on depression.

Recently, it has been shown that the efficacy of traditional psychopharmacological treatment of major depression can indeed be enhanced using ESM-I person-tailored daily life feedback on patterns of positive affect [19]. It was demonstrated that this ESM-I was associated with a linear decrease in depressive symptoms in the six months following the intervention, a pattern not observed in the other two conditions. The present study further examined the effects of this ESM-I by investigating its effects on patients reported empowerment. With ESM-I, mental health problems may be better monitored and managed with the participation of the patient him/herself, giving the patient an active role in the treatment process and mobilizing individual resources. One of the potential mechanisms explaining the impact of person-tailored daily life feedback thus may involve patient empowerment. Empowerment is recognized as a dynamic, contextually-driven multidimensional construct that can be conceived of as a social process of enhancing an individual's ability to meet their own needs, solve their own problems, and mobilize the necessary resources in order to feel in control of their own lives $[20,21]$. Person-tailored daily life feedback may thus increase patient empowerment in the sense of having better information, more informed choices and thus enhanced shared decision-making [5, 22]. However, the effects of actively 
involving patients with depression in the data collection and interpretation of daily life mental states on patient empowerment have not been examined.

\section{Aims of the study}

This study examined whether providing patients with tools to self-monitor their own mental states increases experienced empowerment. It was hypothesized that self-monitoring combined with person-tailored daily life feedback increases patient empowerment.

\section{Materials and methods}

\section{Participants}

For the current randomized controlled trial (registered in the Dutch trial register, www.trialregister.nl, trial id: NTR1974)[19], participants were recruited between January 2010 and February 2012 via mental health care facilities in or near the Dutch cities of Eindhoven and Maastricht, and through local advertisements. The investigation was carried out in accordance with the Declaration of Helsinki (2008). The study was approved by an institutional review board (Medical Ethics Committee of Maastricht University Medical Centre) and all participants provided written informed consent before their enrollment.

Participants were considered eligible when they were between 18 and 65 years of age; a DSM-IV-TR diagnosis of depressive episode (assessed with the Structured Clinical Interview for DSM-IV Axis I Disorders (SCID-I) [23]) with current or residual symptoms (17-item Hamilton Depression Rating Scale (HDRS) score of $>7$ [24]); treated with antidepressants or mood stabilizers. Participants were excluded if they met criteria for a non-affective psychotic disorder according to DSM-IV or if they reported a (hypo) manic or mixed episode within the past month.

\section{Design}

A randomized controlled trial was conducted with three parallel treatment arms [19]. After completion of all baseline assessments, participants were randomly allocated to the experimental, pseudo-experimental, or control group. In addition to treatment as usual (TAU), the experimental group participated in an ESM procedure (three days per week over a six-week period). This group received weekly standardized feedback on personalized patterns of positive affect (PA). The pseudo-experimental group also participated in the ESM procedure (three days per week over a six-week period) 
in addition to TAU, but without feedback. The control group received no additional intervention during TAU.

Randomization (allocation ratio 1:1:1) was stratified by (i) duration of antidepressant pharmacotherapy (receiving the current antidepressant or mood stabilizing medication for shorter vs. longer than 8 weeks prior to study entry), and (ii) current psychotherapy (yes or no). Interviewers were not blind to the patients' treatment allocation. After randomization, the participants were considered part of the study regardless of whether they decided to leave the study prematurely.

Participants allocated to the experimental group engaged in a weekly three-day ESM procedure for six consecutive weeks and received standardized feedback based on the participant's ESM data in six feedback sessions, in addition to TAU. The pseudoexperimental group was identical in procedure to the experimental group except that no feedback was given. Instead, during these weekly sessions, participants engaged in a structured conversation with the researcher, i.e. an HDRS interview, to keep duration of contacts equivalent to the experimental group. During these six consecutive weeks, participants allocated to the control group received TAU only.

\section{Procedure}

The study protocol consisted of a telephone interview, a screening, a baseline assessment (week 0), a six-week intervention period (weeks 1 to 6), a post-assessment (week 7), and five follow-up assessments (at weeks 8, 12, 16, 20, 32). The recruitment process started with a short telephone interview conducted by a psychologist or psychiatrist to establish whether inclusion criteria were likely met. During a face-to-face screening, two weeks before randomization, the SCID-I and HDRS were administered as assess whether individuals met inclusion criteria. ESM-assessments took place as part of the baseline assessment, during the six-week intervention period, and at the post-assessment. Empowerment was assessed twice, at screening and at post-assessment, with nine weeks between the two assessments. Figure 1 shows participant flow and procedure throughout the trial period from enrolment to post-assessment.

\section{Empowerment}

Empowerment was assessed with the Dutch Empowerment questionnaire [25]. This is a 40-item self-rating scale to assess patient empowerment developed by the Dutch Trimbos Institute and validated for use in severe mental illness. It incorporates the dimensions professional help, social support, own wisdom, sense of belonging, selfmanagement, and community inclusion. Items are formulated in positive statements of strengths as perceived by the participant and are rated on five-point Likert scales ranging from 1 ('strongly disagree') to 5 ('strongly agree'), with four items regarding 
professional health care having the additional option 'not applicable'. A total score (range 40-200) was calculated, with higher scores indicating more empowerment. Cronbach's alpha for the 40 items was 0.92 at pre-assessment and 0.94 at postassessment. Previous research has shown a similar Cronbach's alpha of 0.93 and has indicated satisfactory construct validity with correlations with related instruments ranging from small to large in the expected directions [25].

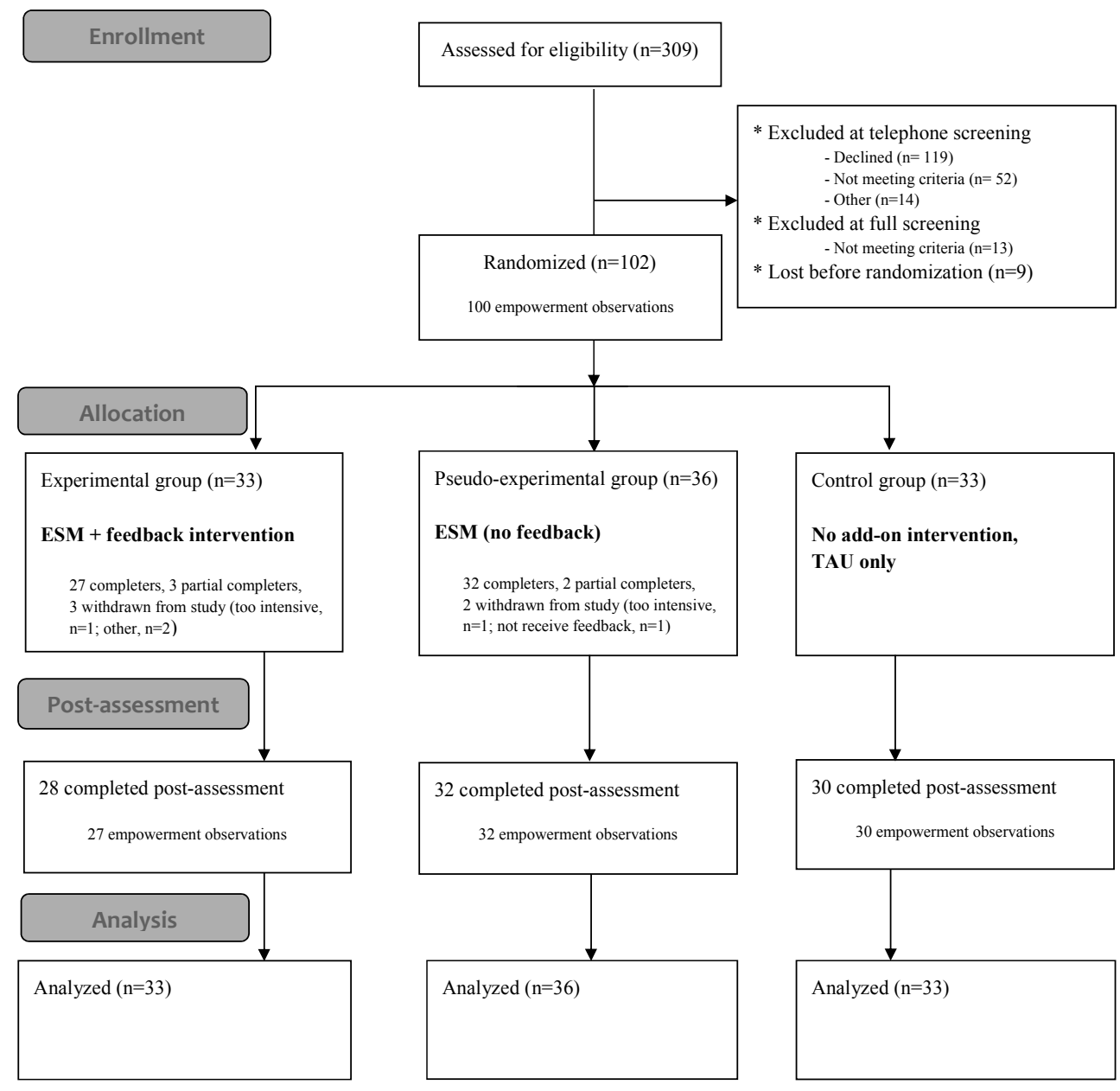

Figure 1 | Flow diagram of the study. ESM= Experience Sampling Method; TAU = treatment as usual 


\section{Experience Sampling Method}

ESM, a validated, structured diary technique consisting of repeated in-the-moment micro-measurements of affect and context, was carried out in accordance with previous studies [2, 12, 26-28]. Participants received a dedicated electronic ESM device ('PsyMate', [29]) to digitally collect daily life momentary assessments of affect, activity and context. The PsyMate was programmed to emit a signal (beep) ten times per day at random intervals in each of ten 90-min time blocks between 07:30 am-10:30 pm, prompting participants to fill in self-assessments. At each beep, participants used the PsyMate to digitally complete a brief questionnaire including current affect (positive and negative affect) as well as current context and activities ("daily life activities", "people present", "physical activity", and "events"). Positive affect indicators included the adjectives "cheerful", "satisfied", "enthusiastic" and "relaxed". Negative affect was indexed by the adjectives "down", "suspicious", "guilty", "irritated", "lonely" and "anxious". The self-assessments were rated on 7-point Likert scales (ranging from 1="not at all" to $7=$ "very"). Participants were instructed to complete the questionnaire as quickly as possible after the beep.

The ESM procedure was explained to the participant in an initial briefing session, and a practice run was performed to ensure that the participants understood the questions and the device.

\section{Intervention}

For six consecutive weeks, participants in the experimental group received standardized feedback based on the participant's ESM data. The six feedback sessions immediately followed the weekly three-day ESM procedure. In these face-to-face sessions, protocolled feedback was provided by the researcher (a psychologist or psychiatrist, $n=5$ ). Feedback on participants' momentary affective state in specific daily life contexts and the association with depressive symptoms was given verbally, graphically, and in writing. Feedback showed actual levels of PA in the context of daily life activities, events, and social situations, and changes in PA level over the course of the ESM-intervention (see [19] for examples). A written bullet-point summary report of the feedback based on a fixed template was given to both the participant and the mental health professional.

\section{Feedback structure}

Every feedback session consisted of two parts. In the first part, information with respect to experiences during the most recent week was presented. In the second part, this information was placed in the context of the previous ESM weeks. 


\section{Feedback content}

The feedback intervention was divided in three modules. Each feedback session consisted of information regarding magnitude of and fluctuations in PA experienced during the past week was presented, as well as graphs displaying the course of experienced PA across the weeks. In addition to these fixed feedback elements, the first two weeks of the intervention (module 1), focused on PA experience during daily activities. The third and fourth week (module 2) focused on daily events differentiating between affect experienced during events appraised with an internal vs. external locus of control. The last two weeks (module 3) focused on positive affect experienced during social interactions in daily life.

\section{Statistical analysis}

Statistical analyses were conducted using STATA 13.1 [30], using all available data from participants included at randomization. The data had a hierarchical structure. This means that multiple assessments (pre- and post-assessment) of empowerment are clustered within participants. Multilevel regression analysis is suitable for this type of data because it takes the variability associated with each level of nesting into account. It is preferred to ANOVA, because it processes all available data and can handle missing values, thus retaining statistical power. The xtmixed command was used to perform a multilevel regression analysis with the two-way interaction between assessment (pre- vs. post-intervention) and group as fixed effects and participants as random effects. Model fit was restricted maximum likelihood. Estimated between- and within-group effects were calculated by linear combination of the appropriate terms in the model containing the assessment $\times$ group interaction term (Stata's lincom procedure). Between-group differences were also translated to standardized mean differences (Cohen's d) using the pooled standard deviation of the observed scores obtained at pre-assessment.

Additionally, groups were compared at the level of individual participant change. A reliable change index was calculated according to the widely used method of Jacobson and Truax [31]: (empowerment score at post-assessment - empowerment score at pre-assessment) $/ \mathrm{SE}_{\text {diff. }}$ The standard error of the difference, $\mathrm{SE}_{\text {diff, }}$ was calculated using the formula $S E_{\text {diff }}=\sqrt{ }\left(2\left[S_{1} \sqrt{ }(1-r)\right]^{2}\right)$, where $S_{1}$ is the standard deviation $\left(\operatorname{SD}_{\text {pre }}\right.$ $=18.4$ ) and $\mathrm{r}$ is the reliability, in this case the internal reliability (Cronbach's $\alpha_{\text {pre }}=$ 0.92). Individual reliable change scores $>1.96$ were considered to reflect statistically reliable positive change; change scores $<-1.96$ reflected reliable negative change; and change scores in between these values reflected no reliable change [31]. $\mathrm{X}^{2}$-tests were used to test for differences between groups in the proportions of participants showing statistically reliable change (increased, decreased, no change). 


\section{Results}

Characteristics of the included participants sample are shown in Table 1. Pre-intervention empowerment scores were available for respectively 32 of 33 (control), 35 of 36 (pseudo-experimental), and 33 of 33 (experimental) participants. Post-intervention empowerment scores were available for 30 (control), 32 (pseudo-experimental), and 27 (experimental) participants. Two participants had incomplete assessments of empowerment (front page only, i.e. 15 items), their total scores (mean item score $\times 40$ ) were retained in the analyses. Analyses were thus conducted in 102 participants of whom 87 had pre- and post-assessment empowerment scores (i.e., 189 observations).

Table 1 | Characteristics of study participants at screening.

\begin{tabular}{|c|c|c|c|c|c|c|}
\hline \multirow[t]{2}{*}{ Variable } & \multirow{2}{*}{$\begin{array}{l}\text { Total } \\
(n=102)\end{array}$} & \multirow{2}{*}{$\begin{array}{l}\text { Experimental } \\
(n=33)\end{array}$} & \multirow{2}{*}{$\begin{array}{l}\text { Pseudo- } \\
\text { experimental } \\
(n=36)\end{array}$} & \multirow{2}{*}{$\begin{array}{l}\text { Control } \\
(n=33)\end{array}$} & \multicolumn{2}{|c|}{ Between-group comparison } \\
\hline & & & & & test parameter & $p$ \\
\hline Age & $\begin{array}{l}48.0 \\
(S D=10.2)\end{array}$ & $\begin{array}{l}48.7 \\
(S D=10.2)\end{array}$ & $\begin{array}{l}46.7 \\
(S D=9.6)\end{array}$ & $\begin{array}{l}48.9 \\
(S D=10.9)\end{array}$ & $\chi_{\mathrm{df}=2}^{2}=2.06$ & $0.36^{\mathrm{a}}$ \\
\hline Sex M/F & $46 / 56$ & $17 / 16$ & $14 / 22$ & $15 / 18$ & $\chi_{\mathrm{df}=2}^{2}=1.11$ & 0.57 \\
\hline Ethnicity: Dutch & 91 & 27 & 35 & 29 & $\chi_{\mathrm{df}=2}^{2}=4.34$ & $0.11^{\mathrm{b}}$ \\
\hline \multicolumn{7}{|l|}{ Educational level } \\
\hline no/primary low secondary & 25 & 6 & 9 & 10 & & \\
\hline high school/ low vocational & 38 & 12 & 14 & 12 & $\chi_{\mathrm{df}=4}^{2}=1.73$ & 0.79 \\
\hline higher vocational/university & 39 & 15 & 13 & 11 & & \\
\hline Full- or part-time work & 35 & 13 & 10 & 12 & $\chi_{\mathrm{df}=2}^{2}=1.12$ & 0.57 \\
\hline Illness/unemployment benefits & 62 & 18 & 20 & 24 & $\chi_{\mathrm{df}=2}^{2}=1.06$ & 0.59 \\
\hline Living with partner/own family & 53 & 18 & 17 & 18 & $\chi_{\mathrm{df}=2}^{2}=0.50$ & 0.78 \\
\hline Bipolar disorder & 9 & 5 & 2 & 2 & $\chi_{\mathrm{df}=2}^{2}=2.43$ & 0.39 \\
\hline DSM Axis-I comorbidity & 40 & 12 & 16 & 12 & $\chi_{\mathrm{df}=2}^{2}=0.64$ & 0.73 \\
\hline Empowerment scores & $\begin{array}{l}126.9 \\
(S D=18.4)\end{array}$ & $\begin{array}{l}126.9 \\
(S D=17.5)\end{array}$ & $\begin{array}{l}124.6 \\
(S D=19.6)\end{array}$ & $\begin{array}{l}129.5 \\
(S D=18.2)\end{array}$ & $\mathrm{F}_{(99,2)}=0.56$ & 0.56 \\
\hline
\end{tabular}

${ }^{\mathrm{a}}$ Kruskal-Wallis test adjusted for tied ranks,

${ }^{\mathrm{b}}$ Fisher exact $p$-value

The results from the multilevel regression analysis are displayed in Figure 2. The experimental group as well as the pseudo-experimental group showed a significant increase in empowerment scores from pre- to post-assessment $(B=5.85,95 \% \mathrm{CI}$ $0.40-11.29 p=0.035$, and $\mathrm{B}=9.7895 \%$ CI 4.68-14.87, $p<0.001$, respectively). The experimental group, compared to the control group, showed a larger, but statistically imprecise, increase in empowerment sum scores from pre- to post-assessment $(\mathrm{B}=7.26,95 \% \mathrm{CI}-0.32-14.84, p=0.061, \mathrm{~d}=0.44)$. The pseudo-experimental group also 


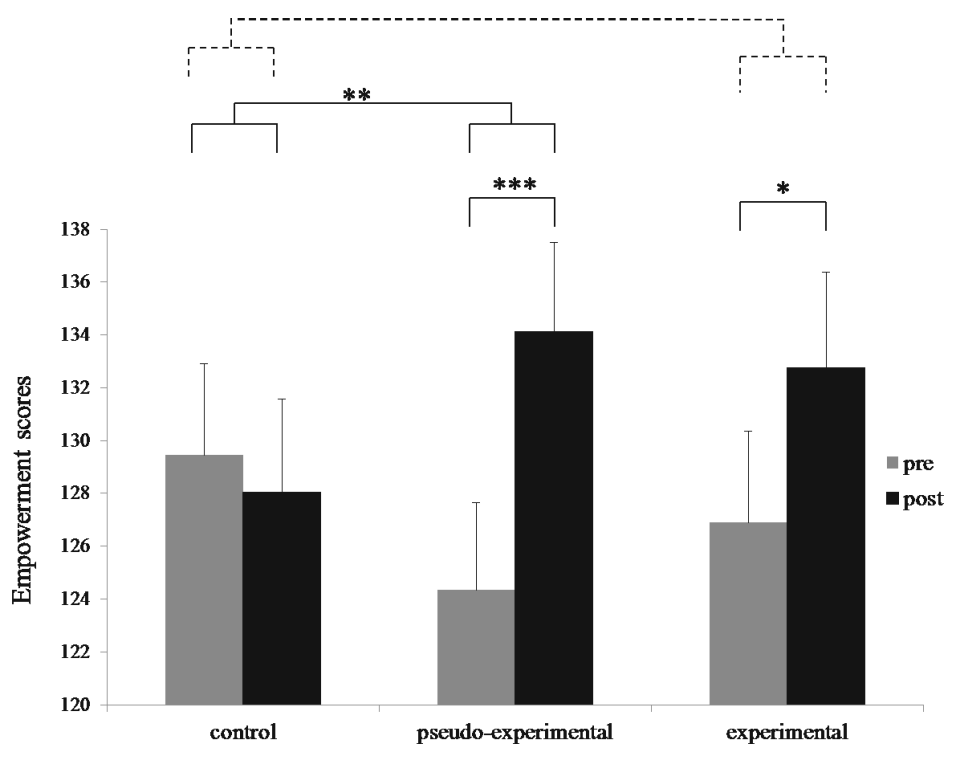

Figure 2 | Estimated marginal means with standard errors for pre- and post-intervention empowerment sum scores, stratified for condition [n=102, $189 \mathrm{obs}] .{ }^{*} p<0.05,{ }^{* *} p<0.01,{ }^{* * *} p<0.001$, dashed line $p<0.10$

showed a significantly larger increase in empowerment sum scores from pre- to postassessment compared to the control group (B=11.19, 95\% CI 3.86-18.52, $p=0.003$, $\mathrm{d}=0.76)$. The experimental group did not differ significantly in pre-to-post change in empowerment scores compared to the pseudo-experimental group ( $\mathrm{B}=-3.93,95 \% \mathrm{CI}$ -11.38-3.52, $p=0.30, \mathrm{~d}=-0.37$ ).

At post-assessment, however, there were no significant between-group differences in empowerment scores (experimental vs. control group: $B=4.70,95 \% \mathrm{CI}-5.18-14.59$, $p=0.35, \mathrm{~d}=0.36$; pseudo-experimental vs. control group: $\mathrm{B}=6.07,95 \% \mathrm{CI}-3.50-15.64$, $p=0.21, \mathrm{~d}=0.23$; experimental vs. pseudo-experimental group: $\mathrm{B}=-1.37,95 \% \mathrm{CI}$ $-11.07-8.34, p=0.78, \mathrm{~d}=-0.04$ ).

Figure 3 shows the changes in empowerment scores (post-assessment minus preassessment) and the cut-off levels of the 95\% confidence interval of the JacobsonTruax reliability change index [31]. In the pseudo-experimental group, 29\% of the participants showed a reliable increase and $0 \%$ a reliable decrease, in the experimental group $19 \%$ showed a reliable increase and $4 \%$ a reliable decrease, compared to $17 \%$ reliable increase and $21 \%$ reliable decrease in the control group. The pseudoexperimental group differed significantly form the control group in terms of individual change scores $\left(\chi^{2}=7.48\right.$, Fisher exact $\left.p=0.02\right)$, whereas the experimental group did not differ significantly from the control group $\left(\chi^{2}=3.74\right.$, Fisher exact $\left.p=0.18\right)$. 


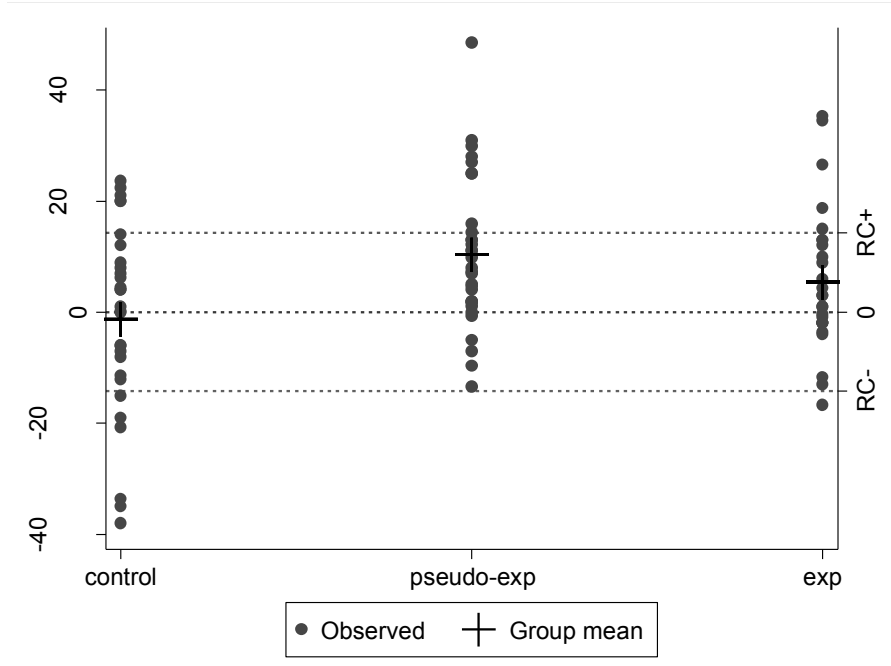

Figure 3 | Scatterplot of post- minus pre-assessment empowerment scores, stratified for condition [ $\mathrm{n}=87$ ]. $\mathrm{RC}$ - is lower threshold (reliable decrease) for reliable change, $\mathrm{RC}+$ is upper threshold for reliable change (reliable increase); control = control group, pseudo-exp = pseudo-experimental group, exp = experimental group.

\section{Discussion}

Experience sampling methodology allows for the collaborative monitoring of symptoms and context by the patient-clinician dyad to aid person-tailored treatment. Instead of being a passive receiver of care, the patient assumes an active role, possibly enhancing empowerment and mobilizing individual resources. The results of the current study are inconclusive. Allocation to the ESM-intervention was associated with an increase in empowerment scores, whereas no pre-to-post change in empowerment scores was observed in the control group. This tentatively suggests that the use of ESM to complement standard antidepressant treatment may indeed increase empowerment in patients suffering from mild to severe depressive disorder. However, these results need to be carefully interpreted given that no between-group effects were observed at post-assessment and the larger increase in the experimental compared to the control group was statistically imprecise. Furthermore, there were no significant differences between the experimental and pseudo-experimental group, and only the pseudo-experimental group showed a significantly higher percentage of participants with reliable increase in empowerment compared to the control group. These results may suggest that ESM self-monitoring (independent of feedback) may be beneficial 
with regard to feelings of empowerment, as ESM self-monitoring may allow patients to become more mindful of affective states, increasing awareness of variability of their emotions, including moments of high affective states [32]. However, it cannot be excluded that the increase in empowerment scores is attributable to the weekly in-the-office appointments in the intervention period.

In contrast to the hypothesis, the ESM-intervention group did not show larger effects on empowerment compared to the pseudo-intervention group that received ESM selfmonitoring without feedback. It may be hypothesized that providing the patient with systematic feedback about self-collected ESM-data, and, more specifically, feedback focused on daily positive affective experience, is an important factor in empowering patients, by giving patients insight into their own strengths and moments of daily life successes, setting the path for potential self-reinforcing changes in daily life dynamic patterns. That is, the feedback focused on daily life patterns of PA may motivate an individual to explore PA-evoking activities in daily life, engagement in these activities leads to increased PA, which may broaden attention towards reward-oriented behaviors, increasing the likelihood of future experiences of PA [33]. ESM feedback intervention could thus be a tool for creating affective changes through behavioral activation, which has been shown to be an effective strategy in reducing depressive symptoms $[34,35]$. The present study, however, could not support a (additional) beneficial role of providing feedback in terms of increasing patient's self-reported empowerment at immediate post-assessment. It may be argued that effects of self-monitoring interventions may not be observable directly after the intervention, because patients need some time to apply their newly developed insight about their dynamic emotional patterns into their daily lives and to experience changes in their daily lives as a result thereof, and only then may feel more empowered. In line with this, effectiveness of the feedback intervention in terms of reduction of depressive symptoms was not evident directly after the intervention [19]. Initially, both the experimental group receiving ESM with feedback and the pseudo-experimental group receiving ESM without feedback showed a decrease in depressive symptoms. However, depressive symptoms in the experimental group continued to decline over the six-month follow-up period, whereas the depressive symptoms in the pseudo-experimental group again worsened during the follow-up period. It may be speculated that empowerment scores also continued to increase in the experimental group during the follow-up period, whereas the pattern of empowerment scores over time may have been different in the other two groups. Furthermore, empowerment is a complex construct and relying only on a single self-report questionnaire at post-assessment is likely insufficient to capture the mechanisms explaining the impact of ESM-intervention. More research is 
therefore necessary to investigate long-term effects of self-monitoring in combination with feedback on patient empowerment.

\section{Limitations}

Owing to the nature of the intervention, it was not possible to blind participants, which may have biased the outcomes of the trial. However, if knowledge of allocation resulted in biased empowerment ratings by the patient one would, in contrast to the current results, expect that the experimental group (relative to the control group) demonstrated the largest increase. Instead, the pseudo-experimental group showed the largest increase in empowerment scores. Interviewers were also not blind to treatment allocation, but effects of interviewer bias may be considered minimal given that the assessment of empowerment relied on a self-report questionnaire.

The trial was limited to three arms. It was designed to address the question of interest whether ESM self-monitoring in combination with feedback would be efficacious in reducing depressive symptoms, not to address the question whether ESM self-monitoring per se would be efficacious. The lack of an arm that consisted of selfmonitoring only without weekly visits to the researcher or, alternatively, an arm with weekly visits to the researcher without self-monitoring, precludes separating effects of self-monitoring from effects attributable to the weekly contacts.

\section{Declaration of interest}

M. Wichers was supported by the Netherlands Organization for Scientific Research (Aspasia Grant). The study was funded by the Dutch Health Research Council (ZONMW (grants nos. 171001002 and 91501003). The tool with which momentary assessments were performed (the PsyMate) is developed under the auspices of the Maastricht University technology transfer office, partially supported by unrestricted grants from Servier and Janssen-Cilag, and by funding from the European Community's Seventh Framework Program under grant agreement no. HEALTH-F2-2009-241909 (Project EU-GEI). 


\section{References}

1. aan het Rot M, Hogenelst K, Schoevers RA. Mood disorders in everyday life: A systematic review of experience sampling and ecological momentary assessment studies. Clin Psychol Rev. 2012;32(6):510-23.

2. Csikszentmihalyi M, Larson R. Validity and reliability of the Experience-Sampling Method. J Nerv Ment Dis. 1987;175(9):526-36.

3. Myin-Germeys I, Oorschot M, Collip D, Lataster J, Delespaul P, van Os J. Experience sampling research in psychopathology: opening the black box of daily life. Psychol Med. 2009;39(9):1533-47.

4. Wichers M, Peeters F, Geschwind N, Jacobs N, Simons CJP, Derom C, et al. Unveiling patterns of affective responses in daily life may improve outcome prediction in depression: A momentary assessment study. J Affect Disord. 2010;124(1-2):191-5.

5. van Os J, Delespaul P, Wigman J, Myin-Germeys I, Wichers M. Beyond DSM and ICD: introducing 'precision diagnosis' for psychiatry using momentary assessment technology. World Psychiatry. 2013;12(2):113-7.

6. Wichers M. The dynamic nature of depression: a new micro-level perspective of mental disorder that meets current challenges. Psychol Med. 2014;44(07):1349-60.

7. Collip D, Wigman JTW, van Os J, Oorschot M, Jacobs N, Derom C, et al. Positive emotions from social company in women with persisting subclinical psychosis: lessons from daily life. Acta Psychiatr Scand. 2014;129(3):202-10.

8. Wichers MC, Myin-Germeys I, Jacobs N, Peeters F, Kenis G, Derom C, et al. Evidence that moment-tomoment variation in positive emotions buffer genetic risk for depression: a momentary assessment twin study. Acta Psychiatr Scand. 2007;115(6):451-7.

9. Höhn P, Menne-Lothmann C, Peeters F, Nicolson NA, Jacobs N, Derom C, et al. Moment-to-moment transfer of positive emotions in daily life predicts future course of depression in both general population and patient samples. PLoS One. 2013;8(9):e75655.

10. Wichers M, Lothmann C, Simons CJP, Nicolson NA, Peeters F. The dynamic interplay between negative and positive emotions in daily life predicts response to treatment in depression: a momentary assessment study. Br J Clin Psychol. 2012;51(2):206-22.

11. Geschwind N, Peeters F, Jacobs N, Delespaul P, Derom C, Thiery E, et al. Meeting risk with resilience: high daily life reward experience preserves mental health. Acta Psychiatr Scand. 2010;122(2):12938.

12. Delespaul P. Assessing schizophrenia in daily life: The experience sampling method. Maastricht: University of Limburg; 1995.

13. Wichers M, Simons CJP, Kramer IMA, Hartmann JA, Lothmann C, Myin-Germeys I, et al. Momentary assessment technology as a tool to help patients with depression help themselves. Acta Psychiatr Scand. 2011;124(4):262-72.

14. Van der Poel EGT, Delespaul PAEG. The applicability of ESM in personalized rehabilitation. In: deVries M, editor. The experience of psychopathology: Investigating mental disorders in their natural settings. Cambridge: Cambridge University Press; 1992. p. 290-303.

15. Wichers M, Hartmann JA, Kramer IMA, Lothmann C, Peeters F, van Bemmel L, et al. Translating assessments of the film of daily life into person-tailored feedback interventions in depression. Acta Psychiatr Scand. 2011;123(5):402-3.

16. Cuijpers P, Dekker J, Hollon SD, Andersson G. Adding psychotherapy to pharmacotherapy in the treatment of depressive disorders in adults: a meta-analysis. J Clin Psychiatry. 2009;70(9):1219-29. 
17. Lampe L, Coulston CM, Berk L. Psychological management of unipolar depression. Acta Psychiatr Scand. 2013;127:24-37.

18. Castrén E. Neuronal network plasticity and recovery from depression. JAMA Psychiatry. 2013;70(9):983-9.

19. Kramer I, Simons CJP, Hartmann JA, Menne-Lothmann C, Viechtbauer W, Peeters F, et al. A therapeutic application of the experience sampling method in the treatment of depression: a randomized controlled trial. World Psychiatry. 2014;13(1):68-77.

20. Gibson CH. A concept analysis of empowerment. J Adv Nurs. 1991;16(3):354-61.

21. Zimmerman MA. Psychological empowerment: issues and illustrations. Am J Community Psychol. 1995;23(5):581-99.

22. Hamann J, Leucht S, Kissling W. Shared decision making in psychiatry. Acta Psychiatr Scand. 2003;107(6):403-9.

23. First MB, Spitzer RL, Gibbon M, Williams JBW. Structured clinical interview for DSM-IV axis I disorders - patient edition (SCID-I/P, version 2.0). New York: Biometrics Research Department, New York State Psychiatric Institute, 1996.

24. Hamilton M. A rating scale for depression. J Neurol Neurosurg Psychiatry. 1960;23:56-62.

25. Boevink W, Kroon H, Giesen F. Empowerment: constructie en validatie van een vragenlijst [Empowerment: Construction and validation of a questionnaire]. Utrecht: Trimbos-instituut; 2008.

26. Myin-Germeys I, van Os J, Schwartz JE, Stone AA, Delespaul PA. Emotional reactivity to daily life stress in psychosis. Arch Gen Psychiatry. 2001;58(12):1137-44.

27. Wichers M, Myin-Germeys I, Jacobs N, Peeters F, Kenis G, Derom C, et al. Genetic risk of depression and stress-induced negative affect in daily life. Br J Psychiatry. 2007;191:218-23.

28. Palmier-Claus JE, Myin-Germeys I, Barkus E, Bentley L, Udachina A, Delespaul PAEG, et al. Experience sampling research in individuals with mental illness: reflections and guidance. Acta Psychiatr Scand. 2011;123(1):12-20.

29. Myin-Germeys I, Birchwood M, Kwapil T. From environment to therapy in psychosis: A real-world momentary assessment approach. Schizophr Bull. 2011;37(2):244-7.

30. StataCorp. Stata Statistical Software: Release 13. College Station, TX: StataCorp LP; 2013.

31. Jacobson NS, Truax P. Clinical significance: a statistical approach to defining meaningful change in psychotherapy research. J Consult Clin Psychol. 1991;59(1):12-9.

32. Telford C, McCarthy-Jones S, Corcoran R, Rowse G. Experience Sampling Methodology studies of depression: the state of the art. Psychol Med. 2012;42(6):1119-29.

33. Fredrickson BL. The role of positive emotions in positive psychology: The broaden-and-build theory of positive emotions. Am Psychol. 2001;56(3):218.

34. Dimidjian S, Hollon SD, Dobson KS, Schmaling KB, Kohlenberg RJ, Addis ME, et al. Randomized trial of behavioral activation, cognitive therapy, and antidepressant medication in the acute treatment of adults with major depression. J Consult Clin Psychol. 2006;74(4):658-70.

35. Cuijpers P, van Straten A, Warmerdam L. Behavioral activation treatments of depression: a metaanalysis. Clin Psychol Rev. 2007;27(3):318-26 


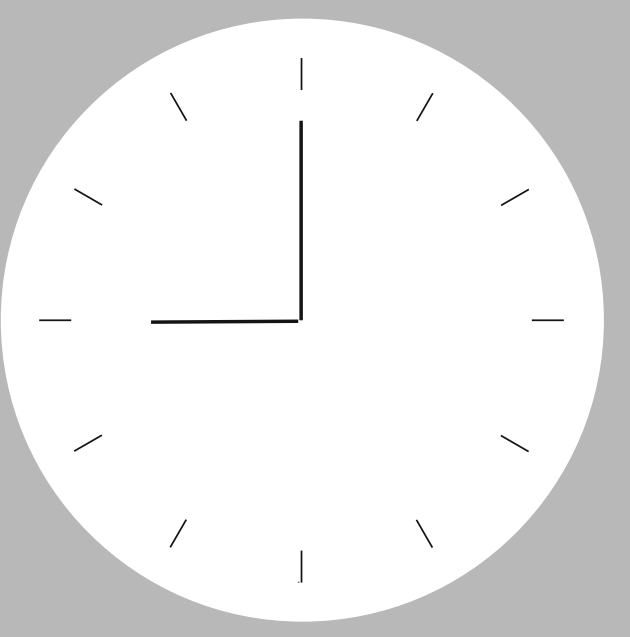

Chapter 9 


\section{Discussion}



In the present thesis, two unique characteristics of ambulatory assessment techniques were utilized to (1) measure micro-level mechanisms potentially underlying depression, and to (2) intervene on these micro-mechanisms in depression. In the first part, ambulatory assessments derived from the experience sampling method (ESM) and prospective sleep diaries (chapter 2) were used to investigate sleep- and affect-related mechanisms at a micro-level which may underlie depression (chapter 3-5). It was identified that subjective sleep, which was particularly associated with next-day momentary positive affect (PA), predicted depressive symptoms in a large female sample (chapter 3). The strength of the observed association between perceived sleep and subsequent PA appeared to be genetically predetermined (chapter 4). Furthermore, it was shown that the diurnal dynamic patterns of PA and negative affect (NA) differed between depressed patients and the general population, possibly indicative of a disturbed endogenous rhythm underlying depression (chapter 5).

In the second part, ESM-based self-reports in the form of personalized feedback ('ESM-I') were used to influence these micro-mechanisms in a randomized controlled trial (RCT) in clinically depressed patients (chapter 6, 7 and 8). In this study, depressed patients were given feedback on personalized patterns of PA. It was shown that, although the training did reduce depressive symptoms on the long term, there were no acute changes in affect or the PA-related concept of empowerment during, or shortly after the intervention period.

In the following sections, the findings of the present thesis are discussed. First, the results of the 'measure' part of the thesis (part 1: chapters 2 to 5) are placed into the context of both the emotion homeostasis model and the circadian hypothesis of depression; and further integrated into a new potential model of micro-mechanisms of depression. Second, the results of the 'intervention' part of this thesis (part 2: chapters 6 to 8) are discussed, followed by a synthesis and integration of all chapters in a valorisation, clinical implication, and future directions section.

\section{Measure: Linking sleep, affect and depression}

\section{The emotion homeostasis model}

In Chapter $\mathbf{3}$ we have shown that subjective sleep and momentary affect are closely intertwined. Using a study design in which both affect and perceived sleep were measured prospectively and ambulatory (using a sleep diary as validated in Chapter 2), we identified that sleep and affect were related both at a micro-level of day-today associations and at the macro-level of longitudinal associations. In other words, worse perceived sleep was associated with reduced momentary PA (and to a lesser 
extent increased momentary NA) the next day as well as with increased depressive symptoms in the long-term. Remarkably, the associations between self-reported sleep and everyday affect were not bidirectional. Sleep appeared to be more strongly associated with subsequent affect rather than with previous affect.

Our findings are in concordance with the notion of sleep having an important affect-regulating role [1]. Increasing evidence suggests that rapid-eye-movement sleep (REM sleep, i.e., dream sleep) may play an especially prominent role in affective brain modulation during the night $[2,3]$. Previous studies have shown that the sleep-deprived brain processes negative emotional memories to a greater extent (or positive memories to a lesser extent) than the non-sleep deprived brain, leading to an imbalance in memory formation [3]. Furthermore, sleep-deprived subjects show an increased limbic response towards emotional stimuli, possibly due to decreased inhibition by prefrontal cortex areas [4]. Based on this information, the emotion homeostasis model of sleep has been formulated [1-3]. In this model, sleep is given an important affect-regulating role with two specific functions. First, it functions to properly process emotional experiences during the day. Sleep - with an emphasis on REM sleep - is seen as an 'affective therapist' [1]: affective experience is both semantically incorporated into the cortical network (i.e., the information is consolidated) and uncoupled of its affective tone. In the long-term, emotional events are retained in memory without evoking the emotions initially associated with that event [1-3]. Second, sleep is thought to 'recalibrate' brain function. Such a recalibrating function is thought to be necessary to appropriately process next-day emotional events, including the proper appraisal and response to environment signals (i.e. the approach of reward and the avoidance of danger). In more concrete terms, sleep is associated with the instauration of neurotransmitter activity in limbic and prefrontal regions, likely related to the absence of monoaminergic neurotransmission during REM sleep. Accordingly, a good night's sleep is associated with a 'brain reset' to ideal affective reactivity [1-3]. In the absence of the opportunity to regenerate, as seen in sleep deprivation, activity in the affective brain network (brainstem structures, amygdala, and prefrontal cortex) is altered [1-3]. The emotion homeostasis model is supported by studies showing that sleep deprivation is associated with elevated activity in the amygdala, decreased activity in the prefrontal cortex, and lower connectivity in the amygdala-prefrontal cortex network [4-6].

The findings of Chapter 3 add to the emotion homeostasis model by supporting the hypothesis that sleep may be necessary for ideal affective reactivity the next day. However, while the emotion homeostasis model proposes emotional over-activity for both negative and positive affectivity, the current findings suggest that poor sleep is associated with an overactive NA system accompanied by a blunted PA system: Poor 
sleep was associated with increased NA but reduced PA the next day. The notion of a blunted, instead of an overactive PA system, is supported by two naturalistic studies. Bower and colleagues [7] have shown that general levels of PA are positively associated with perceived sleep quality, denoting that poor perceived sleep quality is associated with less PA. Similarly, Zohar and colleagues [8] have demonstrated that the experience of goal-enhancing events is associated with less PA when sleep deprived. Conversely, Gujar and colleagues [5] have shown that a lack of sleep enhanced reactivity towards positive, pleasurable stimuli: sleep deprivation was associated with heightened limbic activity in response to positive stimuli. A possible explanation for these discrepant findings may relate to the degree of sleep disturbance. A lack of sleep may be associated with emotional blunting of the PA system, potentially transitioning to an over-active PA system if a certain threshold is reached (i.e. total sleep deprivation) $[6,9]$. This explanation may also account for the paradoxical observation that sleep deprivation in depression can have rapid antidepressant effects $[5,10]$; a phenomenon discussed in detail below.

\section{The circadian hypothesis of depression}

We have shown the amount of experienced PA during the day is associated with the previous night's sleep (chapter 3), and the strength of this association seems to be genetically predetermined (chapter 4). Prior research has demonstrated that mood is not only influenced by the previous night's sleep (i.e. homeostatic influences), but it is also under circadian control [11]. Specifically, it has been proposed that PA is subjected to circadian oscillations, leading to a characteristic diurnal course resembling an inverted 'u-curve' over the waking day, while NA, not being subjected to such influences remains relatively stable [12-14]. Our findings on the diurnal variation of NA and PA in a real-time ambulatory design (chapter 5) converge with these prior hypotheses and previous studies describing the typical diurnal variation of affect. We identified a diurnal variation of PA similar to the hypothesized inverted U, with a relative constant course of NA across the day. Although the study design in chapter 5 did not allow to draw conclusions about the origin of these fluctuations, it was speculated (based on previous research [15]) that it may partially reflect circadian impacts. Likewise, Chapter 5 showed that patients with a diagnosis of major depression did not only exhibit altered mean levels of affect compared to the general population, but they also showed a deviant diurnal variation of PA and NA. Compared to the general 
population, depressed patients demonstrated an attenuated decrease of PA during the evening hours, a later peak of PA and a more pronounced diurnal variation of NA. This potentially reflects an altered underlying endogenous rhythm [13, 16-18], although this has yet to be directly tested.

Our findings provide indirect support of the circadian theory of depression, in which a disturbed underlying circadian rhythm is considered a critical pathogenic mechanism $[19,20]$. In this theory, a change in circadian parameters, such as a phase shift (advance or delay) [21-23] or a blunted amplitude [16, 24, 25] of the circadian oscillator is proposed to underlie mood disorders. Evidence for an altered endogenous rhythmicity stems from several studies that have shown changed periodicity parameters for depressed patients in an array of physiological variables such as body temperature [e.g. 26], cortisol [e.g. 27], and melatonin [e.g. 28]. Furthermore, the efficacy of some chronotherapeutics targeted at synchronizing the circadian oscillator, such as bright light therapy, social rhythm therapy, and wake therapy in depression $[18,29]$, provide support for the circadian hypotheses of depression.

\section{Circadian rhythms and neurotransmission}

As mentioned in chapter 1 (introduction), wake therapy (i.e. partial or total sleep deprivation) is associated with an improvement of mod in $40-60 \%$ of depressed patients $[30,31]$. This paradoxical phenomenon has been related to the serotonergic system, possibly mimicking the functioning of pharmacological treatments in depression [32]. As discussed in chapter $\mathbf{4}$, serotonin appears to play a role in the regulation of both sleep and mood. Serotonin (5-HT) has been linked to mood and mood disorders for a long time, and is the major target of antidepressant medication [32]; most notably, serotonergic functioning has been linked to positive affectivity [33,34]. Recent research has shown interactions and reciprocal connections between circadian and serotonin systems [35]. Light exposure has been shown to increase 5-HT turnover [36]. Acute sleep restriction has been associated with elevated serotonergic activity [37], while chronic sleep deprivation has been demonstrated to induce changes in serotonin-receptor sensitivity [38]. Furthermore, as shown in chapter $\mathbf{4}$, the association between perceived sleep and PA is moderated by the serotonin transporter 5-HTTLPR polymorphism. Taken together, these findings provide strong evidence that serotonin is functionally involved in the connection between sleep, mood and circadian rhythms.

Considering that the circadian system may modulate PA or the behavioural approach system (chapter 5), therefore possibly influencing motivation and reward function, a potential involvement in the circadian/sleep/affect link has also been proposed for the dopaminergic system [39]. Well known for its reward-related functioning, the 
mesolimbic dopamine system has been implicated in mood disorders, especially in anhedonic depression [40,41]. Furthermore, it may play an important role in sleep regulation and has been shown to be subjected to clock genes [41]. In contrast to the serotonergic system, however, no direct connections between the dopaminergic and circadian system have been established thus far.

\section{A model for depression}

In the context of the existing literature, the combined findings of chapters 3,4 and 5 can be integrated into a model of micro-mechanisms potentially underlying depres$\operatorname{sion}^{1}$. At its core, there may be alterations in endogenous rhythms $[19,20]$ (not tested directly in this thesis), which are plausibly associated with sleep disturbances as well as changes in affect regulation through a possible link to dysfunctional behavioural activation and behavioural inhibition systems (BAS and BIS) (chapter 5). On a phenomenological and behavioural level, this may translate into the emotion of 'depressed mood', reduced motivation, and decreased goal-directed activities as seen in anhedonia. In concrete terms, too little PA and too much NA during moments requiring high engagement with the environment (i.e. during daytime) could imply that potentially rewarding situations are not approached. On the other hand, (relatively) high PA and

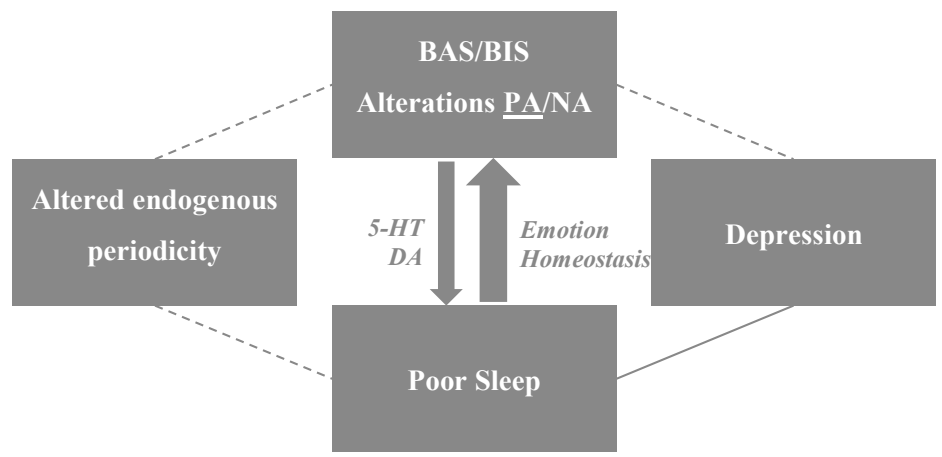

Figure 1 | Possible micro-mechanisms underlying depression. Dotted lines indicate that the associations were not tested directly in the current thesis and rely on previous research and assumptions (see text).

BAS=Behavioural activation system; BIS=Behavioural inhibition system; PA=Positive affect; NA=Negative affect; DA=Dopamine; 5HT=Serotonin

1 Harvey and colleagues (42) proposed a related model of micro mechanisms, considering sleep disturbances as a trans-diagnostic process, not underlying depression specifically, but psychiatric disorders in general. However, as the results of the current thesis (i.e. chapter 5) speak more in favor of a relative specificity for depression, the model presented here considers depression specifically. 
low NA levels at moments requiring disengagement with the environment (i.e. during the evening/night) could interfere with sleep-related processes.

As presented in chapter 3, sleep and daily affect regulation are closely associated. This relationship appeared to be not entirely bidirectional, as the associations between affect and previous nights' sleep was stronger than between affect and subsequent sleep (indicated by the varying thickness of arrows in Figure 1). Thus, our findings provide support for the emotion homeostasis model as proposed by Walker [1-3]. Furthermore, the strength of the association between sleep and affect appeared to be genetically predetermined; the monoaminergic neurotransmitters serotonin and dopamine possibly play a role in these associations [chapter 4 , but see also 35, 39, 42]. Together, the interaction and potential mutual maintenance of changed sleepand affect related processes, may be associated with the development of depression. Here, a special role has to be ascribed to PA. Not only did PA appear to have a stronger association with perceived sleep than NA in the current thesis, it has also been shown elsewhere to be crucial in predicting the development, recovery and course of depression [43-48]. As such, the PA system seems an essential element in depression, and therefore a key target for interventions, as explored further in chapters 6-8.

\section{Intervention: Using ESM to target PA}

In chapters 6, 7, and 8, the use of ambulatory assessments was extended from monitoring for fundamental research purposes (i.e. unravel underlying mechanisms as in chapters 3 to $\mathbf{5}$ ) to therapeutic applications in depression. By capitalizing on recent developments concerning the shift from paper- and pencil-based to electronic ESM data collection, it was possible to feed back the fine-grained, micro-level information collected by ESM directly to the depressed patient, creating a new form of intervention. As PA has been shown to play a crucial role in depression [43-47, 48, see also previous paragraphs], the PA system was selected to be the target of this novel feedback intervention based on data electronically collected within an ESM protocol (ESM-I, chapter 6). In chapters $\mathbf{7}$ and 8, we tested the effectiveness of this therapeutic application, which consisted of feedback focussing on previous weeks' mood, activities, social company and experienced events.

Although it could not be directly demonstrated that the PA-focused intervention was effective in bringing about short-term changes in PA (chapter 7), nor in the PA-related concept of empowerment (chapter 8), the RCT has been observed to be effective in decreasing depressive symptoms [49]. This decrease in depressive symptoms was only apparent in the long run, commencing at three weeks post-intervention with the 
peak effect observed on the last measurement occasion, ten weeks post-intervention [49]. Affect and empowerment ratings were only assessed during, and shortly after, the intervention period: not during the follow-up period. Therefore, it was argued that the translational process from 'theoretical feedback' to the actual exploration of PA evoking activities, eventually leading to an increase of momentary PA extended past our measurement window (chapter 7). Alternatively, it must be conceded that providing systematic PA-focused feedback about self-collected ESM data may not impact momentary PA (chapter 7). In a similar vein, prolonged monitoring appeared to increase patients' empowerment, without an apparent additional benefit of providing feedback (chapter 8). Although the effects of weekly contact with the researcher could not be separately ascertained, it may be argued that merely the increasingly active role assumed by the patient with ESM self-monitoring may lead to the mobilization of own resources. The recruitment of own resources may, in turn, lead to greater experienced empowerment. Similarly, as demonstrated in chapter 7, NA in the ESM-I group without feedback decreased significantly after the intervention period, as compared to the control group without ESM monitoring. This effect could also be linked to the own resources, mobilized by prolonged self-monitoring in the absence of any other training.

The results of chapters 6, 7 and $\mathbf{8}$ combined, it could be argued that the prolonged engagement of patients in intensive monitoring of their own mental states may be beneficial. However, the parent study of the RCT [49] has shown that the positive effects of self-monitoring may be only short-lived and, to be beneficial in the longer term, this should be combined with feedback. Clearly, as the present RCT was the first study to systematically explore the use of experience sampling as a therapeutic application, more research is needed. Nevertheless, the our findings provide previously unavailable evidence that the joined monitoring (patient and clinician) of affective experiences and symptoms in this context could represent an effective new way to intervene in depression and other mental disorders. In the subsequent section, possible future applications of ambulatory assessment based interventions are discussed. 


\section{References}

1. Goldstein AN, Walker MP. The role of sleep in emotional brain function. Annu Rev Clin Psychol. 2014;10:679-708.

2. Walker MP. The role of sleep in cognition and emotion. Ann N Y Acad Sci. 2009;1156:168-97.

3. Walker MP, van der Helm E. Overnight therapy? The role of sleep in emotional brain processing. Psychol Bull. 2009;135(5):731-48.

4. Yoo SS, Gujar N, Hu P, Jolesz FA, Walker MP. The human emotional brain without sleep--a prefrontal amygdala disconnect. Curr Biol. 2007;17(20):R877-8.

5. Gujar N, Yoo SS, Hu P, Walker MP. Sleep deprivation amplifies reactivity of brain reward networks, biasing the appraisal of positive emotional experiences. J Neurosci. 2011;31(12):4466-74.

6. Motomura Y, Kitamura S, Oba K, Terasawa Y, Enomoto M, Katayose Y, et al. Sleep debt elicits negative emotional reaction through diminished amygdala-anterior cingulate functional connectivity. PLoS One. 2013;8(2):e56578.

7. Bower B, Bylsma LM, Morris BH, Rottenberg J. Poor reported sleep quality predicts low positive affect in daily life among healthy and mood-disordered persons. J Sleep Res. 2010;19(2):323-32.

8. Zohar D, Tzischinsky O, Epstein R, Lavie P. The effects of sleep loss on medical residents' emotional reactions to work events: a cognitive-energy model. Sleep. 2005;28(1):47-54.

9. Deliens G, Gilson M, Peigneux P. Sleep and the processing of emotions. Exp Brain Res. 2014;232(5):1403-14.

10. Gillin JC, Buchsbaum M, Wu J, Clark C, Bunney W, Jr. Sleep deprivation as a model experimental antidepressant treatment: findings from functional brain imaging. Depress Anxiety. 2001;14(1):3749.

11. Boivin DB, Czeisler CA, Dijk DJ, Duffy JF, Folkard S, Minors DS, et al. Complex interaction of the sleep-wake cycle and circadian phase modulates mood in healthy subjects. Arch Gen Psychiatry. 1997;54(2):145-52.

12. Clark LA, Watson D, Leeka J. Diurnal variation in the positive affects. Motiv Emot. 1989;13(3):20534.

13. Murray G, Nicholas CL, Kleiman J, Dwyer R, Carrington MJ, Allen NB, et al. Nature's clocks and human mood: the circadian system modulates reward motivation. Emotion. 2009;9(5):705-16.

14. Watson D, Wiese D, Vaidya J, Tellegen A. The two general activation systems of affect: Structural findings, evolutionary considerations, and psychobiological evidence. J Pers Soc Psychol. 1999;76(5):820.

15. Murray G, Allen NB, Trinder J. Mood and the circadian system: investigation of a circadian component in positive affect. Chronobiol Int. 2002;19(6):1151-69.

16. Murray G. Diurnal mood variation in depression: a signal of disturbed circadian function? J Affect Disord. 2007;102(1-3):47-53.

17. Peeters F, Berkhof J, Delespaul P, Rottenberg J, Nicolson NA. Diurnal mood variation in major depressive disorder. Emotion. 2006;6(3):383.

18. Wirz-Justice A. Diurnal variation of depressive symptoms. Dialogues Clin Neurosci. 2008;10(3):337.

19. Germain A, Kupfer DJ. Circadian rhythm disturbances in depression. Hum Psycopharm Clin Ex. 2008;23(7):571-85.

20. McClung CA. How might circadian rhythms control mood? Let me count the ways. Biol Psychiatry. 2013;74(4):242-9.

21. Lewy AJ, Rough JN, Songer JB, Mishra N, Yuhas K, Emens JS. The phase shift hypothesis for the circadian component of winter depression. Dialogues Clin Neurosci. 2007;9(3):291. 
22. Emens J, Lewy A, Kinzie JM, Arntz D, Rough J. Circadian misalignment in major depressive disorder. Psychiatry Res. 2009;168(3):259-61.

23. Lewy AJ, Lefler BJ, Emens JS, Bauer VK. The circadian basis of winter depression. Proc Natl Acad Sci U S A. 2006;103(19):7414-9.

24. Czeisler CA, Kronauer RE, Mooney JJ, Anderson JL, Allan J. Biologic rhythm disorders, depression, and phototherapy: a new hypothesis. Psychiatr Clin North Am. 1987.

25. Souêtre E, Salvati E, Belugou J-L, Pringuey D, Candito M, Krebs B, et al. Circadian rhythms in depression and recovery: evidence for blunted amplitude as the main chronobiological abnormality. Psychiatry Res. 1989;28(3):263-78.

26. Daimon K, Yamada N, Tsujimoto T, Takahashi S. Circadian rhythm abnormalities of deep body temperature in depressive disorders. J Affect Disord. 1992;26(3):191-8.

27. Posener JA, DeBattista C, Williams GH, Kraemer HC, Kalehzan BM, Schatzberg AF. 24-Hour monitoring of cortisol and corticotropin secretion in psychotic and nonpsychotic major depression. Arch Gen Psychiatry. 2000;57(8):755-60.

28. Claustrat B, Chazot G, Brun J, Jordan D, Sassolas G. A chronobiological study of melatonin and cortisol secretion in depressed subjects: plasma melatonin, a biochemical marker in major depression. Biol Psychiatry. 1984;19(8):1215-28.

29. Wirz-Justice A, Benedetti F, Berger M, Lam RW, Martiny K, Terman M, et al. Chronotherapeutics (light and wake therapy) in affective disorders. Psychol Med. 2005;35(07):939-44.

30. Benedetti F, Barbini B, Colombo C, Smeraldi E. Chronotherapeutics in a psychiatric ward. Sleep Med Rev. 2007;11(6):509-22.

31. Wu JC, Bunney WE. The biological basis of an antidepressant response to sleep deprivation and relapse: review and hypothesis. Am J Psychiatry. 1990.

32. Adrien J. Neurobiological bases for the relation between sleep and depression. Sleep Med Rev. 2002;6(5):341-51.

33. Flory JD, Manuck SB, Matthews KA, Muldoon MF. Serotonergic function in the central nervous system is associated with daily ratings of positive mood. Psychiatry Res. 2004;129(1):11-9.

34. Williams E, Stewart-Knox B, Helander A, McConville C, Bradbury I, Rowland I. Associations between whole-blood serotonin and subjective mood in healthy male volunteers. Biol Psychol. 2006;71(2):171-4.

35. Ciarleglio C, Resuehr H, McMahon D. Interactions of the serotonin and circadian systems: nature and nurture in rhythms and blues. Neuroscience. 2011;197:8-16.

36. Lambert G, Reid C, Kaye D, Jennings G, Esler M. Effect of sunlight and season on serotonin turnover in the brain. Lancet. 2002;360(9348):1840-2.

37. Monti JM. Serotonin control of sleep-wake behavior. Sleep Med Rev. 2011;15(4):269-81.

38. Roman V, Walstra I, Luiten PG, Meerlo P. Too little sleep gradually desensitizes the serotonin $1 \mathrm{~A}$ receptor system. Sleep. 2005;28(12):1505-10.

39. Hasler BP, Allen JJ, Sbarra DA, Bootzin RR, Bernert RA. Morningness-eveningness and depression: preliminary evidence for the role of the behavioral activation system and positive affect. Psychiatry Res. 2010;176(2-3):166-73.

40. Martin-Soelch C. Is depression associated with dysfunction of the central reward system? Biochem Soc Trans. 2009;37(1):313.

41. Nestler EJ, Carlezon Jr WA. The mesolimbic dopamine reward circuit in depression. Biol Psychiatry. 2006;59(12):1151-9. 
42. Harvey AG, Murray G, Chandler RA, Soehner A. Sleep disturbance as transdiagnostic: consideration of neurobiological mechanisms. Clin Psychol Rev. 2011;31(2):225-35.

43. Dunn BD. Helping depressed clients reconnect to positive emotion experience: current insights and future directions. Clin Psychol Psychother. 2012;19(4):326-40.

44. Garland EL, Fredrickson B, Kring AM, Johnson DP, Meyer PS, Penn DL. Upward spirals of positive emotions counter downward spirals of negativity: insights from the broaden-and-build theory and affective neuroscience on the treatment of emotion dysfunctions and deficits in psychopathology. Clin Psychol Rev. 2010;30(7):849-64.

45. Geschwind N, Nicolson NA, Peeters F, van Os J, Barge-Schaapveld D, Wichers M. Early improvement in positive rather than negative emotion predicts remission from depression after pharmacotherapy. Eur Neuropsychopharmacol. 2011;21(3):241-7.

46. Wichers M, Kenis G, Jacobs N, Myin-Germeys I, Schruers K, Mengelers R, et al. The psychology of psychiatric genetics: evidence that positive emotions in females moderate genetic sensitivity to social stress associated with the BDNF Val-sup-6-sup-6Met polymorphism. J Abnorm Psychol. 2008;117(3):699-704.

47. Wichers MC, Barge-Schaapveld DQ, Nicolson NA, Peeters F, de Vries M, Mengelers R, et al. Reduced stress-sensitivity or increased reward experience: the psychological mechanism of response to antidepressant medication. Neuropsychopharmacology. 2009;34(4):923-31.

48. Wichers MC, Myin-Germeys I, Jacobs N, Peeters F, Kenis G, Derom C, et al. Evidence that moment-tomoment variation in positive emotions buffer genetic risk for depression: a momentary assessment twin study. Acta Psychiatr Scand. 2007;115(6):451-7.

49. Kramer I, Simons CJ, Hartmann JA, Menne-Lothmann C, Viechtbauer W, Peeters F, et al. A therapeutic application of the experience sampling method in the treatment of depression: a randomized controlled trial. World Psychiatry. 2014;13(1):68-77. 



$$
\left(\begin{array}{l}
L \\
L
\end{array}\right.
$$




\section{Valorisation, clinical implications and future directions}



Exploration of the use of ESM-I in chapters 6-8 (i.e. the use of therapeutic interventions based on electronic ESM) is just one example of the opportunities offered by the advent of rapidly developing electronic ambulatory techniques. These ambulatory techniques also include a plethora of wearable electronic sensors in the form of wristbands, smart watches, pendants or smart clothing.

Among the possible research and therapeutic applications of this new technology is the integration of several ambulatory procedures such as: (i) ESM, (ii) actigraphy (i.e. the registry of diurnal/nocturnal physical activity), (iii) monitoring of physiological variables (e.g. temperature, heart rate, hormone levels), (iv) luxometry (i.e. the monitoring of light input) and (v) registry of geographic location. This integration may provide unprecedented data richness, fostering exciting new routes of discovery leading to the unravelling of pathogenic mechanisms on a micro-level (part I of this thesis) and the development of new, more effective treatment applications (part II of this thesis). By assimilating the information from these diverse high-resolution information channels, we may be able to reach a more complete representation of an individual's emotional, behavioural and physiological state within the context of his or her daily life. That is, we may go from a black-and-white static photo of a patients' state (i.e. single-point retrospective questionnaires administered in the doctor's office) to a full-colour movie (i.e. continuous, prospective ambulatory assessment integrating multiple psychological and physiological channels). With this increased resolution and detail, new options emerge. These conceivably include the detailed moment-to-moment monitoring of treatment responses, or state monitoring combined with the development of individual relapse logarithms. Recently, a first effort has been undertaken to integrate ambulatory assessments of mood and behaviour (i.e. ESM) with that of physical activity (i.e. motion sensing); however, it remains until now primarily on a conceptual level [1-3].

Within somatic medicine, ambulant monitoring of blood pressure or blood sugar levels represents a routine clinical process. As of today, this situation is very different for the psychiatric context: the ambulant monitoring of mood states, behaviour or physical activity is hardly ever used outside the research context. The research presented in this thesis, especially in chapter 2 (prospective monitoring of perceived sleep quality vs. retrospective assessment of sleep quality) and chapters 6-8 (ESM as potential therapeutic application), may help to incorporate ESM and other related ambulatory assessments as a routine part of (mental health) clinical practice. While concerns could arise about the feasibility and compliance of patients when incorporating these techniques in everyday clinical life, the results presented chapter 6 to 8 as well as by Kramer and colleagues [4], and other related research [5-7] provide evidence refuting these concerns. Ambulatory assessments (even the 
8-week intensive self-monitoring of affective states and behaviour in patients with mild to moderate depression), were well-accepted and compliance rates were high [chapter 7, 4]. Moreover, the high popularity of apps on iOS and Android platforms providing software for self-monitoring (ranging from food intake, sleeping and activity patterns to the integration of medical records) argue in favour of a bright future for ambulatory assessments in mental health care routine. However, the implementation of ambulatory assessment techniques may be impeded by clinicians working within this sector. As noted by Trull and Ebner-Priemer [7] and by the researchers associated with the RCT presented in chapters 6-8 (personal communication), there seems to be a stronger resistance against the incorporation of ambulatory assessments in clinical routine by the clinicians themselves. This resistance should be taken seriously and the mechanisms behind such barriers should be explored and represent an important area of future research.

The apparent resistance of clinicians to the incorporation of ambulatory assessments may be related to some obvious drawbacks associated with the development of novel monitoring methods. The newly developed techniques, including a large spectrum of activity monitors and tracking sensors, seem to lead to a different form of being, also referred to 'quantified self' or 'self-logging'. With it, a number of essential, yet unresolved problems arise. First of all, there is the issue of privacy. What happens to the data collected by the patient? Who is owner of the data and who is authorized to access it? Is it the patient's general practitioner, his/her mental health care professional, or merely the patient? How long are the data going to be stored? Furthermore, security of data storage can be a serious problem. With an increasing amount of channels collecting personal data which is possibly stored at various places, it becomes very vulnerable to cyber criminality such as online hacking. These and other related concerns should be carefully addressed through sound empirical methods before ESM and ESM-I, combined with other forms of ambulatory assessments, are adapted as a regular part of clinical routine.

By integrating the insights of part one ('measuring') and part two ('intervening') of the present thesis, several recommendations can be provided to guide and inform future research. The model of micro-mechanisms potentially underlying depression in part 1 (Figure 1), showed the apparent importance of endogenous rhythms, sleepwake related processes, and PA, warranting future interventions precisely targeting these processes. Therefore, subsequent interventions should be aimed at stabilizing endogenous rhythms, enhancing sleep quality, and enhancing the experience of positive affect. In recent years, considerable progress has been made in chronotherapeutic approaches with the underlying goal of normalizing circadian rhythms and, by extension, enhancing sleep quality. In 2005, a consensus has been reached by the 
Committee on chronotherapeutics considering treatment options [8]. Here, light and stepped wake therapy, either in isolation, combined and/or augmented with pharmacological treatments (i.e. SSRI's), are recommended as first-line treatments for major depression [8].

Furthermore, given the apparent importance of PA, psychological treatments which have been traditionally focused on reducing negative affectivity rather than increasing positivity, should shift their focus on the restoration of the PA system 'to get the individual going'. A number of promising treatments are currently in development, such as behavioural activation approaches [9]. When utilizing ESM to target the PA system (demonstrated in part 2 of this thesis), providing feedback about experienced PA and thereby increasing PA may not be as straight-forward as previously thought. However, by increasing expertise about PA-related mechanisms underlying depression, increasingly targeted and person-tailored interventions can be developed. In concrete terms, it may be more efficient to give person-specific feedback and recommendations on exactly how to adapt behaviour, instead of merely providing passive, data-driven feedback about experienced PA.

On a practical level, chronobiological as well as behavioural activation interventions are par excellence suited to be delivered by, or in combination with, ambulatory assessment approaches, integrating psychological (i.e. mood, symptoms, context), behavioural (i.e. inside/outside, passive/active activities, sleep patterns), and physiological (i.e. heart rate, temperature, light input, hormones such as cortisol or melatonin) variables. Here, it is crucial to not only meticulously brief the patient, but also sufficiently consider potential clinician's concerns. By doing so, 'a good laugh and a long sleep', could indeed be the best cures in a doctor's book. 


\section{References}

1. Bussmann JB. One plus one equals three (or more...): combining the assessment of movement behavior and subjective states in everyday life. Front Psychol. 2013;4.

2. Bussmann JB, van den Berg-Emons RJ. To total amount of activity.... and beyond: perspectives on measuring physical behavior. Front Psychol. 2013;4.

3. Ebner-Priemer UW, Koudela S, Mutz G, Kanning M. Interactive multimodal ambulatory monitoring to investigate the association between physical activity and affect. Front Psychol. 2012;3.

4. Kramer I, Simons CJ, Hartmann JA, Menne-Lothmann C, Viechtbauer W, Peeters F, et al. A therapeutic application of the experience sampling method in the treatment of depression: a randomized controlled trial. World Psychiatry. 2014;13(1):68-77.

5. Ebner-Priemer UW, Kubiak T. The decade of behavior revisited: Future prospects for ambulatory assessment. Eur J Psychol Assess. 2010;26(3):151-53.

6. Trull TJ, Ebner-Priemer U. Ambulatory assessment. Annu Rev Clin Psychol. 2013;9:151-76.

7. Trull TJ, Ebner-Priemer UW. Using experience sampling methods/ecological momentary assessment (ESM/EMA) in clinical assessment and clinical research: introduction to the special section. Psychol Assess. 2009;21(4):457-62.

8. Wirz-Justice A, Benedetti F, Berger M, Lam RW, Martiny K, Terman M, et al. Chronotherapeutics (light and wake therapy) in affective disorders. Psychol Med. 2005;35(07):939-44.

9. Dunn BD. Helping depressed clients reconnect to positive emotion experience: current insights and future directions. Clin Psychol Psychother. 2012;19(4):326-40. 



$$
\left(\begin{array}{l}
L \\
L
\end{array}\right.
$$


Summary 

The current thesis focuses on the use of ambulatory ('in the field') assessment techniques in the area of mental health and sleep research. The ambulatory assessment technique at the heart of this thesis is the Experience Sampling Method (ESM). ESM is a structured diary technique which assesses a person's emotions, experiences and behaviour prospectively and recurrently, 'in the flow of daily life'. Due to its prospective and repeated nature, fine-grained high resolution ('micro-level') information of a person's daily life is gained, enabling investigations into dynamic changes over time, across context, and within a person. At the same time, ambulatory assessment techniques can be used as a therapeutic application by transforming the fine-grained information into personalized feedback. In the present thesis, ambulatory assessments were used to (1) investigate sleep/affect-related micro-mechanisms which may be underlying factors for depression (Chapters 2-5) and to (2) influence these micro-mechanisms in clinically depressed patients by giving personalized feedback based on ESM-assessments (ESM-intervention; Chapters 6-8).

Chapter $\mathbf{1}$ is a general introduction and provides an overview of theoretical concepts and research methods which are central to this thesis. Scientific background about sleep, depression, and positive (PA) and negative affect (NA) regulation, as well as the links between these concepts, are presented. Utilized ambulatory assessment methodologies are introduced and explained.

Subjective sleep quality and affect regulation are central to the first part of this thesis. In Chapter 2, the construct of subjective sleep quality is explored in patients with insomnia. This chapter investigates the role of psychiatric illness in the reporting of subjective sleep quality as assessed with (a) a retrospective measure (the Pittsburgh Sleep Quality Index, PSQI), versus (b) a prospective, ambulatory measure (a sleep diary). Results showed that the association between the prospective sleep diary and the retrospective PSQI was dependent on psychiatric status: the association was weaker in insomnia patients with a comorbid psychiatric condition compared to patients without comorbidity. Furthermore, patients with a psychiatric comorbidity scored significantly higher on the PSQI than those without, a difference which did not remain significant after controlling for anxiety. The insomnia patients, with or without psychiatric comorbidity, did not differ in their sleep quality ratings based on the sleep diary. It was concluded that (1) psychiatric patients may be more biased in their retrospective sleep quality ratings, and (2) the PSQI total score may reflect sleep-related distress.

Poor sleep is a recognized risk factor for depression, however little is known about the underlying mechanisms. In Chapter 3, we aimed at disentangling potential mech- 
anisms by which sleep may be related to depression. First, using ESM, we zoomed down to the 'micro-level' of within-person daily life patterns of subjective sleep and momentary affect. Second, we zoomed out to the 'macro-level' by investigating the association between baseline sleep and future depression in a population-based female sample. Results showed that subjective sleep was associated with affect during the next day, especially PA, while affect during the day was not or only weakly associated with subsequent night-time sleep. Furthermore, sleep reported at baseline predicted depressive symptoms across the follow-up period. We concluded that the subtle, repetitive impact of sleep in (positive) affect may play an underlying role in the development of depression.

Serotonin is associated with the regulation of affective as well as sleep-related processes. A functional polymorphism in the serotonin transporter gene (5-HTTLPR) has been associated with serotonergic functioning. In Chapter 4, we investigated whether allelic variation of this gene moderates the previously identified (Chapter 3) association between subjective sleep and next-day PA. Results showed that the association between subjective sleep quality and PA was dependent on the 5-HTTLPR polymorphism: The association was stronger in carriers of at least one copy of the S-allele compared to homozygous L-carriers. This result supports the theory that serotonin may play a role in the association between sleep and affect.

Studies have demonstrated that PA and NA unfold differentially across the day: while NA remains relatively stable, PA shows a quadratic course ('inverted u-curve'). There is preliminary evidence that the diurnal variation of PA and NA may be deviant in depression. However, it has not yet been systematically investigated and it is not known if this (potentially) deviant pattern is specific for depression. In Chapter 5, the diurnal variation of PA and NA is examined and compared among patients with depression, psychosis and a general population sample using ESM. We identified a quadratic-like course of PA for all three groups. However, the depressed patients showed an attenuated decrease of PA at the end of the day. Furthermore, during the afternoon and evening, NA decreased significantly more in the depressed patients compared to the general population sample. Patients with psychosis showed a course of affect that did not significantly differ from the general population sample. The results confirmed the hypothesis that the diurnal variation of affect may be deviant in patients with depression, which seemed specific for this disorder. This could be related to an altered functioning of the internal biological clock in depression. 
Chapter 6 presents the first results of a randomized controlled trial (RCT), evaluating the feasibility of ESM as a therapeutic application (Chapters 7 and 8 focus on the clinical results of the RCT). In this RCT, an ESM-intervention was examined in which depressed patients collected ESM data over a 6-week period on an electronic ESM device ('PsyMate'). They received weekly feedback on daily life context (i.e., social context, current activities, physical activity etc.) in relation to their momentary emotional responses, with a focus on the experience of PA. The aim was to give patients more insight into functional and dysfunctional behaviours. As continuous mood tracking can be challenging, this chapter presents the first results with respect to tolerability and feasibility of the trial. Although some aspects of the PsyMate were experienced as demanding, the overall feasibility of this ESM-based intervention seemed to be promising.

Chapter 7 examines if the ESM-based intervention introduced in Chapter 6 has an impact on the amount of PA experienced in daily life. The study consisted of three arms: ESM self-monitoring combined with feedback sessions (experimental group); ESM self-monitoring combined with sessions without feedback (pseudo-experimental group); and treatment as usual (control group). The feedback received by the patients in the experimental group was focused on the experience of PA in an everyday context. We investigated if the experimental intervention was associated with an increase in momentary PA during or shortly after the intervention. Results showed that the experimental group did not differ in PA increase compared to the pseudo-experimental or control group. Thus, the feedback did not significantly impact on daily PA during or shortly after the intervention. We argued that the effects of the feedback on PA may evolve slowly and that the period of ESM measures may have been of insufficient length to assess these gradually evolving changes in PA.

Chapter 8 investigates if the ESM-intervention can contribute to more empowerment in depressed patients. Continuous self-monitoring, combined with weekly feedback, assigns the patient an active role, and may form a base for better insight into (dys-)functional behaviours and for improved self-management strategies. This may eventually lead to increased empowerment of the patient. Results showed that both the experimental and pseudo-experimental groups reported a larger increase of empowerment compared to the control group. There was no difference between the experimental and pseudo-experimental group. These results suggest that the longterm, active monitoring of affective responses in daily life may contribute to greater empowerment in depressed patients. 
In Chapter 9, the findings of this thesis are discussed and placed within the context of the emotion homeostasis model and the circadian hypothesis of depression. The results from Chapters 2 to 5 are integrated into a new model of potential micromechanisms of depression. Subsequently, the possibilities provided by ESM in the treatment of depression are further explored (Chapters 6 to 8), followed by a discussion of opportunities for valorisation, clinical implications and future directions for research into sleep/affect related mechanisms and ESM interventions in depression. 



$$
\left(\begin{array}{l}
L \\
L
\end{array}\right.
$$


Samenvatting 

Dit proefschrift focust op het gebruik van ambulante ('ter plaatse') meettechnieken in het onderzoek op het gebied van geestelijke gezondheid en slaap. De ambulante meettechniek die hierbij centraal staat is de Experience Sampling Methode (ESM). ESM is een gestructureerde dagboektechniek die emoties, ervaringen en gedrag van een persoon prospectief en herhaaldelijk, 'in de stroom van het alledaagse leven', in kaart brengt. Door het prospectieve en herhaaldelijke karakter wordt er gedetailleerde, hoge resolutie ('microniveau') informatie van het dagelijks leven van een persoon verkregen. Dit maakt onderzoek naar dynamische veranderingen over tijd, over context, en binnen een persoon mogelijk. Tegelijkertijd kunnen ambulante meettechnieken als therapeutische toepassing worden gebruikt, doordat de nauwkeurige informatie getransformeerd kan worden naar gepersonaliseerde feedback. In dit proefschrift werden ambulante meettechnieken gebruikt voor het (1) in kaart brengen van slaap/ affect gerelateerde micromechanismen, die mogelijk onderliggende factoren zijn voor depressie (hoofdstukken 2-5) en voor het (2) beïnvloeden van deze micromechanismen in klinisch depressieve patiënten door het geven van gepersonaliseerde feedback op basis van ESM-metingen (ESM-interventie; hoofdstukken 6-8).

Hoofdstuk 1 is een algemene introductie en biedt een overzicht van de theoretische concepten en onderzoeksmethoden die in dit proefschrift centraal staan. De wetenschappelijke achtergronden van slaap, depressie, positieve (PA) en negatieve affect (NA) regulatie, en de onderliggende verbindingen tussen deze concepten, worden gepresenteerd. De in dit proefschrift gebruikte ambulante meettechnieken worden geïntroduceerd en toegelicht.

Subjectieve slaapkwaliteit en affectregulatie staan centraal in het eerste deel van dit proefschrift. In Hoofdstuk 2 wordt het construct van subjectieve slaapkwaliteit in insomnia patiënten onderzocht. In dit hoofdstuk wordt de rol van psychiatrische aandoeningen bestudeerd bij de rapportage van subjectieve slaapkwaliteit door middel van (a) een retrospectieve maat (de Pittsburg Sleep Quality Index, PSQI) versus (b) een prospectieve, ambulante maat (een slaapdagboek). Resultaten toonden dat de associatie tussen het prospectieve slaapdagboek en de retrospectieve PSQI afhankelijk was van de psychiatrische status: de associatie was zwakker in insomnia patiënten met een co-morbide psychiatrische conditie dan in patiënten zonder co-morbiditeit. Bovendien scoorden insomnia patiënten met een psychiatrische co-morbiditeit significant hoger op de PSQI dan insomnia patiënten zonder, een verschil dat niet langer significant was na het controleren voor angstklachten. De insomnia patiënten, met of zonder psychiatrische co-morbiditeit, verschilden niet in hun schattingen van subjectieve slaapkwaliteit op het slaapdagboek. Hieruit werd geconcludeerd dat (1) 
psychiatrische patiënten meer bias zouden kunnen vertonen in hun retrospectieve schattingen van slaapkwaliteit en dat (2) de PSQI totaalscore mogelijk slaap-gerelateerde stress reflecteert.

Slechte slaap is een bekende risicofactor voor depressie. Er is echter weinig bekend over onderliggende mechanismen. In hoofdstuk 3 beoogden wij de mogelijke mechanismen te ontrafelen die slaap aan depressie linken. Ten eerste zoomden we, door middel van ESM, in op het 'microniveau' van dagelijkse patronen van subjectieve slaap en affect binnen een persoon. Ten tweede zoomden we uit op het 'macroniveau' door de associatie tussen baseline slaap en toekomstige depressie te onderzoeken in een populatie-gebaseerde steekproef van vrouwen. Resultaten toonden dat subjectieve slaap samenhing met affect tijdens de volgende dag, met name met PA, terwijl affect overdag niet of nauwelijks geassocieerd was met de daarop volgende nachtelijke slaap. Bovendien voorspelde slaap gerapporteerd op baseline depressieve symptomen gedurende de follow-up periode. Deze resultaten suggereren dat de subtiele, repetitieve impact van slaap op (positief) affect een onderliggende rol kan spelen bij het ontwikkelen van een depressie.

Serotonine hangt samen met de regulatie van affectieve- als ook slaap-gerelateerde processen. Een functioneel polymorfisme in het serotonine transporter gen (5-HTTLPR) is geassocieerd met serotonerg functioneren. In hoofdstuk 4 hebben wij onderzocht of allelische variatie in dit gen de in hoofdstuk 3 gerapporteerde associatie tussen subjectieve slaapkwaliteit en PA modereert. Resultaten toonden dat de associatie tussen subjectieve slaapkwaliteit en daaropvolgend PA afhankelijk was van het 5-HTTLPR polymorfisme: de associatie was sterker in dragers van tenminste één $\mathrm{S}$-allel vergeleken met homozygote L-dragers. Deze bevinding ondersteunt de theorie dat serotonine een rol speelt in de associatie tussen slaap en affect.

Studies hebben aangetoond dat PA en NA zich verschillend over de dag ontvouwen: terwijl NA relatief stabiel blijft, vertoont PA een kwadratisch beloop ('omgekeerde u-curve'). Er zijn eerste aanwijzingen dat het dagelijkse beloop van PA en NA een ander patroon kent in depressie. Dit is echter nog niet systematisch onderzocht en het is niet bekend of dit (mogelijk) afwijkende patroon specifiek is voor depressie. In hoofdstuk 5 wordt het dagelijkse beloop van affect door middel van ESM onderzocht en vergeleken tussen patiënten met depressie, patiënten met psychose, en een steekproef uit de algemene populatie. We stelden een kwadratisch beloop van PA vast voor alle drie groepen. Echter, in de groep depressieve patiënten was de daling van PA op het einde van de dag zwakker. Bovendien daalde negatief affect tijdens de middag en 
avond significant meer in depressieve patiënten vergeleken met de steekproef uit de algemene populatie. De patiënten met psychose vertoonden een beloop van affect dat niet significant afweek vergeleken met de steekproef uit de algemene populatie. De resultaten bevestigden de hypothese dat het dagelijks beloop van PA en NA in depressieve patiënten mogelijk een ander patroon kent, iets dat specifiek lijkt voor deze stoornis. Dit zou kunnen samenhangen met een veranderde werking van de interne biologische klok in depressie.

In Hoofdstuk 6 worden de eerste resultaten besproken van een gerandomiseerde gecontroleerde trial (RCT) die de bruikbaarheid van ESM als therapeutische toepassing onderzoekt (in hoofdstukken 7 en 8 wordt ingegaan op de klinische resultaten van deze RCT). In deze RCT werd een ESM-interventie onderzocht waarbij depressieve patiënten gedurende zes weken ESM data registreerden met een digitaal ESM apparaat ('PsyMate') en wekelijks feedback ontvingen op de alledaagse context (sociale context, actuele activiteit, fysieke activiteit etc.) in relatie tot hun affectieve respons, met de focus op het ervaren van PA. Het doel was om de patiënten meer inzicht te geven in hun functionele en disfunctionele gedragingen. Omdat het langdurige meten van stemming belastend kan zijn, presenteert dit hoofdstuk de eerste resultaten met betrekking tot de verdraagbaarheid en haalbaarheid van deze trial. Ondanks dat sommige aspecten van de PsyMate als zwaar werden ervaren, bleek de haalbaarheid van deze ESM- gebaseerde interventie veelbelovend.

In hoofdstuk 7 wordt onderzocht of de in hoofdstuk 6 geïntroduceerde ESM-interventie impact heeft op de mate van PA in het dagelijks leven. De studie bestond uit drie armen: ESM zelf-monitoring gecombineerd met feedbacksessies (experimentele groep); ESM zelf-monitoring gecombineerd met sessies zonder feedback (pseudoexperimentele groep); en standaardbehandeling (controlegroep). De feedback die deelnemers in de experimentele groep ontvingen was gericht op het ervaren van PA in de alledaagse context. We onderzochten of de experimentele interventie geassocieerd was met een toename van PA tijdens en direct na de interventie. Resultaten toonden dat de experimentele groep niet verschilde in toename van PA vergeleken met de pseudo-experimentele of controlegroep. De feedback had dus geen significante invloed op dagelijks PA tijdens of vlak na de interventie. We beargumenteerden dat de effecten van de feedback op PA zich mogelijk geleidelijk ontwikkelen en de periode van ESM metingen onvoldoende lang was om deze geleidelijke veranderingen in PA in kaart te kunnen brengen. 
In hoofdstuk 8 wordt onderzocht of de ESM-interventie kan bijdragen aan meer empowerment bij de depressieve patiënten. Langdurige zelf-metingen gecombineerd met wekelijkse feedback, geeft de patiënt een actieve rol en zou een basis kunnen vormen voor een beter inzicht in (dis-) functionele gedragingen en voor verbeterde zelfmanagementstrategieën. Dit zou uiteindelijk tot een empowerment van de patiënt kunnen leiden. Resultaten toonden dat de experimentele en de pseudo-experimentele groep een grotere toename in empowerment rapporteerden vergeleken met de controlegroep. Er was geen verschil tussen de experimentele en pseudo-experimentele groep. Deze resultaten suggereren dat het langdurige, actief monitoren van affectieve responsen in het dagelijkse leven mogelijk bijdraagt aan meer empowerment in depressieve patiënten.

In hoofdstuk 9 worden de bevindingen van dit proefschrift besproken en binnen de context van het emotie homeostase model en de circadiane theorie van depressie geplaatst. De resultaten uit de hoofdstukken $2 \mathrm{t} / \mathrm{m} 5$ worden geïntegreerd in een nieuw model van potentiële micro-mechanismen van depressie. Vervolgens wordt ingegaan op de mogelijkheden die het meten van affect biedt voor de behandeling van depressie (hoofstukken $6 \mathrm{t} / \mathrm{m} \mathrm{8}$ ), gevolgd door een bespreking van de valorisatie, klinische implicaties en toekomstige richtingen van onderzoek naar slaap/affect mechanismen en ESM-interventies in depressie. 



$$
\left(\begin{array}{l}
L \\
L
\end{array}\right.
$$




\section{Publications}





\section{Refereed journal articles}

Hartmann J.A., Carney C.E., Lachowski A., Edinger J.E. Exploring the construct of subjective sleep quality in those with insomnia. Journal of Clinical Psychiatry, accepted for publication.

Hartmann J.A., Wichers M. , Derom C., Thiery E., Van Bemmel A.L., Jacobs N., Van Os, J., Simons C.J.P. The serotonin transporter 5-HTTLPR polymorphism in the association between sleep quality and positive affect. European Neuropsychopharmacology 2014; 24:1086-90.

De Wild-Hartmann J.A., Wichers M., Van Bemmel A.L., Derom C., Thiery E., Jacobs N., Van Os, J., Simons, C.J.P. Day-to-day associations between subjective sleep and affect in regard to future depression in a female population-based sample. British Journal of Psychiatry 2013;202:407-12.

Kramer I*, Simons CJ*, Hartmann J.A., Menne-Lothmann C., Viechtbauer W., Peeters F., et al. A therapeutic application of momentary assessment in the treatment of depression: A randomized controlled trial. World Psychiatry 2014; 13: 68-77. *contributed equally

Wichers M., Hartmann J.A., Kramer I.M.A., Lothmann C., Peeters F., Van Bemmel, L., Myin-Germeys, I., Delespaul, Ph., Van Os, J., Simons, C.J.P. Translating assessments of the film of daily life into person-tailored feedback interventions in depression. Acta Psychiatrica Scandinavica 2011;123:402-403.

Wichers, M., Simons, C. J., Kramer, I. M., Hartmann, J. A., Lothmann, C., Myin-Germeys, I., et al. Momentary assessment technology as a tool to help patients with depression help themselves. Acta Psychiatrica Scandinavica 2011;124:262-272.

\section{Chapters}

De Wild-Hartmann, J. A., Wichers, M., van Bemmel, A. L., Derom, C., Thiery, E., \& Simons, C. Self-reported sleep as predictor of positive affect in daily life. In T. Deboer, V. van Kasteel, P. Meerlo, R. Raymann \& J. Verbraecken (Eds.), Sleep-Wake Research in the Netherlands 2013;23. Enschede: PrintPartners Ipskamp BV.

Hartmann, J. A., Wichers, M., van Bemmel, A. L., Derom, C., Thiery, E., \& Simons, C. Sleep yourself happy? The association between sleep and affect in daily life. In T. 
de Boer, V. van Kasteel, P. Meerlo, R. Raymann \& J. Verbraecken (Eds.), Sleep-Wake Research in the Netherlands 2012;22:60-62. Enschede: PrintPartners Ipskamp BV.

\section{other}

De Wild-Hartmann J.A., Wichers M., Van Bemmel A.L., Derom C., Thiery E., Jacobs N., Van Os, J., Simons, C.J.P. Evidence that self-reported sleep impacts on momentary affect and predicts follow-up depressive symptomatology. European Neuropsychopharmacology 2012; 22: S230-231.

Hartmann, J.A., Thorne H.C., Groeger, J.A., D.J. Dijk. Effects of Sleep loss and circadian misalignment on performance and alertness: A comparison between objective and subjective measures. Sleep 2009; 32: A60-60.

De Wild-Hartmann, J.A. Onderzoek naar de dagelijkse samenhang tussen subjectieve slaap een affect. Tijdschrift voor Psychiatrie 2013;55:721-721.

Simons, C., Kramer, K., de Wild-Hartmann, J., Lothmann, C., van Bemmel, L., Wichers, M. De Experience Sampling Methode als hulpmiddel bij de behandeling van depressie met gebruik van nieuwe technologie (PsyMate). Metaforum 2012;18:39-48. 



$$
\left(\begin{array}{l}
L \\
L
\end{array}\right.
$$


Dankwoord 

Zittend in de zon van Melbourne, begin ik aan het laatste stuk van mijn proefschrift: het dankwoord. Zo veel mensen - uit diverse hoeken en op diverse manieren - hebben aan de totstandkoming van dit proefschrift bijgedragen. Deze mensen wil ik hier graag bedanken.

Allereerst gaat mijn dank uit naar mijn promotor, Prof. dr. Jim van Os. Jim, bedankt voor de mogelijkheid om mijn promotieonderzoek onder jou supervisie uit te voeren en bedankt voor alle steun en betrokkenheid gedurende deze tijd. Jouw snelheid en efficiëntie in het oplossen van problemen, ten alle tijden en door alle tijdzones heen, is meer dan indrukwekkend. Mijn bewondering voor jou als wetenschapper en als mens is gedurende de afgelopen jaren alleen maar gaan groeien.

Daarnaast wil ik graag mijn co-promotores, Dr. Claudia Simons en Dr. Marieke Wichers, bedanken. Claudia, bedankt voor je geweldige begeleiding in Eindhoven: Je wist altijd precies in te schatten wanneer hulp nodig was en wanneer ik het wel alleen kon. Ik heb zo veel waardering voor jouw manier van onderzoek doen en heb gedurende de laatste jaren heel veel van jou mogen leren. Bedankt dat je ook in drukke tijden mijn begeleiding doorgaans prioriteit hebt gegeven. Marieke, ook jij bedankt voor je fantastische begeleiding. Jouw optimisme, enthousiasme, inspiratie en creativiteit hebben zo veel bijgedragen aan het eindresultaat. Talloze keren dat ik gefrustreerd jouw kamer binnen liep en geïnspireerd en gemotiveerd er weer uit kwam. Jij bent echt een toptalent, op zo veel vlakken! En alle drie, Jim, Claudia en Marieke: bedankt voor de vrijheid die ik altijd heb gekregen.

Tevens gaat mijn dank naar Dr. Lex van Bemmel. Lex, bedankt voor je steun en begeleiding van al mijn slaap-gerelateerde vraagstukken. Ik was zo blij dat ik bij jou als slaap-expert altijd kon aankloppen - jouw passie voor het vak is en blijft indrukwekkend. Eveneens bedankt voor je continue inzet voor de REMOD depressiestudie vanuit jouw positie als psychiater en opleider bij GGzE.

Furthermore, I would like to thank Dr. Colleen Carney for the opportunity to visit her 'Sleep and Depression Lab' at Ryerson University in Toronto, Canada. Colleen, you welcomed me so warmly - I had such a great time. I would like to thank you, but also Prof. dr. Jack Edinger, for the opportunity to make use of the insomnia dataset while in Toronto, and for the support in preparing the 'PSQI paper'. I hope we can keep up our collaboration in the future.

I am very grateful to all my co-authors of the different papers: thank you for your critical input, your ideas, and your support. You significantly improved the quality of my papers. Daarnaast wil ik Prof. dr. Catherine Derom en Prof. dr. Evert Thiery bedanken dat ik gebruik mocht maken van het Oost-Vlaamse tweelingregister, waarop drie hoofstukken in dit proefschrift zijn gebaseerd. Verder wil ik graag de leden van mijn beoordelingscommissie, Prof. dr. Rudolf Ponds (voorzitter), Prof. dr. Derk-Jan Dijk, 
Prof. dr. Eus van Someren, Dr. Nancy Nicolson en Dr. Rob Havermans bedanken dat ze bereid waren om zich te buigen over mijn manuscript. Derk-Jan, jij tevens bedankt voor de mogelijkheid om mijn masterstage in jouw slaap-lab te doen. Ik heb er zoveel geleerd; een ervaring die ook mijn werk als promovendus heeft beïnvloed.

Lieve collega's van GGzE, in het bijzonder Marius, Leon, Lisette, Birgit, Lex, en Monique. Heel erg bedankt voor jullie inzet voor het 'veerkracht onderzoek'. Zonder jullie hulp in het doorverwijzen van patiënten was de studie nooit mogelijk geweest. Ik begrijp dat wij van het onderzoeksteam soms als lastig konden worden ervaren wanneer we weer eens bij jullie binnen liepen om 'aan de werving te trekken'....Tevens bedankt voor de koffies en praatjes toen ik aan het testen was op de Grijze Generaal. Wendy, Truda, Karin en Ron: heel erg bedankt voor jullie hulp in het coördineren van REMOD en het afhandelen van alle soorten PsyMate- en dataperikelen. Jullie inzet was (en is) ongeëvenaard! Petra, Esther, en Karina: heel erg bedankt voor jullie hulp bij het verzamelen van de data (en natuurlijk bedankt voor jullie gezelligheid!). Ingrid, wat was REMOD voor een project hé...Het heeft ons allebei heel wat bloed, zweet en tranen gekost. Uiteindelijk hebben wij het tot een goed einde kunnen brengen. Bedankt voor al die fijne gesprekken die we hebben gehad. En ten laatste, maar minstens even belangrijk, gaat mijn dank uit naar alle deelnemers van de REMOD/veerkrachtstudie. Ik wil jullie van harte bedanken voor jullie wekenlange, ja zelfs maandenlange inzet. Ik snap zo goed dat het soms niet makkelijk was!

Wolfgang, vielen Dank für deinen statistischen Rat. Deine Geduld scheint schier endlos...Du bist nicht nur Meister deines Fachs, sondern hast auch ein Händchen dieses Wissen zu vermitteln. Unsere Abteilung profitiert so viel von deinem Wissen (und deinem Humor)!

Lieve AiO-lichting, Claudi, Nicole, Sanne, Petra, Martine, Zuzanne, Feikje, Mayke, Ehsan, Dennis: ook al kwam ik vanuit Eindhoven pas de laatste maanden 'full time' op de afdeling te zitten, jullie gezelschap is mij niet minder dierbaar geworden... Bedankt dat ik ten alle tijden bij jullie mocht binnenlopen voor een 'wetenschappelijk verantwoorde vraag' of gewoon een koffie. Lieve Evelien, ook al was je pas helemaal op het einde mijn kamergenootje, ik vond het wel erg gezellig en jammer dat we maar zo kort bij elkaar zaten.

Meine liebsten Paranimphen Claudi und Nicole, wie dankbar ich bin dass es euch gibt! Manch schwere Stunde hab ich nur durch eure Unterstützung, euren Humor und gute Zurede überlebt. Wie ich euch vermisse hier in Oz.... Nicole, buch deinen Flug! Und Claudi, ich bin froh dass wir über Skype genauso gut quatschen können wie bei einem Kaffee in Aachen oder Maastricht.

Birgit, danke dass du seit so vielen Jahren mein ,steun en toeverlaat' bist, auch liegen meistens ,einige' Kilometer zwischen uns. Was haben wir schon alles zusammen 
erlebt...Außerdem tausend Dank, auch an Guillaume, für das Design meines Covers: es ist toll geworden. Charlotte, ik ben zo dankbaar voor de dag dat ik op de Dr Poletlaan 40 een kopje koffie ging halen en ik opeens een bekend gezicht zag. 'Wat doe jij hier?!' Bedankt voor alle urenlange gesprekken, pep-talks en wijntjes. Jij bent geweldig! En aan alle andere vrienden, ook aan diegene die ik nu helemaal niet meer zie: bedankt voor jullie steun en interesse. Ik mis jullie.

Liefste Joa, bedankt voor al die jaren met jou. Bedankt voor jou onvoorwaardelijke steun. Zonder jou zou ik niet staan waar ik nu sta en zou ik niet zijn wie ik nu ben. Heel veel liefs.

Oma und Opa, danke für eure Unterstützung und Vertrauen in mich. Ich bin so glücklich dass ihr dabei sein könnt. Mama und Papa, wie kann ich euch jemals genug danken... Danke dass ihr immer an mich geglaubt habt und in jeder Lebenssituation, ganz egal wie schwierig oder kompliziert es scheint, wie eine Festung hinter mir steht. Immer.

Meine liebste Lissy, beste Schwester der Welt, beste Zuhörerin, schärfste Kritikerin, größter Fan, beste Komikerin, liebster Mensch, verständnisvollste Person, größter (H) $\operatorname{Ar}{ }^{* * *}(\mathrm{t})$ mann. Was wäre ich nur ohne dich...Danke für all das, was du fuer mich bist.

Jesse, what can I say? Thank you for all you've done for me. Thank you for moving mountains (and worlds) with me. Together we can do anything, right? 


$$
\left(\begin{array}{l}
L \\
L
\end{array}\right.
$$


Curriculum vitae 

Jessica Anna Hartmann was born on the $27^{\text {th }}$ of March, 1983 in Siegburg (Germany). In 2003, after completion of her Abitur at the Dietrich-Bonhoeffer-Gymnasium (Hilden, Germany), she moved to Maastricht, the Netherlands to embark upon her studies at Maastricht University. In 2006, she obtained her Bachelor degree in Biological Psychology, followed by her Research Master degree in Cognitive and Clinical Neuroscience in 2008 (cum laude). The research presented in her Master's thesis was conducted at the Surrey Sleep Research Centre, Surrey University, United Kingdom (supervised by Prof. dr. Derk-Jan Dijk). In 2009, she commenced work as a Research Assistant for a large trial in depression, a collaborative project between GGzE (Mental Health Care Institution 'Geestelijke Gezondheid Eindhoven en de Kempen') and Maastricht University. This position culminated in her PhD candidature at the School for Mental Health and Neuroscience (MHeNS) commencing in 2011 (supervised by Prof. dr. Jim van Os). The research presented in this thesis was conducted at MHeNS and at the Sleep and Depression Lab at Ryerson University, Toronto, Canada (supervised by Dr. Colleen Carney).

Currently, Jessica works as a post-doctoral Research Fellow at Orygen, the National Centre of Excellence in Youth Mental Health at the University of Melbourne, Australia. 



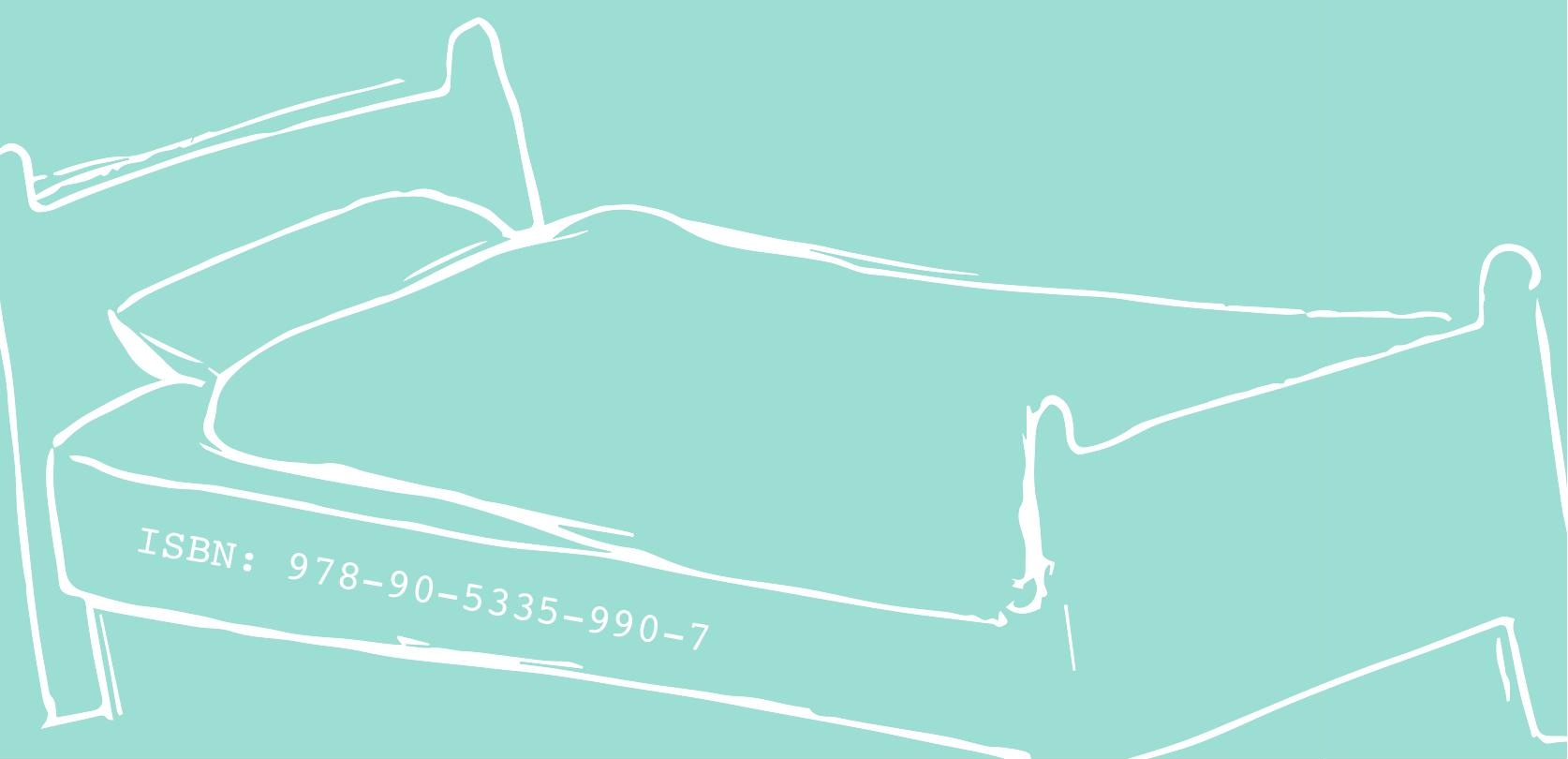

